\author{
UNIVERSIDADE DE SÃO PAULO \\ ESCOLA DE ENGENHARIA DE SÃO CARLOS
}

Christian Salaro Bresci

Caracterização de túnel de vento de baixo nível de turbulência e execução de experimento piloto para detecção de ondas Tollmien-Schlichting artificiais

São Carlos 

Christian Salaro Bresci

\section{Caracterização de túnel de vento de baixo nível de turbulência e execução de experimento piloto para detecção de ondas Tollmien-Schlichting artificiais}

Dissertação apresentada à Escola de Engenharia de São Carlos da Universidade de São Paulo, para obtenção do título de Mestre em Ciências - Programa de Pós-Graduação em Engenharia Mecânica.

Área de concentração: Aeronaves

Orientador: Prof. Dr. Marcello A. F. de Medeiros

ESTE EXEMPLAR TRATA-SE DA VERSÃO
CORRIGIDA. A VERSÃO ORIGINAL
ENCONTRA-SE DISPONÍVEL JUNTO AO
DEPARTAMENTO DE ENGENHARIA
MECÂNICA DA EESC-USP.

São Carlos 
AUTORIZO A REPRODUÇÃO TOTAL OU PARCIAL DESTE TRABALHO POR QUALQUER MEIO CONVENCIONAL OU ELETRONNICO, PARA FINS DE ESTUDO E PESQUISA, DESDE QUE CITADA A FONTE.

Ficha catalográfica elaborada pela Biblioteca Prof. Dr. Sérgio Rodrigues Fontes da EESC/USP com os dados inseridos pelo(a) autor(a).

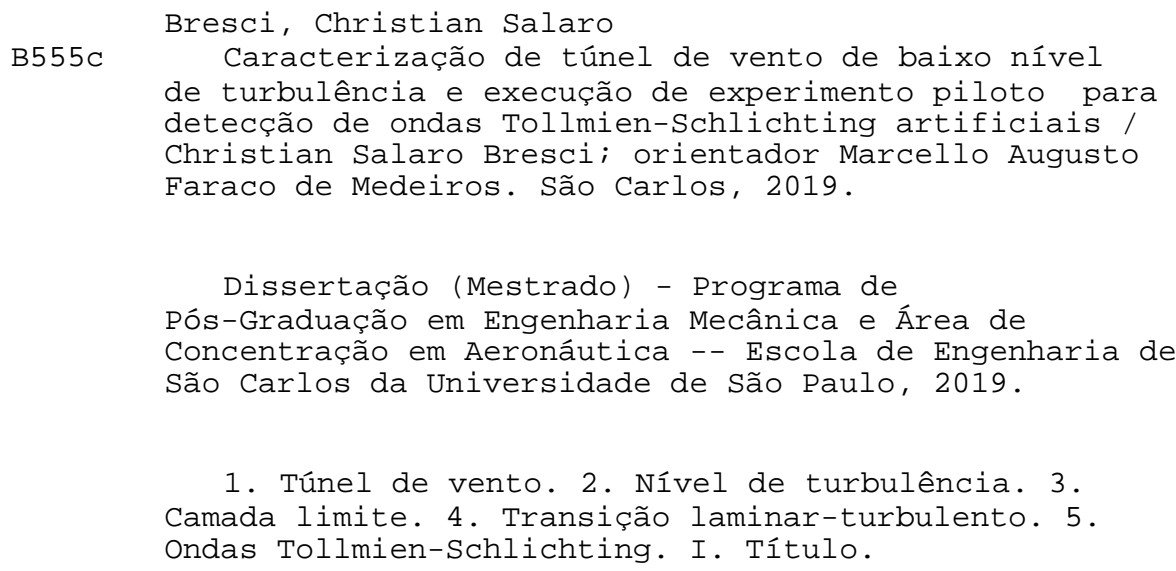

Eduardo Graziosi Silva - CRB - 8/8907 


\section{FOLHA DE JULGAMENTO}

Candidato: Engenheiro CHRISTIAN SALARO BRESCI.

Título da dissertação: "Caracterização de túnel de vento LANT $€$ execução de experimento piloto para detecção de ondas Tollmienschlichting artificiais".

Data da defesa: 20/03/2019

Comissāo Julgadora:

Resultado:

Prof. Associado Marcello Augusto Faraco de Medeiros APhOV APO (Orientador)

(Escola de Engenharia de São Carlos/EESC)

Prof. Dr. Igor Braga de Paula

(Pontificia Universidade Católica do Rio de Janeiro/PUC-Rio)

Dr. Márcio Teixeira de Mendonça

(Instituto Nacional de Pesquisas Espaciais/INPE)

Coordenador do Programa de Pós-Graduaçāo em Engenharia Mecânica:

Prof. Titular Gherhardit Ribatski

Presidente da Comissão de Pós-Graduação:

Prof. Titular Murilo Araujo Romero 

A minha esposa Gisele e minha filha Kátia, por seu apoio e inspiração em todos os momentos desta caminhada. 



\section{AGRADECIMENTOS}

Primeiramente agradeço ao apoio de minha esposa Gisele, aos meus pais e a minha irmã Melissa Salaro Bresci, pelo suporte nos momentos necessários. Agradeço aos meus companheiros de trabalho; Juan Carlos Serrano Rico, pela presteza e paciência na atualização do projeto do sistema de posicionamento tridimensional; Filipe Ramos do Amaral, pela ajuda na execução de experimentos, na escrita e correção desta dissertação; Matheus Beraldo, por sua ajuda na construção e montagem do sistema de posicionamento, bem como na execução dos experimentos aqui apresentados; e Marlon Mathias por sua contribuição na construção de códigos de processamento de dados e de solução da equação de Orr-Sommerfeld. Agradeço ao meu amigo, colega e professor da UFSCar, Paulo Sérgio Silva Junior, por nossas discussões sobre tratamento de erros e forma de representação, bem como disponibilizar a estrutura do Departamento de Física da UFSCar para auxílio na reparação de equipamentos. Agradeço ao técnico da UFSCar, Denis Pereira de Lima, no suporte à construção do programa para aquisição de dados e controle do sistema de posicionamento, e também por construir a asa de suporte para sondas. Faço um agradecimento especial ao técnico do Departamento de Física da UFSCar, Luis Roberto Contri Lopes, por reparar os sistemas de anemometria DISA, sem os quais este trabalho não seria possível. Também agradeço ao meu orientador, Marcello Augusto Faraco de Medeiros, e a Universidade de São Paulo, pela oportunidade de ter realizado este trabalho. 

Uma coisa eu aprendi em uma vida longa: que toda a nossa ciência, medida contra a realidade, é primitiva e infantil - e, no entanto, é a coisa mais preciosa que temos. Albert Einstein (CALAPRICE, 1996). 



\section{RESUMO}

BRESCI, C. S. Caracterização de túnel de vento de baixo nível de turbulência e execução de experimento piloto para detecção de ondas

Tollmien-Schlichting artificiais. 2019. 109p. Dissertação (Mestrado) - Escola de Engenharia de São Carlos, Universidade de São Paulo, São Carlos, 2019.

O estudo da camada limite, conceito inaugurado por Prandtl, tem fundamental importância para a aerodinâmica, sendo relevante em duas grandes áreas de estudo: a instabilidade aerodinâmica e a aeroacústica. Os mecanismos de transição da camada limite tem sido estudados, no âmbito da instabilidade aerodinâmica, desde o início dos anos 30 com as contribuições fundamentais de Tollmien e Schlichting. Embora tenha evoluído muito nos últimos 90 anos, os mecanismos responsáveis por esta transição ainda não são completamente explicados. Por outro lado, a camada limite tem papel relevante no som gerado aerodinamicamente, um fenômeno ainda não completamente compreendido. Dentro deste contexto, o grupo de pesquisa em transição, turbulência e aeroacústica construiu um túnel de vento com baixa turbulência e baixo ruído. Este túnel, denominado LANT (Low Acoustic Noise and Turbulence), foi desenvolvido para realizar diversos tipos de experimentos, entre eles a transição e geração de som da camada limite. Um dos objetivos deste trabalho de mestrado é caracterizar a qualidade do escoamento gerado pelo túnel de vento, avaliando os níveis de turbulência, uniformidade do escoamento e nível de ruído de fundo. Outro objetivo é testar a qualidade do túnel executando um experimento piloto de detecção de ondas Tollmien-Schlichting artificiais; neste contexto foi projetado e construído um sistema de posicionamento tridimensional para movimentação de sondas para aferição do escoamento. As técnicas experimentais utilizadas são a anemometria a fio quente HWA (Hot Wire Anemometry) e beamforming acústico. O LANT apresenta não uniformidades no escoamento da ordem de $1 \%$ e nível de turbulência de $0,07 \%$ para a faixa de velocidades $10 \mathrm{~m} / \mathrm{s}$ à $25 \mathrm{~m} / \mathrm{s}$. Também foi comprovada a qualidade do túnel pela execução de experimentos de transição, sendo caracterizadas ondas TS forçadas (ou artificiais) e sua taxa de amplificação.

Palavras-chave: Túnel de Vento. Nível de Turbulência. Ruído. Camada limite. Transição laminar-turbulento. Ondas Tollmien-Schlichting. 



\section{ABSTRACT}

\section{BRESCI, C. S. Characterization of a low turbulence level wind tunnel and performing of a pilot experiment for detection of artificial}

Tollmien-Schilichting waves. 2019. 109p. Dissertação (Mestrado) - Escola de Engenharia de São Carlos, Universidade de São Paulo, São Carlos, 2019.

The boundary layer, a concept inaugurated by Prandtl, is of fundamental importance for aerodynamics, being relevant in two large areas of study: aerodynamic instability and aeroacoustics. The boundary layer transition mechanisms have been studied in the framework of aerodynamic instability since the beginning of the 1930's with fundamental contributions of Tollmien and Schlichting. Although the boundary layer has been studied the past 90 years, the mechanisms responsible for transition are still not fully comprehended. On the other hand, the boundary layer has a relevant role in aerodynamically-generated sound, a phenomenon not yet completely understood. Within this context, the University of Sao Paulo research group on transition, turbulence and aeroacoustics built a wind tunnel of low turbulence and low noise. This tunnel, called LANT (Low Acoustic Noise and Turbulence), was developed to perform several types of experiments, including boundary layer transition and aeroacoustics. An objectives of this master's project is to characterize the wind tunnel flow quality, through the evaluation of the turbulence level, flow uniformity and background noise level. Another objective is to test the tunnel quality by performing a experiment in order to detect artificial Tollmien-Schlichting waves; in this context, a three-dimensional traverse gear was designed and built for the positioning of the probes for measurements of punctual flow characteristics, through, e.g., a hot wire anemometry (HWA) measurement system. The experimental techniques employed in this study were HWA and acoustic beamforming. The LANT wind tunnel exibiths flow non-uniformities of the order of $1 \%$ of free stream speed, turbulence level of $0,07 \%$ in the speed range of $10 \mathrm{~m} / \mathrm{s}$ to $25 \mathrm{~m} / \mathrm{s}$. Such non-uniformity, turbulence and acoustic noise levels are within international standards for wind-tunnels employed for transition and aeraocoustic experiments. The tunnel quality was also demonstrated by the performing of transition experiments, including the charcterization of forced (or artificial) TS waves.

Keywords: Wind Tunnel. Turbulence Level. Noise. Boundary Layer. Laminar-turbulent transition. Tollmien-Schlichting Waves. 



\section{LISTA DE ILUSTRAÇÕES}

Figura 1 - Montagem experimental de Reynolds para estudo de turbulência, retirado de Reynolds (1883). . . . . . . . . . . . . . . . . . 31

Figura 2 - Fotografia de uma camada limite laminar, retirado de Dyke (1988). . . 32

Figura 3 - Instabilidade na camada limite $(\mathrm{Re}=100000)$, onde aparecem as ondas TS, retirado de Dyke (1988) . . . . . . . . . . . . . . . . . . 33

Figura 4 - Experimentos de Schbauer e diagrama de estabilidade, retirado de Houghton (2013) . . . . . . . . . . . . . . . . 33

Figura 5 - Efeitos 3D em ondas TS, retirado de Dyke (1988) . . . . . . . . . . . 34

Figura 6 - Circuito aerodinâmico do túnel de vento. (1) seção de testes, (2) difusor 1, (3) curvas 1 e 2, (4) difusor 2, (5) ventilador, (6) difusor 3, (7) curvas 3 e 4, (8) difusor 4 / de grande ângulo, (9) câmara de estabilização e (10) contração. Dimensões em milímetros, retirado de Serrano Rico et al. (2018) . . . . . . . . . . . . . . . . . . . . 38

Figura 7 - Visão geral LANT, retirado de Serrano Rico et al. (2018). . . . . . . . 38

Figura 8 - Visões do inflow, (a), e do outflow, (b), do ventilador do LANT. . . . . 40

Figura 9 - Detalhes das guias defletoras e do revestimento de espuma nas curvas, LANT. . . . . . . . . . . . . . . . . . . . . . . 40 40

Figura 10 - Câmara de estabilização. . . . . . . . . . . . . . . . . . . . 41

Figura 11 - Contração, retirado de Serrano Rico et al. (2018) . . . . . . . . . . . . 42

Figura 12 - Câmara de ensaios de janelas e módulos de parede intercambiáveis. . 43

Figura 13 - Incerteza na estimativa da velocidade no LANT. . . . . . . . . . . . . 45

Figura 14 - Uma sonda 1D com o fio posicionado paralelamente ao escoamento médio, retirado de Bruun (1995). . . . . . . . . . . . . . . 45

Figura 15 - Sonda de camada limite . . . . . . . . . . . . . . . 46

Figura 16 - Circuito básico anemômetro em modo CTA, retirado de Bruun (1995). 47

Figura 17 - Curvas típicas de calibração da técnica de HWA. . . . . . . . . . . . 51

Figura 18 - Conjunto de sondas disponíveis, retirado de Jorgensen (2002). . . . . . 53

Figura 19 - Sistema para reparação de sondas de anemômetro . . . . . . . . . . . . 54

Figura 20 - Resposta dos anemômetros para cada tomada de dados. . . . . . . . . 57

Figura 21 - Espectro dos anemômetros DISA 01 e Próprio. . . . . . . . . . . . . . 58

Figura 22 - Croqui do sistema de posicionamento, elaborado por Juan Carlos Serrano Rico. . . . . . . . . . . . . . . . . . . . . . . . . . 59

Figura 23 - Face frontal de acrílico do posicionador. . . . . . . . . . . . 59

Figura 24 - Acoplamento horizontal-vertical. . . . . . . . . . . . . . . 60 
Figura 25 - Detalhes mesa: (1) eixo de esferas; (2) motor de passo; (3) guia linear, (4) haste; (5) e (6) guias horizontais. . . . . . . . . . . . . . . 61

Figura 26 - Frequências de desprendimento de vórtices da haste cilíndrica do posicionador, em relação à velocidade do escoamento. . . . . . . . . . . . . . 62

Figura 27 - Seleção do perfil aerodinâmico. . . . . . . . . . . . . . . . 63

Figura 28 - Projeto de hastes aerodinâmicas para experimentos de HWA. . . . . . 64

Figura 29 - Variação da temperatura na câmara de ensaios. . . . . . . . . . . . . . 67

Figura 30 - Evolução da temperatura interna para $10 \mathrm{~m} / \mathrm{s}$. . . . . . . . . . . . . 68

Figura 31 - Diferenças entre as temperaturas interna e externa do túnel. . . . . . . 68

Figura 32 - Perfis de velocidade da camada limite do LANT à 10 m/s. . . . . . . . 70

Figura 33 - Variação do nível de turbulência em relação a parede do LANT, para

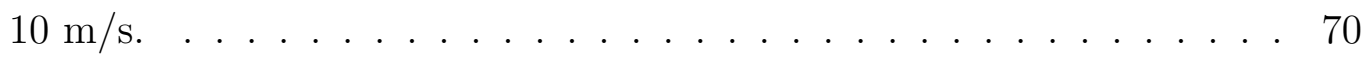

Figura 34 - Critério para determinação da camada limite do LANT. . . . . . . . . 71

Figura 35 - Área útil da câmara de ensaios LANT . . . . . . . . . . . . . . . . 71

Figura 36 - Regiões da camada limite LANT. . . . . . . . . . . . . . . . . 72

Figura 37 - Locais utilizados para aferição da uniformidade do LANT. . . . . . . . 73

Figura 38 - Exemplo de resposta dos diferentes filtros de mesma ordem. . . . . . . 75

Figura 39 - Resposta do filtro passa banda Chebyshev Tipo II utilizado. . . . . . . 75

Figura 40 - Comparação entres os sinais o anemômetro para a velocidade de $25 \mathrm{~m} / \mathrm{s}$. 76

Figura 41 - Variação do nível de turbulência com o tempo de aquisição. . . . . . . 77

Figura 42 - Variação do nível de turbulência com o filtro escolhido. . . . . . . . . . 78

Figura 43 - Espectro de frequências do sinal obtido com HWA no LANT. . . . . . 78

Figura 44 - Espectro de vibrações do conjunto asa + haste, medidas com acelerômetro. 79

Figura 45 - Colapso do espectro de frequências obtido com as medições de HWA no LANT. . . . . . . . . . . . . . . . . . . . . . . . . 79

Figura 46 - Comparação entre os níveis de turbulência de diferentes túneis. Os dados entre parenteses representam os filtros passa banda utilizados, as linhas tracejadas indicam equipamentos nacionais e as linhas ponto-traço indicam equipamentos estrangeiros. . . . . . . . . . . . . . . 80

Figura 47 - Rotação do ventilador necessária para atingir velocidades semelhantes, com e sem tela de pressão. . . . . . . . . . . . . . . . . . . 81

Figura 48 - Aumento no nível de turbulência, filtrado em $5 \mathrm{~Hz}$ até $20 \mathrm{kHz}$. . . . . 81

Figura 49 - Modelo utilizado para os experimentos de caracterização de ondas TS. 83

Figura 50 - Comparação entre o perfil teórico de Blasius e o perfil medido com a técnica de HWA, para $R e_{x} \approx 460.000$. . . . . . . . . . . . 85

Figura 51 - Bidimensionalidade da camada limite para $R e_{x} \approx 450.000$. . . . . . . . 86

Figura 52 - Coeficiente de pressão $\left(c_{p}\right)$ sobre a placa plana. . . . . . . . . . . . 87 
Figura 53 - Comparação entre os valores de $\delta^{*}$ medidos e a teoria de Blasius para diferentes valores de $x$ e $U_{\infty}$. As linha traço-ponto indicam a previsão teórica para os valores de $\delta^{*}$ em cada velocidade. . . . . . . . . . . . 88

Figura 54 - Varição do fator de forma $H$ com o número de Reynolds; a linha tracejada indica a previsão teórica para a camada limite laminar. . . 89

Figura 55 - Varição do fator de forma $H$ com o número de Reynolds. . . . . . . . . 89

Figura 56 - Espectro frequências na camada limite para a posição $\eta=1$ para diferentes valores de $R e_{\delta^{*}}$, medidos a $10 \mathrm{~m} / \mathrm{s}$. . . . . . . . . . . . . . 91

Figura 57 - Diagrama de instabilidade para a perturbação de $10 \mathrm{~Hz}$, medida nas velocidades de escoamento de $10 \mathrm{~m} / \mathrm{s}$ e $20 \mathrm{~m} / \mathrm{s}$. . . . . . . . . . . . 92

Figura 58 - Espectro de frequências para a posição $\eta=1$ para as distâncias de 1000 $\mathrm{mm}$ e $1500 \mathrm{~mm}$ do bordo de ataque. As linhas tracejadas indicam os limites de frequências instáveis para a posição $1000 \mathrm{~mm}$ e as linhas traço-ponto indicam os limites das frequências instáveis para a posição $1500 \mathrm{~mm}$. . . . . . . . . . . . . . . . . . . . . 93

Figura 59 - Diagrama de instabilidade para ondas TS, a linha sólida vermelha demonstra o caminho de evolução da onda 2D. A estrela indica a posição da fonte de excitação e as linhas tracejadas indicam a primeira e a última estação de medição. . . . . . . . . . . . . . . . . . . . . . . 94

Figura 60 - Perfil de velocidades da perturbação medida a $200 \mathrm{~mm}$ da fonte. . . . . 95

Figura 61 - Tridimensionalidade da onda TS gerada artificialmente para a distância de $200 \mathrm{~mm}$ a partir da fonte. . . . . . . . . . . . . . . . . . 96

Figura 62 - Comparação entre a previsão da teoria linear 2D e os resultados experimentais para a distância de $400 \mathrm{~mm}$ da fonte. . . . . . . . . . . . . . . 97

Figura 63 - Valores dimensionais da parte imaginária dos autovalores instáveis da onda TS 2D. . . . . . . . . . . . . . . . . . . . . . 98

Figura 64 - Comparação entre a taxa de amplificação da perturbação medida experimentalmente e os valores previstos pela teoria linear 2D. . . . . . . . 98

Figura 65 - Autofunção da onda TS para diferentes intensidades de perturbação inicial, medidas a $300 \mathrm{~mm}$ da fonte. . . . . . . . . . . . . . . . 99

Figura 66 - Efeito da amplitude inicial de perturbação na taxa de amplificação medidas experimentalmente. . . . . . . . . . . . . . . . . 99 



\section{LISTA DE TABELAS}

Tabela 1 - Características do túnel de vento. . . . . . . . . . . . . . . . . 39

Tabela 2 - Características técnicas dos sensores. . . . . . . . . . . . . . . 43

Tabela 3 - Comparação entre modos CTA e CCA. . . . . . . . . . . . . . 47

Tabela 4 - Etapas de configuração do anemômetro. . . . . . . . . . . . . . 54

Tabela 5 - Etapas de calibração do anemômetro. . . . . . . . . . . . . . 55

Tabela 6 - Variação do sinal de saída dos diversos anemômetros. . . . . . . . . . 56

Tabela 7 - Variação do sinal de saída dos diversos anemômetros. . . . . . . . . . . 57

Tabela 8 - Parâmetros experimentais do modelo de aquecimento. . . . . . . . 66

Tabela 9 - Diferenças percentuais entre a velocidade atual e a média, para a posição $(\mathrm{x}, \mathrm{y}, \mathrm{z})$ medida em milímetros a partir do ponto de referência, que se encontra no plano central da entrada da câmara de ensaios. . . . . . . 74

Tabela 10 - Nível de turbulência do LANT. . . . . . . . . . . . . . . . . . 77

Tabela 11 - Regiões de frequências instáveis para as posições $1000 \mathrm{~mm}$ e $1500 \mathrm{~mm}$ do bordo de ataque, para as velocidades de $10 \mathrm{~m} / \mathrm{s}$ e $20 \mathrm{~m} / \mathrm{s}$. . . . . . 92 



\section{LISTA DE ABREVIATURAS E SIGLAS}

AoA Ângulo de ataque (Angle of Attack)

CCA Anemometria à corrente constante (Constant Current Anemometry)

CFD Dinâmica dos Fluidos Computacional (Computational Fluid Dynamics)

CTA Anemometria à temperatura constante (Constant Temperature Anemometry)

DNS Simulação numérica direta (Direct Numeric Simulation)

DAQ Aquisição de dados (Data acquisition)

DCTA Departamento de Ciência e Tecnologia Aeroespacial

HWA Anemometria à fio quente (Hot Wire Anemometry)

EESC Escola de Engenharia de São Carlos

FINEP Financiadora de Estudos e Projetos

FSAT Túnel Aeroacústico da Universidade Florida State (The Florida State Aeroacoustic Tunnel)

GATT Grupo de Aeroacústica, Transição e Turbulência (Escola de Engenharia de São Carlos, Universidade de São Paulo)

LANT Túnel de vento de baixo ruído e baixa turbulência (Low Acoustic Noise ant Turbulence Wind Tunnel)

MTL Túnel de nível mínimo de turbulência (Minimum Turbulence Level)

LAE Laboratório de Aerodinâmica Experimental

LNSE Equações Navier-Stokes Linearizada (Linearized Navier-Stokes Equations)

NACA Comitê Nacional para Aconselhamento sobre Aeronáutica (National Advisory Committee for Aeronautics)

NDF Instalação nacional de diagnóstico (National Diagnostic Facility)

NI National Instrumets

NSE Equações Navier-Stokes (Navier-Stokes Equations) 


$\begin{array}{ll}\text { OSE } & \text { Equação de Orr-Sommerfeld (Orr-Sommerfeld Equation) } \\ \text { PIV } & \text { Velocimetria por Imagem de Partículas (Particle Image Velocimetry) } \\ \text { PSD } & \text { Densidade de Potência Espectral (Power Spectral Density) } \\ \text { RMS } & \text { Raiz do valor quadrático médio (Root Mean Square) } \\ \text { RPM } & \text { Rotações por minuto } \\ \text { TA-2 } & \text { Túnel de Vento Aerodinâmico } 2 \\ \text { TS } & \text { Ondas Tollmien-Schlichting } \\ \text { UFSC } & \text { Universidade Federal de Santa Catarina } \\ \text { UFSCar } & \text { Universidade Federal de São Carlos } \\ \text { USP } & \text { Universidade de São Paulo }\end{array}$




\section{LISTA DE SÍMBOLOS}

\begin{tabular}{|c|c|}
\hline$A$ & amplitude de perturbação \\
\hline$A_{w}$ & área de seção transversal \\
\hline$c_{p}$ & coeficiente de pressão \\
\hline$d$ & diâmetro \\
\hline$d \dot{Q}_{c}$ & taxa de transferência de calor por condução \\
\hline$d \dot{Q}_{e}$ & taxa de geração de calor elétrico \\
\hline$d \dot{Q}_{f c}$ & taxa de transferência de calor por convecção forçada \\
\hline$d \dot{Q}_{r}$ & taxa de transferência de calor por radiação \\
\hline$d \dot{Q}_{s}$ & taxa de acúmulo de energia \\
\hline$E$ & tensão de saída no anemômetro \\
\hline$E_{w}$ & tensão na sonda \\
\hline$f_{c}$ & frequência de corte \\
\hline g & função de transferência \\
\hline$h$ & coeficiente de transferência de calor convectiva \\
\hline$H$ & fator de forma \\
\hline$i$ & $\sqrt{-1}$ \\
\hline$I$ & corrente \\
\hline$k$ & condutividade térmica \\
\hline$l$ & comprimento \\
\hline$N u$ & número de Nusselt \\
\hline$P_{a t m}$ & pressão atmosférica \\
\hline$R^{*}$ & constante específica dos gases \\
\hline$R_{0}$ & resistência na temperatura de referência \\
\hline
\end{tabular}




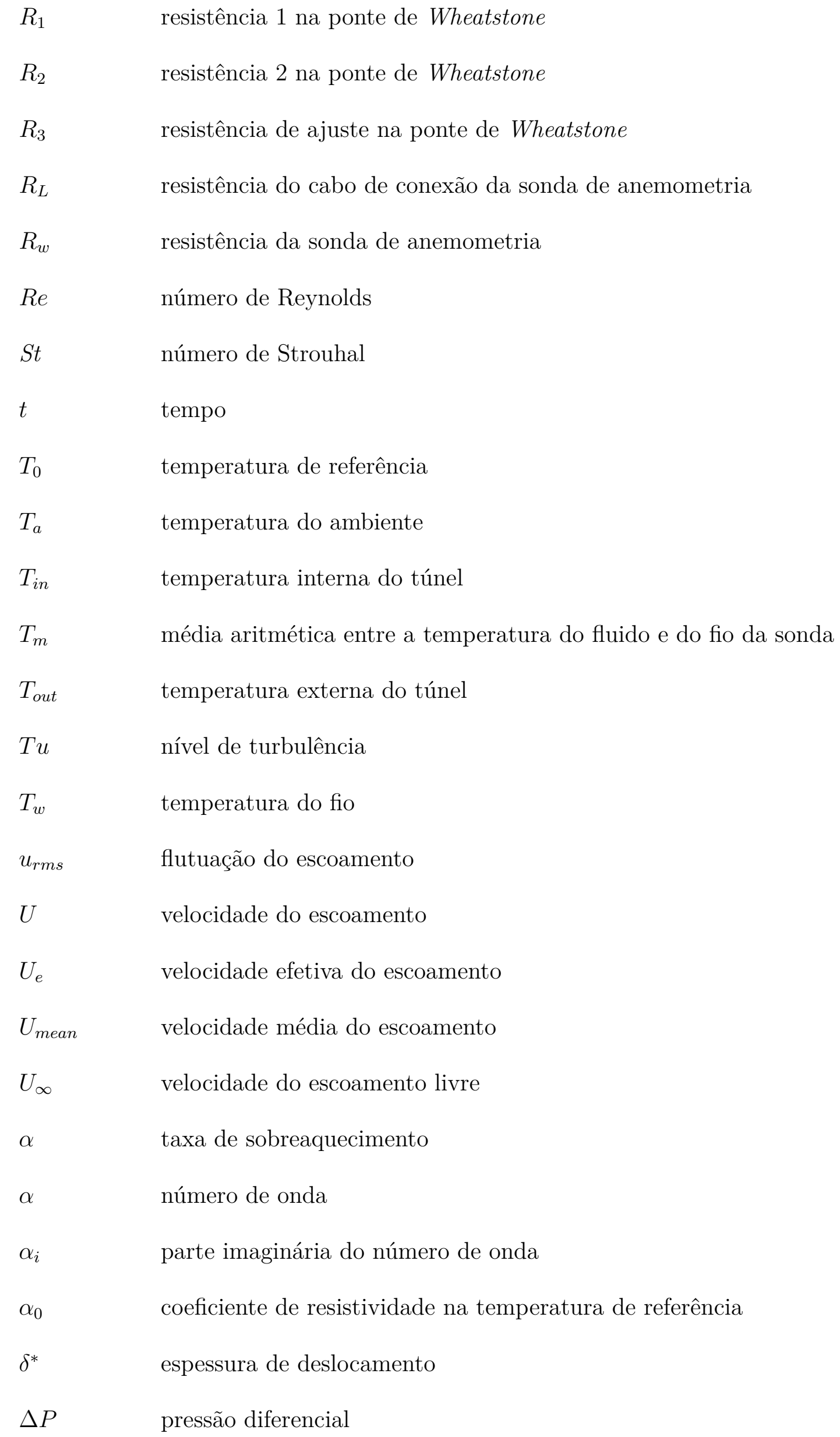


transformação de similaridade

$\Theta$

espessura de quantidade de movimento

$\lambda_{c}$ comprimento de onda de corte

$\nu$

viscosidade cinemática

$\rho$

densidade do ar

$\phi$

potencial de velocidades

$\chi_{w}$

resistividade

$\Psi$

função potencial

$\omega$

frequência 



\section{SUMÁRIO}

INTRODUÇÃO $\ldots \ldots \ldots \ldots \ldots \ldots$

METODOLOGIA EXPERIMENTAL . . . . . . . . . . . 37

$3.1 \quad$ Túnel de vento $\ldots \ldots \ldots \ldots \ldots \ldots$

$3.1 .1 \quad$ Ventilador . . . . . . . . . . . . . . . . . . . . . 39

$3.1 .2 \quad$ Curvas . . . . . . . . . . . . . . . . . 40

3.1.3 Câmara de Estabilização . . . . . . . . . . . . . . . . . . . 41

3.1.4 Contração . . . . . . . . . . . . . . . . . . . . . . . 41

3.1 .5 Câmara de Ensaios . . . . . . . . . . . . . . . . . 42

3.1.6 Sensores e sistema de controle . . . . . . . . . . . . . . . . . 43

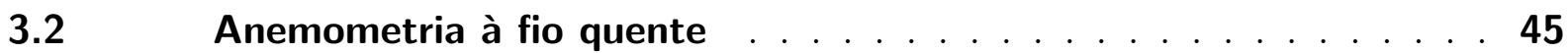

3.2.1 Modos de operação . . . . . . . . . . . . . . . . . . 46

3.2.1.1 Modo de temperatura constante - CTA . . . . . . . . . . . . 46

3.2.2 Modelo térmico do anemômetro à fio quente . . . . . . . . . 48

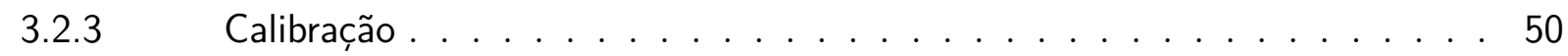

3.2.4 Equipamentos disponíveis . . . . . . . . . . . . . . . . . . . . . . 52

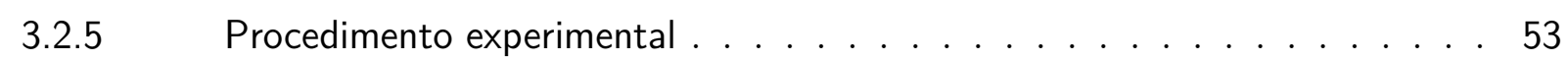

3.2.5.1 Calibração . . . . . . . . . . . . . . . . . . 53

3.2.5.2 Velocidade do Escoamento . . . . . . . . . . . . . . . . . . 55

3.2.6 Seleção Anemômetro . . . . . . . . . . . . . . . . . . . 56

$3.3 \quad$ Sistema de Posicionamento . . . . . . . . . . . . . . . 58

3.3.1 Movimento vertical e horizontal . . . . . . . . . . . . . 60

3.3.2 Mesa . . . . . . . . . . . . . . . . . . . 61

3.3.3 Haste . . . . . . . . . . . . . . . . . . . . 61

4 CARACTERIZAÇÃO DO ESCOAMENTO DO LANT . . . . . . 65

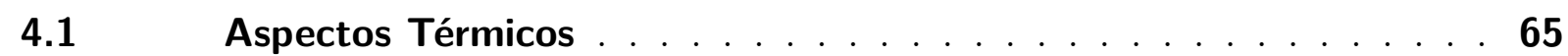

$4.2 \quad$ Área Útil . . . . . . . . . . . . . . . . . . . . . . . . . 69

$4.3 \quad$ Uniformidade do Escoamento . . . . . . . . . . . . . . 73

$4.4 \quad$ Nível de Turbulência . . . . . . . . . . . . . . . . . . . . . . . . . . 74

4.4.1 Seleção de Filtro . . . . . . . . . . . . . . . . . . . . . . . 75

4.4 .2 Tempo de aquisição . . . . . . . . . . . . . . . . . . 76

4.4 .3 Turbulência . . . . . . . . . . . . . . . . . . . . . . . 77

4.4.4 Comparação com outros túneis de vento . . . . . . . . . . . . . . 79 
$4.5 \quad$ Efeitos da Rotação do Ventilador . . . . . . . . . . . . . . . . 80

5 EXPERIMENTO PILOTO: ONDAS TOLLMIEN-SCHLICHTING . . 83

$5.1 \quad$ Camada Limite da Placa Plana . . . . . . . . . . . . . . . . . 83

5.1.1 Perfil da Camada Limite . . . . . . . . . . . . . . . . . . . 85

5.1.2 Camada Limite Bidimensional . . . . . . . . . . . . . . . . 85

5.1.3 Transição Natural da Camada Limite . . . . . . . . . . . . . . . . . 85

5.2 Ondas Tollmien-Schlichting . . . . . . . . . . . . . 89

5.2.1 Ondas Tollmien-Schlichting Naturais . . . . . . . . . . . . . . . . . . . 91

5.2.2 Ondas Tollmien-Schlichting Artificiais . . . . . . . . . . . . . . . . 93

5.2.2.1 Autofunção . . . . . . . . . . . . . . . . 94

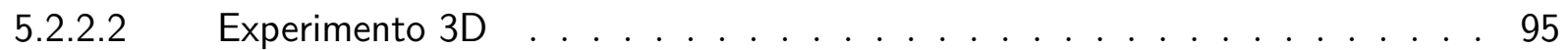

5.2.2.3 Comparação com a Teoria 2D . . . . . . . . . . . . . . . . . 96

5.2.2.4 Taxa de Crescimento . . . . . . . . . . . . . . . . . . . 97

5.2.2.5 Efeito da Perturbação Inicial . . . . . . . . . . . . . . . . . . . . . 98

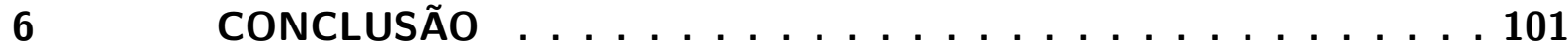

REFERÊNCIAS . . . . . . . . . . . . . 105 


\section{INTRODUÇÃO}

O conceito da camada limite, inaugurado por Prandtl (1905), revolucionou o estudo da mecânica de fluidos no início do século XX, permitindo o cálculo do arrasto de fricção ( skin friction drag) gerado pela viscosidade, um problema insolúvel até então, pois o arrasto calculado pela teoria potencial, que considerava o escoamento invíscido, era sempre zero, o que contradizia as observações experimentais, dando origem ao que é conhecido como paradoxo de D'Alembert. A partir de estudos sobre a camada limite foi possível descobrir que esta, similarmente a escoamentos em tubos, apresentava regiões em que o escoamento era laminar e depois se tornava turbulento. O estudo da transição de escoamentos laminares para turbulentos data do final do século XIX, com o trabalho pioneiro de Lord Rayleigh (RAYLEIGH, 1880). Entretanto, somente no início dos anos 1930 é que houveram avanços significativos sobre a transição da camada limite, com as contribuições de Walter Tollmien e Hermann Schlichting, que postularam a existência de ondas instáveis responsáveis pela transição. A detecção destas ondas instáveis ocorreu muito tempo depois, com o advento do túneis de vento de baixa turbulência.

O estudo sobre estes mecanismos de transição da camada limite, tem dominado a ciência aeronáutica desde então. Embora muito se tenha avançado na compreensão destes mecanismos, a interação destas ondas com estruturas, como degraus e cavidades, ainda é um problema em aberto. Por outro lado, do ponto de vista prático, a importância da transição na camada limite reside no fato que, uma camada limite laminar gera menor arrasto de fricção que uma turbulenta. Estima-se que mais de $50 \%$ do arrasto das aeronaves tem origem no arrasto de fricção (SCHRAUF, 2005); assim, se for possível suprimir ou mesmo atrasar a transição da camada limite, será possível produzir aeronaves mais eficientes no consumo de combustível, reduzindo a emissão de gases do efeito estufa e os custos de operação. Num cenário de restrições na emissão de poluentes, isso possui grande valor na industria aeronáutica.

Outro problema relevante a ser estudado é o do som gerado pela camada limite, baseado na ciência da aeroacústica desenvolvida por (LIGHTHILL, 1952). Os mecanismos de geração deste som ainda não são completamente compreendidos e tampouco se a transição da camada limite tem papel relevante na geração de som. A análise destes fenômenos baseia-se quase que exclusivamente em simulações numéricas, devido a pouca disponibilidade de túneis de vento de baixo ruído, uma vez que são ruídos pouco intensos. Embora seja de baixa intensidade, o som gerado pela camada limite é proporcional à área de incidência do escoamento, ou seja, para veículos com uma grande área superficial, por exemplo os submarinos, o ruído da camada limite contribui significativamente para o ruído 
total de banda larga. Este é um campo de estudo relativamente novo e de grande aplicação prática.

Dentro deste panorama de pesquisas, o Grupo de Aeroacústica, Transição e Turbulência (GATT) do Departamento de Engenharia Aeronáutica da Escola de Engenharia de São Carlos da Universidade de São Paulo (EESC-USP), construiu, com o auxílio da Financiadora de Estudos e Projetos (FINEP), um túnel de vento de circuito fechado de baixo nível de turbulência e baixo ruído acústico de fundo, denominado LANT (Low Acoustic Noise and Turbulence Wind Tunnel), capaz de realizar diversos tipos de experimentos, entre eles a transição e geração de som da camada limite.

A comunidade científica dispõe de uma variedade de túneis capazes de realizar experimentos em transição da camada limite, entre os quais destacam-se; o KlebanoffSaric, localizado na Texas A $\&$ M University (HUNT et al., 2010); o MTL (Minimum Turbulence Level or Marten Theodore Landahl), do KTH Royal Institute of Technology (LINDGREN; JOHANSSON, 2002); o NDF (National Diagnostic Facility), do Illinois Institute of Technology (NAGIB et al., 1994); e o Túnel de Instabilidade da Virginia Tech. O LANT se somará a estes túneis de referência e, juntamente aos túneis TA-2 do Departamento de Ciência e Tecnologia Aeroespacial - DCTA (AVELAR, 2005), e o túnel do Laboratório de Aerodinâmica Experimental - LAE da EESC-USP(SANTANA et al., 2010), aumentará a capacidade do Brasil em realizar experimentos aerodinâmicos e de transição na camada limite.

O objetivo desta dissertação de mestrado é demonstrar a capacidade do LANT para a execução de experimentos de transição na camada limite, primeiramente caracterizando a qualidade do escoamento, utilizando a técnica de anemometria à fio quente, e executando um experimento piloto de detecção de ondas Tollmien-Schlichting artificiais. O túnel de vento LANT é de circuito fechado e foi parte do trabalho de doutorado do ex-aluno Juan Carlos Serrano Rico.

Este trabalho está organizado na seguinte forma: o Capítulo 2 apresenta uma pequena revisão bibliográfica sobre os fenômenos que serão tratados pelo LANT, a transição e o ruído gerado na camada limite; no Capítulo 3 serão apresentados as técnicas experimentais utilizadas, em especial a anemometria à fio quente (HWA), bem como os equipamentos disponíveis, entre eles o túnel de vento, o sistema de posicionamento, com o detalhamento de sua construção, os sistemas de HWA;no Capítulo 4 serão mostrados resultados de qualificação do escoamento do túnel; no Capítulo 5 é apresentada a execução do experimento piloto de detecção de ondas Tollmien-Schlichting e no Capítulo 6 é apresentada a conclusão deste trabalho. 


\section{REVISÃO BIBLIOGRÁFICA: TRANSI- ÇÃO DA CAMADA-LIMITE}

Pode-se dizer que o estudo moderno sobre a transição de um escoamento laminar para turbulento remonta à segunda metade do século XIX com o trabalho de Lord Rayleigh (RAYLEIGH, 1880) sobre a estabilidade de alguns tipos de escoamento. A partir do estudo de escoamentos paralelos em fluidos incompressíveis, Rayleigh concluiu que uma condição necessária para a instabilidade seria a existência de uma inflexão no perfil de velocidades no escoamento. Assim sendo, perfis de velocidade côncavo ou convexo seriam estáveis e não ocorreria a transição laminar-turbulenta.

Na mesma época, outro trabalho de destaque foi o de Osbourne Reynolds (REYNOLDS, 1883), sobre a existência de duas regiões distintas em um escoamento interno de água, dentro de um tubo. Utilizando um jato de corante conforme a Fig.1, Reynolds chama as regiões distintas do escoamento de "movimento Direto" e "movimento Sinuoso" (Direct and Sinuous). Em seu trabalho subsequente (REYNOLDS, 1895), ele procura explicar a posição da transição do escoamento, de "direto" para "sinuoso", por meio de um parâmetro adimensional que relaciona a velocidade do escoamento, a viscosidade do fluido e uma dimensão característica, tomada como sendo o diâmetro do tubo. Atualmente, este parâmetro é conhecido como número de Reynolds, sendo representado por Re.

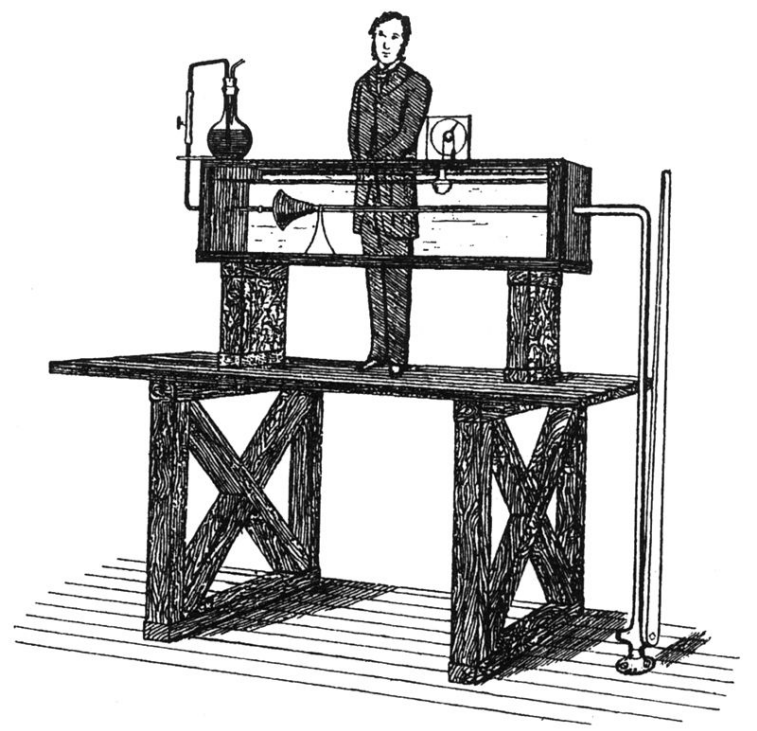

(a) Montagem experimental de Reynolds
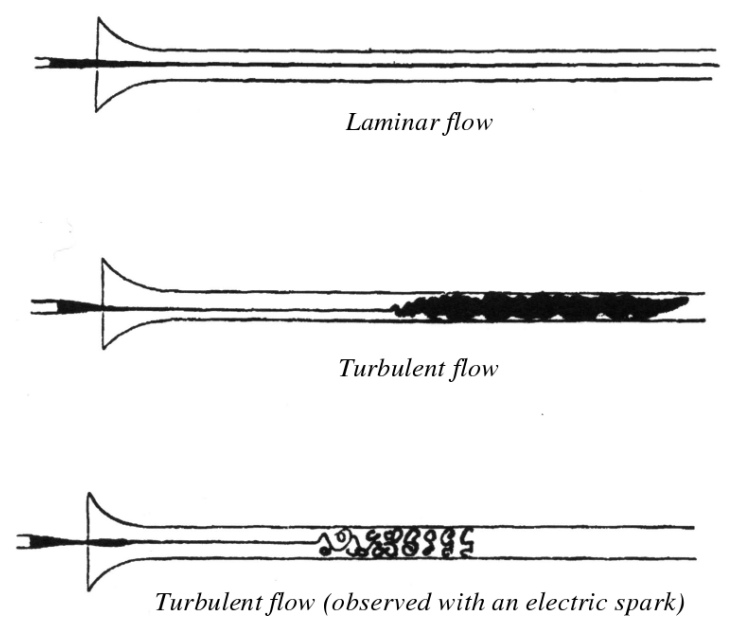

(b) Observações experimentais

Figura 1 - Montagem experimental de Reynolds para estudo de turbulência, retirado de Reynolds (1883).

De forma independente no início do século XX, William McFadden Orr (ORR, 
1909a; ORR, 1909b) e Arnold Sommerfeld (SOMMERFELD, 1908) derivaram uma equação de autovalores para determinar os modos de estabilidade bidimensionais em escoamentos viscosos e paralelos. Estes trabalhos complementaram e generalizaram os resultados de Lord Rayleigh a partir da equação linearizada de Navier-Stokes (Linearized Navier-Stokes Equations - LNSE), obtendo assim a fundamental equação de Orr-Sommerfeld (OrrSommerfeld Equation - OSE).

No ano de 1905 ocorreu a publicação de um trabalho fundamental da mecânica dos fluidos feito por Ludwig Prandtl (PRANDTL, 1905) e traduzido para o inglês por Dwight M. Miner (PRANDTL, 1928). Prandtl teoriza que a fricção do fluido o faria aderir a superfície adjacente, e que os efeitos da fricção seriam experimentados em uma fina região próxima a superfície; fora desta região o fluido se comportaria como se fosse invíscido. Esta região do escoamento ele chamou de Übergangsschicht (camada de transição), a qual atualmente é chamada de camada limite (boundary layer). O conceito de camada limite foi tão importante que permitiu a Prandtl estimar o arrasto aerodinâmico devido a fricção, tarefa até então impossível de ser realizada. A partir das ideias de Prandtl, seu aluno Heinrich Blasius (BLASIUS, 1908; BLASIUS, 1950), apresentou a primeira solução das equações da camada limite bidimensional para a placa plana e para um cilindro circular. Em seu trabalho, Blasius apresentou soluções mais precisas para o arrasto de fricção para a placa plana e os pontos de separação atrás do cilindro do que as estimadas anteriormente por Prandtl. A Fig. 2 apresenta a solução de Blasius para a camada limite de uma placa plana.

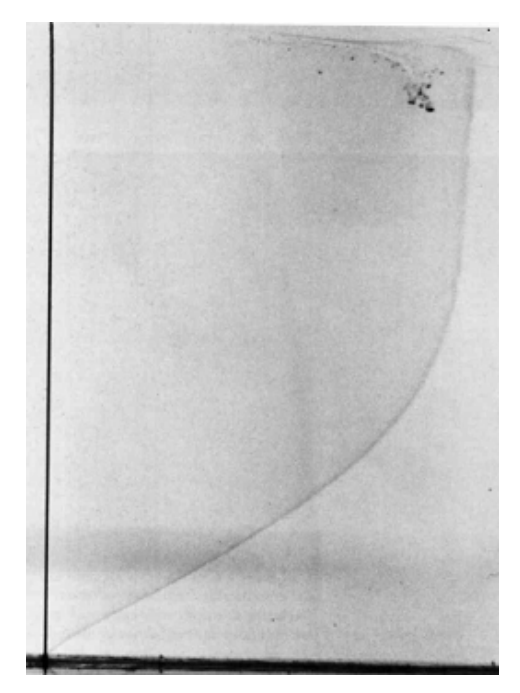

Figura 2 - Fotografia de uma camada limite laminar, retirado de Dyke (1988).

Entre o final dos anos 20 e início da década de 30, Walter Tollmien (TOLLMIEN, 1929) e Hermann Schlichting (SCHLICHTING, 1933) estudaram os efeitos de pequenas perturbações no perfil de camada limite derivado por Blasius. Estas perturbações foram modeladas como ondas que seriam atenuadas ou amplificadas dependendo da estabilidade do escoamento, sendo conhecidas como ondas Tollmien-Schlichting (TS), que podem ser 
observadas na Fig.3. Em seu trabalho, Tollmien desenvolveu o diagrama de instabilidade das ondas TS e Schlichting calculou as suas taxas de amplificação. Na mesma época, Squire (1933) demonstra que para cada modo instável tridimensional, existe um modo bidimensional associado com número de Reynolds menor; implicando portanto, que os modos bidimensionais são mais instáveis.

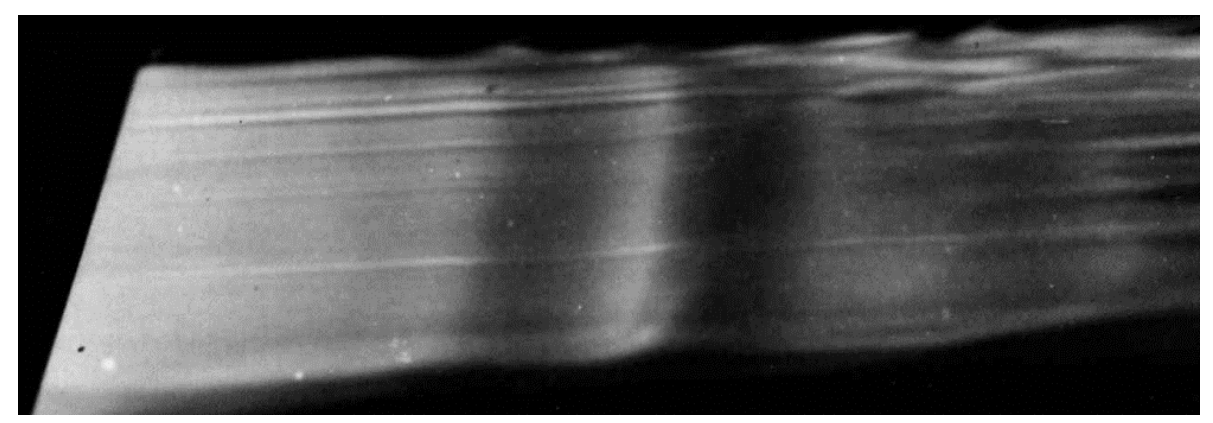

Figura 3 - Instabilidade na camada limite $(\mathrm{Re}=100000)$, onde aparecem as ondas TS, retirado de Dyke (1988).

Até o advento dos túneis de vento de baixa turbulência as ondas TS não puderam ser comprovadas experimentalmente. Somente nos anos 40 que Schubauer (SCHUBAUER; SKRAMSTAD, 1947), utilizando a técnica de fita vibrante (vibranting ribbon), conseguiu gerar ondas periódicas controladas dentro da camada limite laminar e observar a taxa de amplificação. Os resultados obtidos eram coerentes com a teoria desenvolvida por Tollmien-Schlichting. A Fig.4 apresenta esquematicamente o experimento de Schubauer.

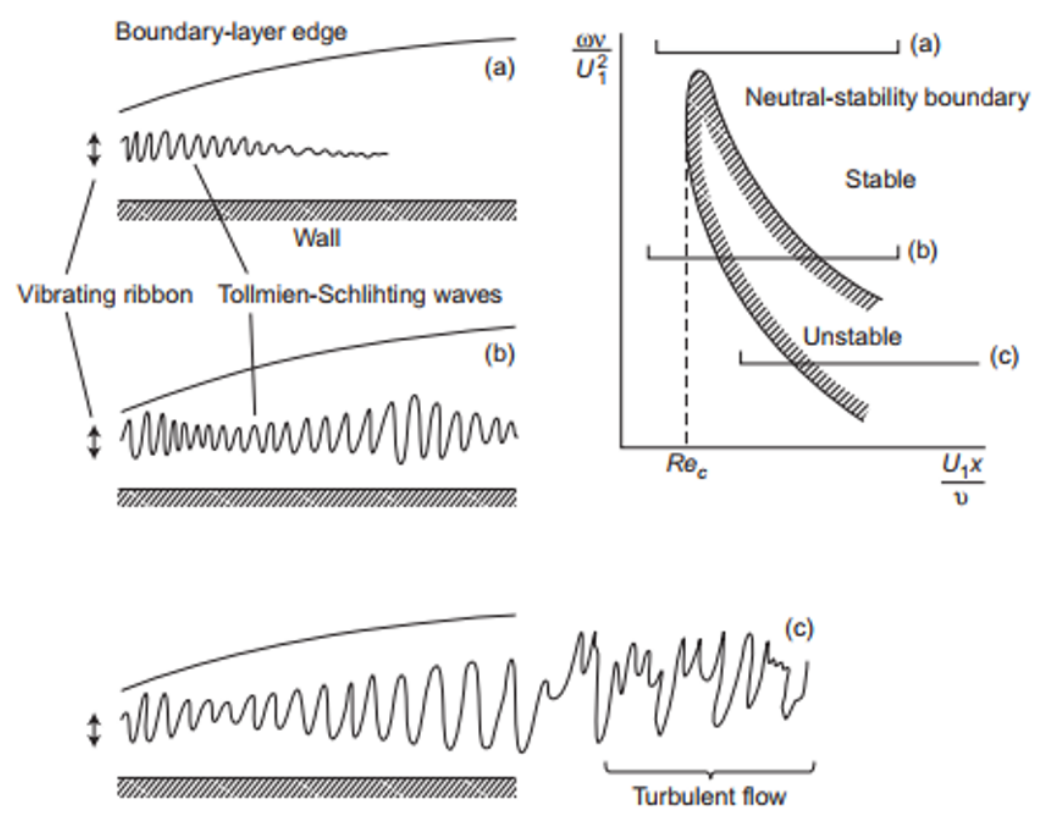

Figura 4 - Experimentos de Schbauer e diagrama de estabilidade, retirado de Houghton (2013). 
Embora elegante e funcional, a teoria desenvolvida por Tollmien-Schlichting é baseada na LNSE, que é valida apenas para pequenas perturbações. Neste contexto, Landau (1944) é um dos primeiros a estudar os efeitos não lineares na transição da camada limite, seguido por diversos pesquisadores nos anos seguintes. No início dos anos 50, Emmons (1951) procura descrever o surgimento das "explosões de turbulência" (turbulent spots) por meio de uma teoria probabilística. Estes spots turbulentos foram primeiramente observados por Schubauer e Skramstad (1947), precedendo o escoamento totalmente turbulento. Klebanoff, Tidstrom e Sargent (1962) associa alguns efeitos não lineares a oscilações nas ondas TS na direção da envergadura (spanwise), para uma camada limite de uma placa plana, gerando efeitos tridimensionais. A Fig. 5 apresenta imagens deste efeitos tridimensionais.

Do ponto de vista prático, Ingen (1956) propôs um método semi-empírico de previsão do ponto de transição a partir das taxas de amplificação das perturbações. Este procedimento é conhecido como método do "N crítico". Este método consiste em integrar a taxa de amplificação através da camada limite e assumir que a transição ocorre quando esta integral atinge o valor limite $e^{N}$. O método do "N crítico" é o método padrão para estimar o ponto de transição em aerofólios.

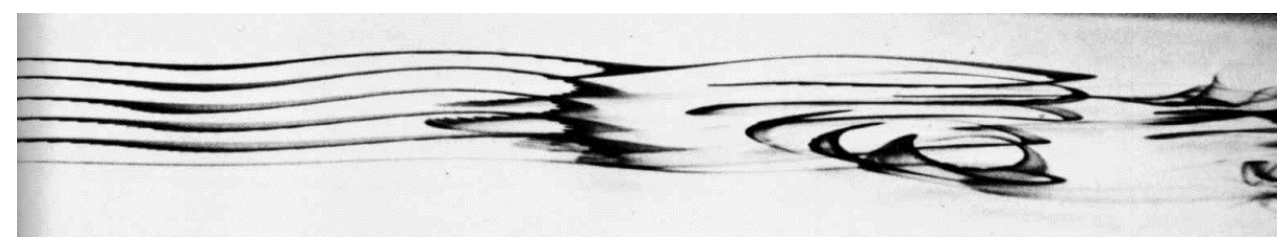

(a) Transição vista lateral: ondas TS 2D a esquerda, 3D ao centro, escoamento turbulento à direita.

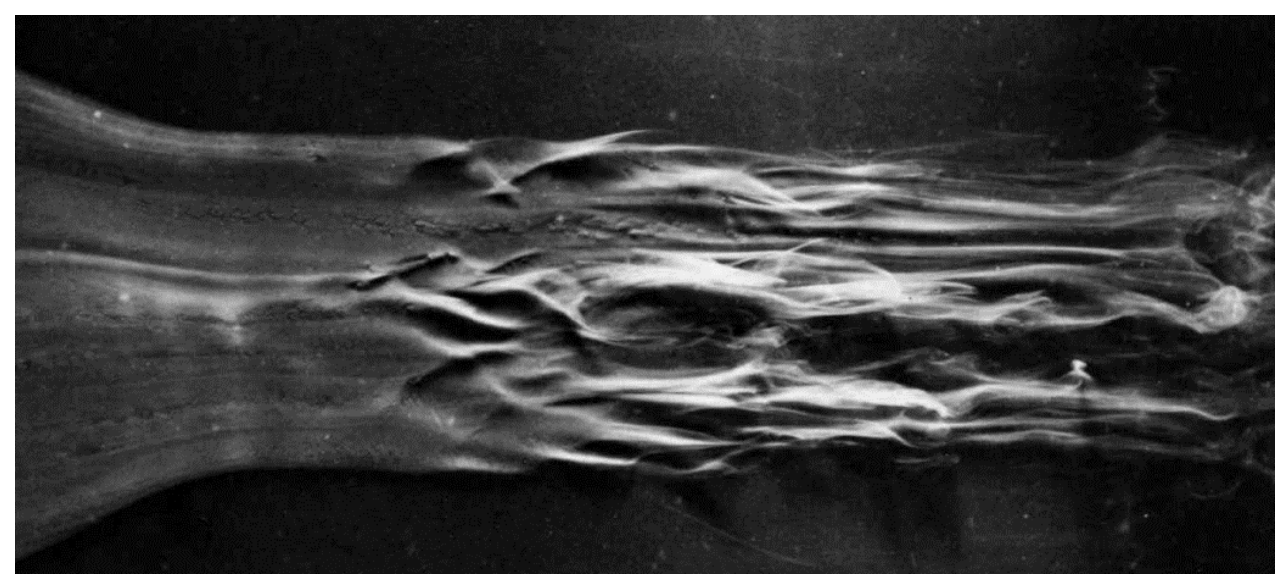

(b) Transição natural para placa plana levemente inclinada, ângulo de ataque (Angle of Attack - AoA) de $1^{\circ}$.

Figura 5 - Efeitos 3D em ondas TS, retirado de Dyke (1988).

Também nos anos 60, Gaster (GASTER, 1962; GASTER, 1965) propõe uma forma de associar o crescimento temporal das perturbações, que podem ser calculados teoricamente, ao crescimento espacial que é observado experimentalmente. A solução 
proposta consistia em resolver os modos espacias da equação de Orr-Sommerfeld.

Até o início dos anos 70 a maioria dos experimentos em transição eram realizados por meio de ondas bidimensionais monocromáticas geradas artificialmente para uma camada limite de uma placa plana. No entanto, Gaster e Grant (1975) realizaram experimentos de pacotes de ondas (wave-packets) através de um pulso excitando todas as frequências possíveis. Neste trabalho, eles observam a formação de ondas oblíquas que crescem rapidamente após a aparição das primeiras flutuações no escoamento. Observam também que estas ondas eventualmente tornam-se grandes o bastante para gerar harmônicos através de processos não lineares.

Em 1991, Cohen, Breuer e Haritonidis (1991) verificaram experimentalmente a transição da camada limite de uma placa plana produzida por wave-packets. Neste trabalho, identificam 3 estágios no processo de transição: (1) a fase linear, em que o wave-packet pode ser tratado como uma superposição de ondas bi e tridimensionais onde a energia se encontra centralizada no modo de maior amplificação; (2) no segundo estágio a maior parte da energia é transferida para ondas oblíquas, com a energia concentrada na onda com aproximadamente a metade do comprimento da onda de maior amplificação linear; e (3) o estágio final surgem os spots turbulentos, em que a amplitude das perturbações alcançam valores de aproximadamente $27 \%$ da velocidade do escoamento livre.

Medeiros e Gaster (1999) realizaram experimentos com pacotes de onda (wavepackets) para estudar a origem das ondas oblíquas. Neste trabalho, os autores verificaram que no regime não linear, independentemente do wave-packet, o surgimento de ondas oblíquas com mesmo número de onda na direção do escoamento (streamwise) e de envergadura (spanwise). Entretanto, o mecanismo de geração deste modos ainda é incerto. Embora a ressonância sub-harmônica tenha sido observada, ela por si só não explica o comportamento não linear da transição. Portanto deve haver um outro mecanismo contribuindo para o fenômeno.

Como pode ser visto pelo exposto anteriormente, apesar de ficar claro que as ondas TS sejam uma das principais responsáveis pela transição da camada limite, o fenômeno ainda não é completamente explicado. Há também questões relevantes como a interação entre as ondas TS e estruturas (por exemplo degraus, cavidades, etc.) afetam a transição da camada limite. Para tratar este tipo de problema foi construído o túnel LANT. 



\section{METODOLOGIA EXPERIMENTAL}

Neste capítulo serão apresentados os principais aspectos de infraestrutura utilizadas nos experimentos, ou seja, túnel de vento, sistema de posicionamento, anemometria a fio quente e sistema de medição acústica. Também serão apresentados os procedimentos experimentais e as técnicas de pós-processamento utilizadas neste trabalho.

\subsection{Túnel de vento}

Objeto de estudo deste trabalho, o túnel de vento de baixo ruído e baixa turbulência (LANT), inaugurado no final de 2016 no Departamento de Engenharia Aeronáutica da Escola de Engenharia de São Carlos (EESC-USP), é a instalação base para a realização dos experimentos. Este túnel foi originalmente projetado para realização de experimentos de transição em camada limite e ensaios aeroacústicos e, para tanto, ele necessita de baixo nível de turbulência, alta uniformidade de escoamento e baixo nível de ruído acústico. Nesta seção, serão apresentadas as principais características do LANT baseando-se no trabalho de Serrano Rico et al. (2018).

O circuito aerodinâmico do túnel, detalhado na Fig. 6, é disposto da seguinte forma: (1) seção de testes com $3 \mathrm{~m}$ de comprimento e $1 \mathrm{~m} \times 1 \mathrm{~m}$ de seção transversal, de paredes desenhadas para compensar o crescimento da camada limite divergindo a partir da entrada (inlet) até a saída (outlet); seguidos pelo difusor 1 (2), projetado para recuperação de pressão; ligando os difusores 1 e 2, tem-se as curvas 1 e 2 (3), de seção constante; ligando o difusor 2 (4) e o ventilador (5), há uma seção de transição de seção transversal quadrada para circular, ligada ao difusor 2 por meio de uma junta flexível; o ventilador (5), propelido por motor elétrico Siemens de 110 kW, e seguido por uma seção de transição, é ligado ao difusor 3 (6) novamente por uma junta flexível; o escoamento deixa o difusor 3 para entrar nas curvas 3 e 4 (7), de seção transversal constante; um difusor de grande ângulo (8), precedido por uma tela, faz com que o escoamento entre na câmara de estabilização (9), sendo constituída por uma colmeia (honeycomb), 5 telas e uma câmara; seguindo pela contração (10), que une a câmara de estabilização à seção de testes.

Um dos principais critérios para o projeto do túnel (Serrano Rico et al., 2018) foi a facilidade da montagem/desmontagem de cada seção, sendo construído de forma modular. A estrutura do túnel é majoritariamente feita de perfis de aço de seção quadrada de 50 mm de largura e 1,5 mm de espessura, as paredes são feitas de compensado naval de 15 mm de espessura. A contração e as pás do ventilador são feitas de fibra de vidro, sendo estas últimas reforçadas internamente com um estrutura de aço. 


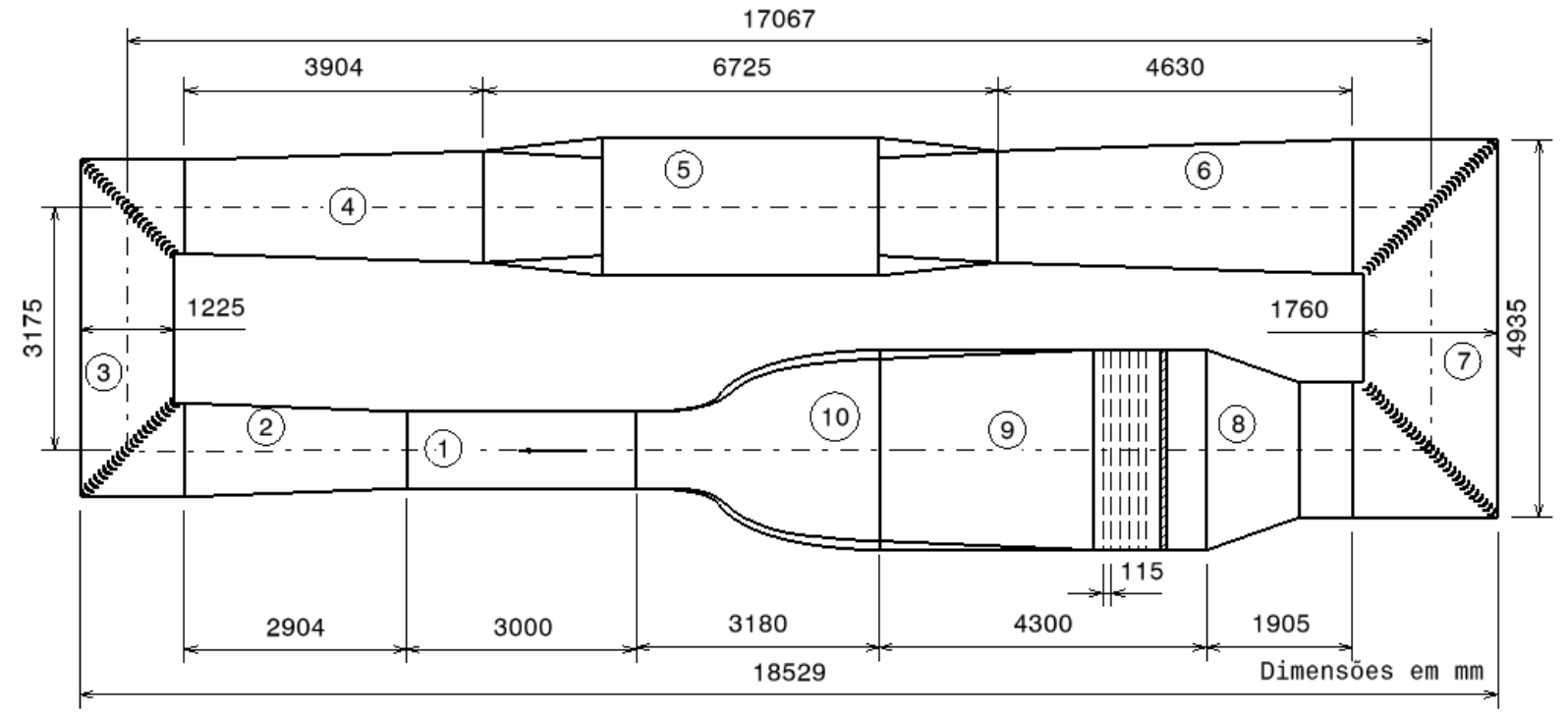

Figura 6 - Circuito aerodinâmico do túnel de vento. (1) seção de testes, (2) difusor 1, (3) curvas 1 e 2, (4) difusor 2, (5) ventilador, (6) difusor 3, (7) curvas 3 e 4, (8) difusor 4 / de grande ângulo, (9) câmara de estabilização e (10) contração. Dimensões em milímetros, retirado de Serrano Rico et al. (2018).

Para se obter o baixo nível de turbulência exigido para experimentos de transição e aeroacústica, o projeto do túnel de vento se utilizou de diferentes soluções, como por exemplo, ventilador e contração construídos sob medida, utilização de espumas e guias de curva acústicas, telas e colmeia de alumínio e câmara de estabilização estendida.

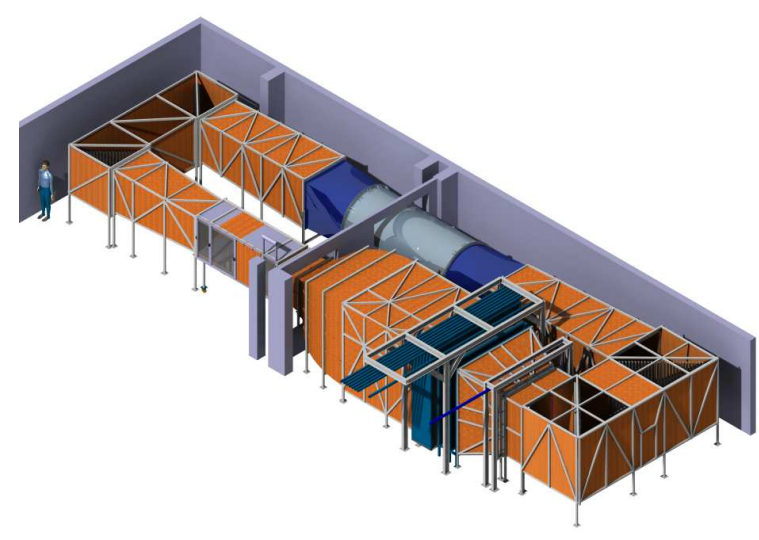

(a) Visão 3D do LANT

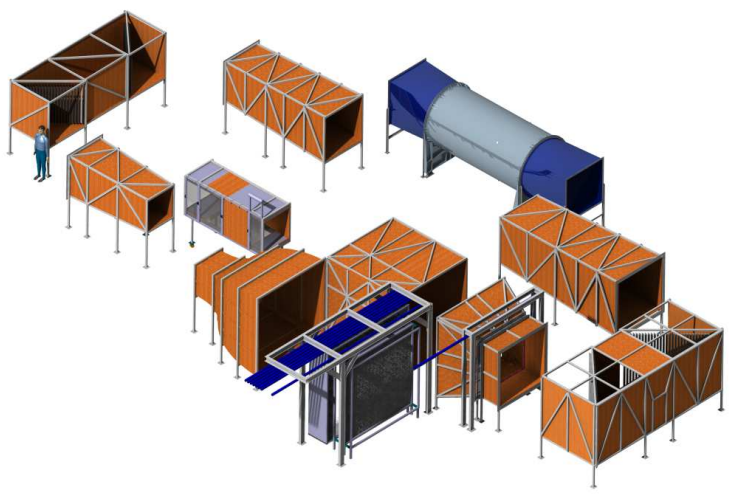

(b) Caráter modular do LANT

Figura 7 - Visão geral LANT, retirado de Serrano Rico et al. (2018).

A Tab. 1 apresenta as principais características técnicas das seções do túnel de vento, contendo as áreas de entrada e saída de cada seção, $A_{1}$ e $A_{2}$, respectivamente, bem como a razão entre estas áreas, o comprimento de cada seção, $L$, o ângulo de divergência, $\theta$, a vazão volumétrica, $Q$, e a razão de contração, $R C$. 


\begin{tabular}{|c|c|c|}
\hline Seção & $A_{2} / A_{1}$ & Comentários \\
\hline Câmara de ensaios & $1,0 / 1,0=1,0$ & $L=3000 \mathrm{~mm}$ \\
\hline Difusor 1 & $1,5 / 1,0=1,5$ & $\begin{array}{l}2 \theta=5^{\circ} \\
L=2900 \mathrm{~mm}\end{array}$ \\
\hline Curvas 1 e 2 & $1,5 / 1,5=1,0$ & $\begin{array}{l}\text { guias defletoras e paredes com trata- } \\
\text { mento acústico }\end{array}$ \\
\hline Difusor 2 & $2,1 / 1,5=1,4$ & $\begin{array}{l}2 \theta=3,8^{\circ} \\
L=3900 \mathrm{~mm}\end{array}$ \\
\hline Ventilador & $2,5 / 2,5=1,0$ & $\begin{array}{l}D=1800 \mathrm{~mm} \\
Q=60 \mathrm{~m}^{3} \mathrm{~s} \\
\text { transição de seção transversal de } \\
L=1700 \mathrm{~mm}\end{array}$ \\
\hline Difusor 3 & $3,1 / 2,1=1,5$ & $\begin{array}{l}2 \theta=4,2^{\circ} \\
L=4600 \mathrm{~mm}\end{array}$ \\
\hline Curvas 3 e 4 & $3,1 / 3,1=3,1$ & $\begin{array}{l}\text { guias defletoras e paredes com es- } \\
\text { puma acústica }\end{array}$ \\
\hline Difusor de grande ângulo & $7,0 / 3,1=2,3$ & $\begin{array}{l}2 \theta=29,4^{\circ} \\
L=1900 \mathrm{~mm} \\
1 \text { tela com } 58 \% \text { de área aberta }\end{array}$ \\
\hline Câmara de estabilização & $7,0 / 7,0=1,0$ & $\begin{array}{l}L=4300 \mathrm{~mm} \\
5 \text { telas com } 58 \% \text { de área aberta } \\
1 \text { colmeia de célula com } 3,2 \mathrm{~mm} \text { de } \\
\text { diâmetro e } 63,5 \mathrm{~mm} \text { de comprimento }\end{array}$ \\
\hline Contração & $7,0 / 1,0=7,0$ & $\begin{array}{l}R C=7 \\
L=4300 \mathrm{~mm}\end{array}$ \\
\hline
\end{tabular}

Tabela 1 - Características do túnel de vento.

\subsubsection{Ventilador}

O ventilador axial apresentado na Fig. 8 foi projetado para fornecer uma vazão volumétrica de $60 \mathrm{~m}^{3} / \mathrm{s}$. Sendo o ventilador uma das principais fontes de ruído acústico de fundo, ele foi construído sob medida para o LANT, para minimização de geração de ruído utilizando soluções como baixa RPM e relação de pás do rotor/estator calculada segunda a teoria de Tyler e Sofrin (1962). A estrutura do ventilador tem $1800 \mathrm{~mm}$ de diâmetro externo e $680 \mathrm{~mm}$ de casulo, e é constituída por um rotor de 16 pás e um estator de 13 pás, ambos de fibra de vidro reforçados com núcleo de aço, sendo propelidos por um conjunto Siemens com motor elétrico de $110 \mathrm{~kW}$ e um inversor Micromaster 440. A fim de evitar a transmissão de vibrações, o ventilador é ligado as demais seções do túnel por juntas flexíveis de $100 \mathrm{~mm}$ e a sua estrutura repousa sob uma base isolada de concreto. 


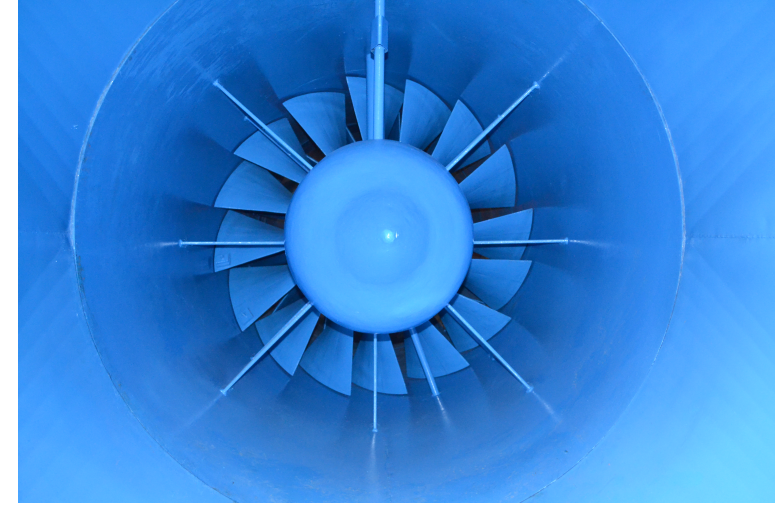

(a) Visão do rotor

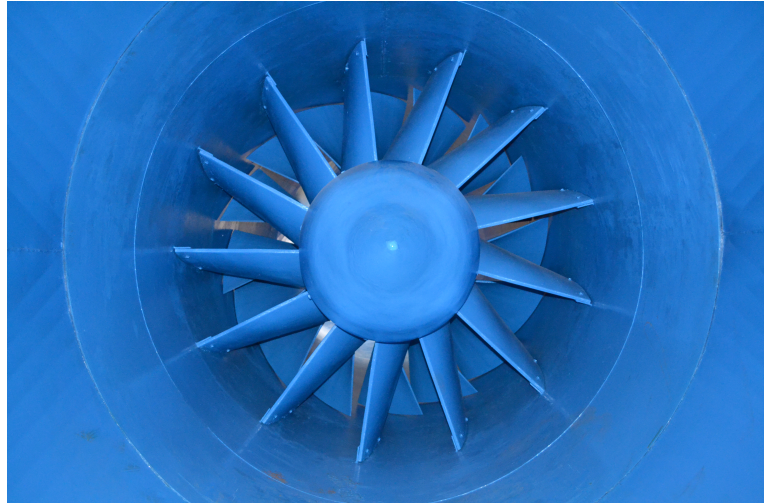

(b) Visão do estator

Figura 8 - Visões do inflow, (a), e do outflow, (b), do ventilador do LANT.

\subsubsection{Curvas}

As curvas tem a função de defletir em $90^{\circ}$ o escoamento com a menor perda de pressão e geração de distúrbios possível. Para evitar a perda de pressão e a separação da camada limite, causando uma má uniformidade e alto nível de turbulência no escoamento na câmara de ensaios, as curvas são equipadas com um "cascata de aerofólios" chamadas de guias defletoras (turning vanes), conforme o trabalho de (SAHLIN; JOHANSSON, 1991). No LANT, de maneira similar ao túnel Klebanoff-Saric (HUNT et al., 2010), foram utilizadas guias defletoras da DUCTMATE que são construídas de aço e preenchidas com material de absorção de ruído, especialmente projetadas para sistemas que precisam de baixo ruído, como ar-condicionado. A superfície das paredes das curvas também são revestidas com espuma acústica à base de melamina da BASF com 100 mm de espessura, conforme a Fig. 9.

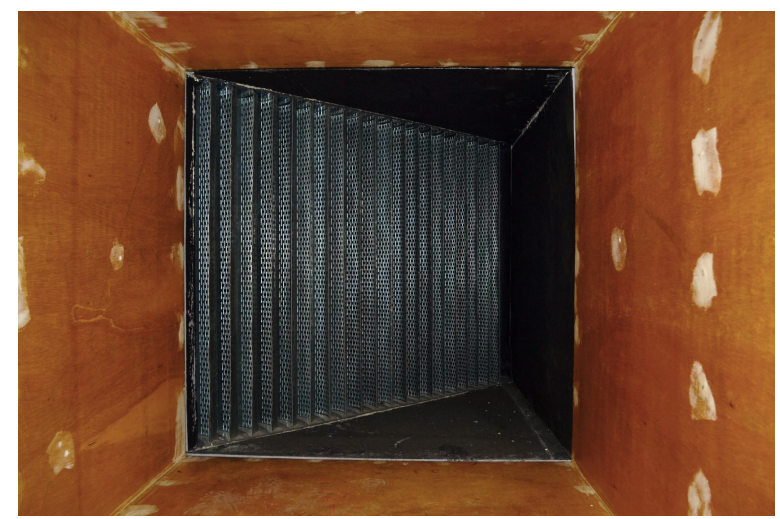

(a) Curva 2

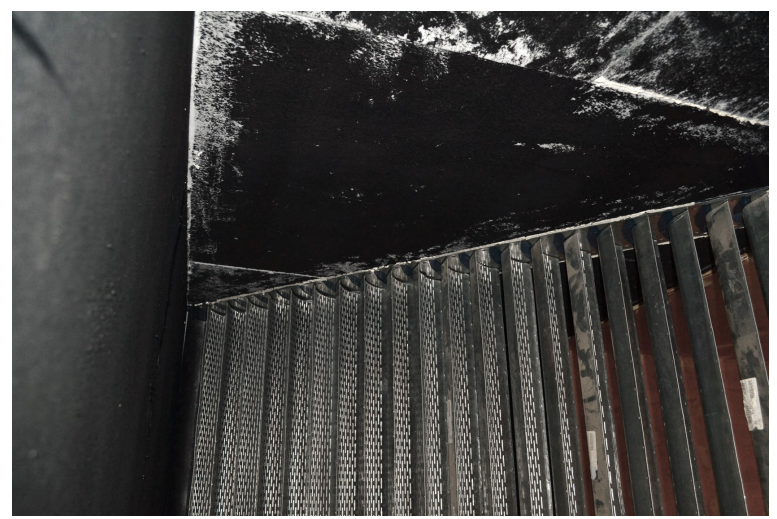

(b) Espuma acústica e guias defletoras

Figura 9 - Detalhes das guias defletoras e do revestimento de espuma nas curvas, LANT. 


\subsubsection{Câmara de Estabilização}

A câmara de estabilização, também chamada de câmara de estagnação ( settling chamber), possui a maior área de seção transversal e, consequentemente, a menor velocidade do túnel de vento. É o local onde geralmente são instalados os dispositivos para tratamento da qualidade do escoamento, tais como a colmeia e as telas, sendo seu objetivo, portanto, produzir um escoamento com baixa turbulência, paralelo ao eixo central do túnel e espacialmente uniforme. No caso do LANT, a câmara de estabilização é constituída em 3 partes: (1) a colmeia, (2) as telas e (3) o duto de relaxação. A colmeia tem a função de retificar o escoamento proveniente da curva 4 e do difusor de grande ângulo e quebrar as flutuações maiores em menores, apresentando uma menor perda de pressão em relação as telas nesta função (LOEHRKE; NAGRIB, 1976). Já as telas tem a função de reduzir a turbulência e melhorar a uniformidade do escoamento (GROTH; JOHANSSON, 1988). Estas soluções, Fig. 10, são instaladas numa estrutura de trilhos e calhas de fácil manutenção, podendo conter até 7 telas. O escoamento proveniente das telas não é exatamente isotrópico (GROTH; JOHANSSON, 1988), o que torna necessário uma região de relaxação antes que o escoamento venha a ser submetido a gradientes adversos de pressão, o que poderia provocar o desprendimento da camada limite e o consequente aumento no nível de turbulência. O duto de relaxação tem, portanto, a função de permitir que o escoamento se torne isotrópico antes que ele adentre na contração. A solução adotada no LANT foi um duto de relaxação estendido com 4,3 m de comprimento.

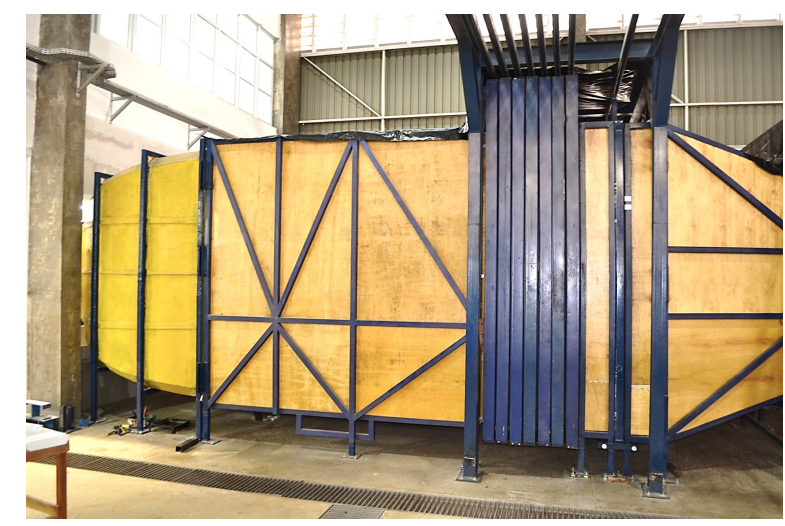

(a) Da esquerda para a direita: contração, câ-(b) Det mara de estabilização, telas, colmeia e difusor de grande ângulo

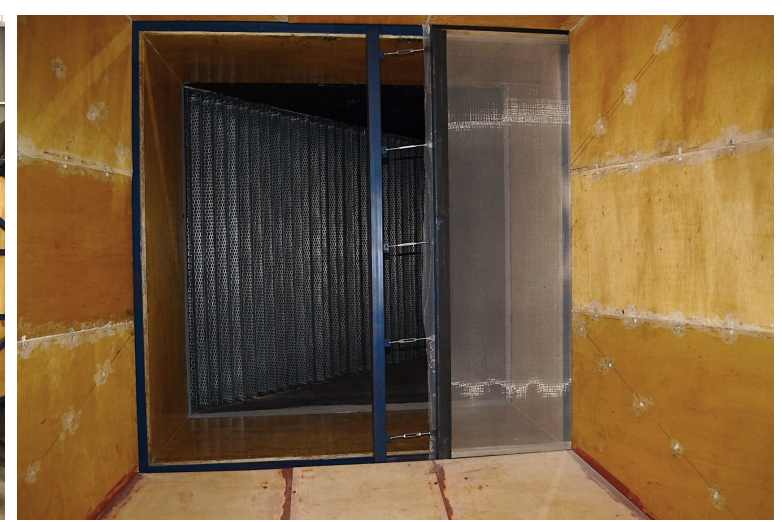

Detalhe da tela parcialmente aberta em fotografia tirada a partir do difusor de grande ângulo

Figura 10 - Câmara de estabilização.

\subsubsection{Contração}

Na sequência da câmara de estabilização vem a contração, cuja função é devolver a seção transversal do túnel novamente nas dimensões da câmara de ensaios, aumentando a velocidade do escoamento (WHITEHEAD; WU; WATERS, 1951). O LANT utiliza uma 
contração com razão de $7: 1$, sendo projetada com o menor comprimento possível de modo a reduzir o crescimento e evitar a separação da camada limite devido a gradientes adversos de pressão (Serrano Rico et al., 2018). Ela foi construída em fibra de vidro imantada por resina de poliéster endurecida. Para evitar o surgimento de escoamentos secundários pela interação entre as camadas limites das paredes da contração, chanfros (corner fillets) de $45^{\circ}$ foram adicionados se iniciando na câmara de relaxação conforme a Fig. 11.

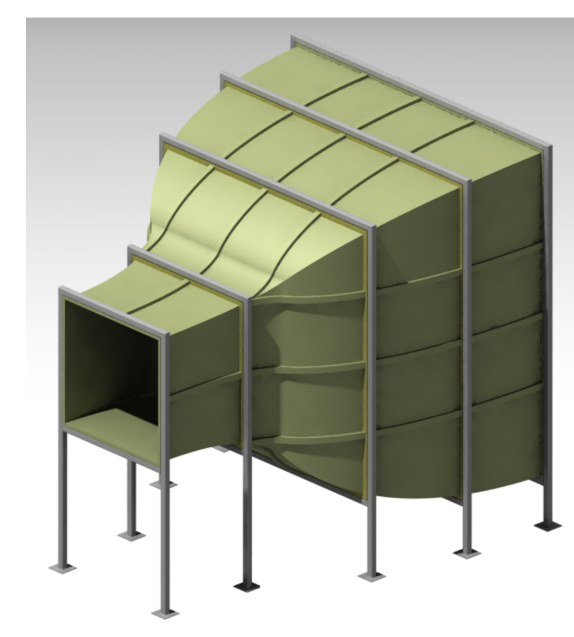

(a) Projeto

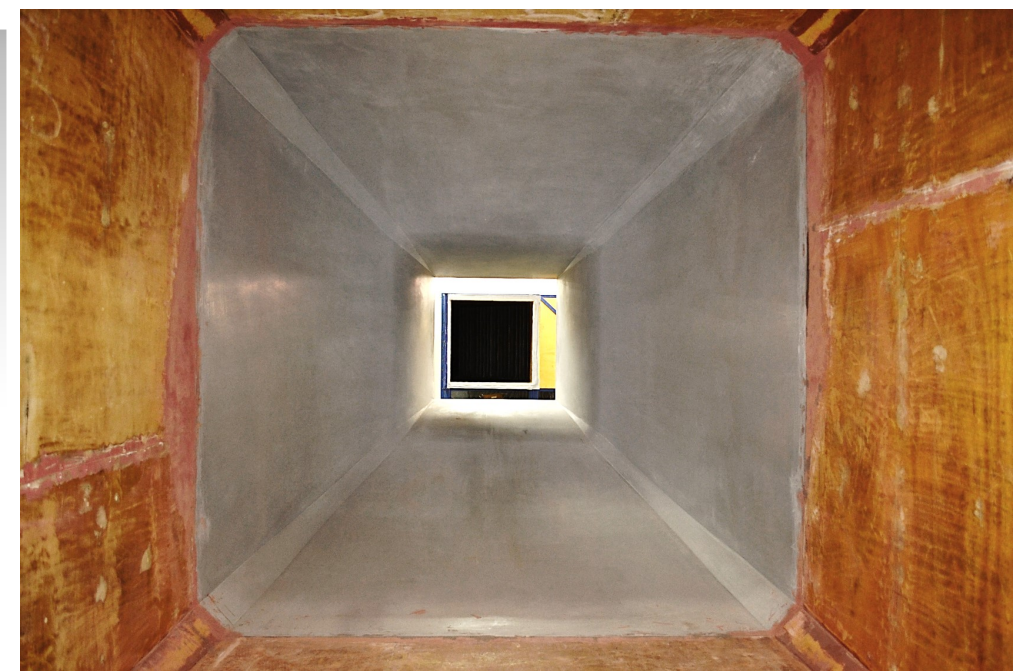

(b) Imagem fotografada a partir da câmara de estabilização

Figura 11 - Contração, retirado de Serrano Rico et al. (2018)

\subsubsection{Câmara de Ensaios}

A câmara de ensaios foi construída em compensado naval, acrílico e espuma, e suportada por uma estrutura de perfis de aço. Possui 4 portas de acrílico intercambiáveis que permitem adaptar rapidamente a câmara de ensaios à instrumentação a ser utilizada em um conjunto de experimentos. O piso e o teto são feitos de painéis intercambiáveis, com um lado de compensado naval e outro de espuma acústica. No caso de experimentos acústicos, a espuma acústica pode ser utilizada para criar uma câmara semi-anecoica. Em experimentos aerodinâmicos a parede rígida deve ser utilizada. Também há 2 janelas de acrílico no piso da câmara, permitindo a realização de experimentos de velocimetria por imagem de partículas (particle image velocimetry - PIV) utilizando uma câmera e um laser. Para a realização de experimentos com a técnica de anemometria à fio quente (Hot Wire Anemometry - HWA), as portas podem ser retiradas e o sistema de posicionamento pode ser acoplado a câmara de ensaios. Para fácil manutenção e substituição, a câmara de ensaios é presa ao túnel por meio de acoplamentos com parafusos e suportada em uma estrutura com rodas, conforme pode ser visto na Fig. 12. 


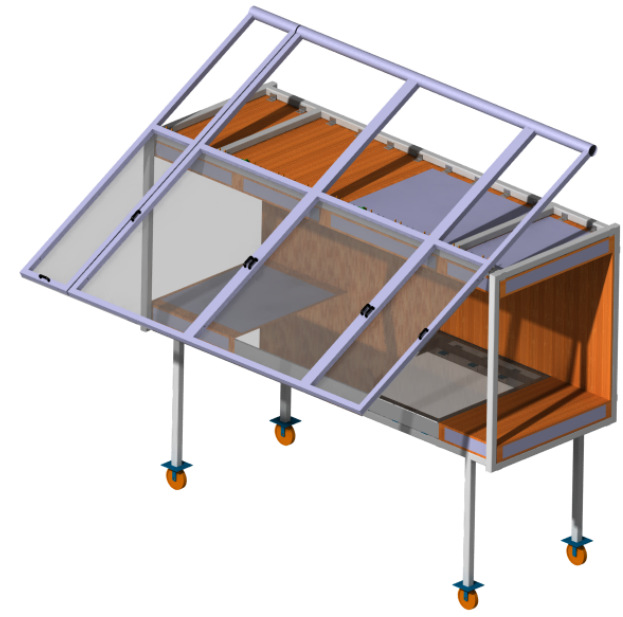

(a) Projeto da câmara de ensaios

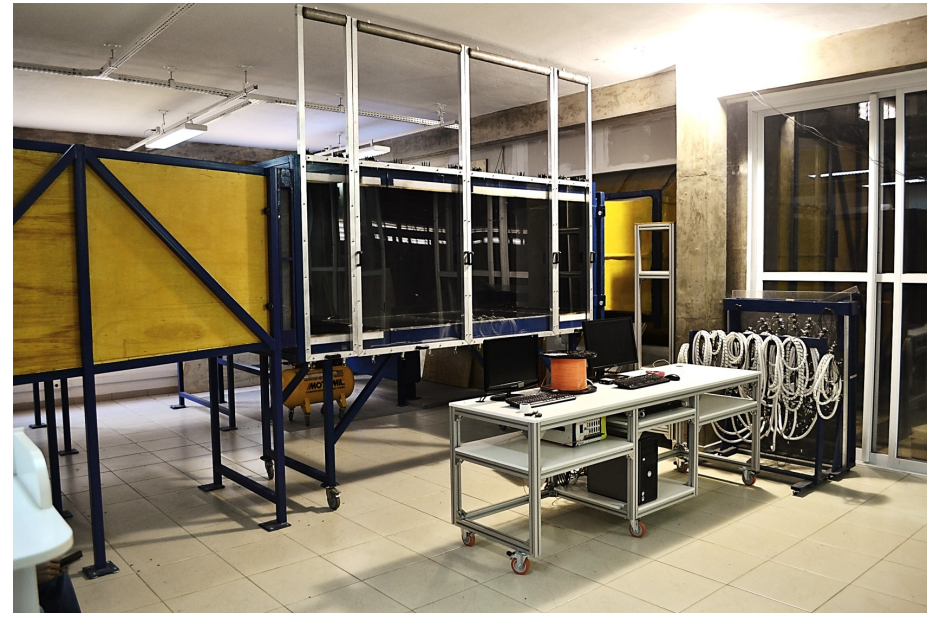

(b) Câmara de ensaios montada

Figura 12 - Câmara de ensaios de janelas e módulos de parede intercambiáveis.

\subsubsection{Sensores e sistema de controle}

A instrumentação para a medição da velocidade do LANT consiste em: 1 tubo de Pitot Dwyer de aço inoxidável, 1 sensor de pressão diferencial analógico Honeywell DCXL05DS, 1 sensor de temperatura digital (12-bits) Dallas DS18B20, 1 sensor de temperatura/pressão Bosh BMP280, 1 módulo conversor A/D Texas Instruments ADS1115 (16 bits) e 1 módulo Arduíno Uno. Para a aferição da velocidade, o sensor de pressão diferencial é ligado ao tubo de Pitot e suas saídas são convertidas em sinais digitais pelo módulo ADS1115, sendo enviados juntamente com os dados dos outros sensores ao módulo Arduíno. Um programa em Labview controla o sistema de aquisição e informa a velocidade do túnel. Com esta informação é possível alterar manualmente a velocidade de rotação do motor através do software Starter da Siemens. A tabela 2 apresenta as características técnicas detalhadas dos sensores.

\begin{tabular}{cccc} 
Sensor & Tipo & Escala de medição & Incerteza \\
\hline \hline DCXL05DS & pressão diferencial & $0 \ldots 1245 \mathrm{~Pa}$ & $0,7 \mathrm{~Pa}$ \\
DS18B20 & temperatura & $-10 \ldots 85^{\circ} \mathrm{C}$ & $0,5{ }^{\circ} \mathrm{C}$ \\
BMP 280 & pressão & $30 \ldots 110 \mathrm{kPa}$ & $0,012 \mathrm{kPa}$ \\
BMP 280 & temperatura & $0 \ldots 65{ }^{\circ} \mathrm{C}$ & $0,5{ }^{\circ} \mathrm{C}$ \\
& & & \\
\hline
\end{tabular}

Tabela 2 - Características técnicas dos sensores.

Partindo dos dados de temperatura e pressão, a velocidade do escoamento na 
câmara de ensaios é dada por

$$
U_{\infty}=\sqrt{\frac{2 \Delta P}{\rho}}
$$

em que, $\Delta P$ é a pressão diferencial medida no tubo de Pitot, em Pascal e $\rho$ é a densidade do ar dentro do túnel, em $\mathrm{kg} / \mathrm{m}^{3}$.

A densidade do ar é estimada através da fórmula

$$
\rho=\frac{P_{a t m}}{R^{*} \cdot T_{\text {in }}}
$$

onde $P_{a t m}$ é a pressão atmosférica, em Pascal, $T_{i n}$ é a temperatura interna do túnel, em Kelvin, e $R^{*}$ é a constante específica dos gases, em Joules por quilograma por Kelvin. Assim, com as informações obtidas pelos sensores de pressão e temperatura, é estimada a velocidade do túnel. Por se tratar de uma medida indireta, é necessário calcular a incerteza na velocidade. Utilizando como base a apostila de física experimental Silva Junior (2014), pode-se demonstrar que a incerteza nas medidas de densidade do ar e da velocidade do túnel são dadas pelas expressões

$$
\operatorname{err}(\rho)=\frac{P_{a t m}}{R^{*} \cdot T_{\text {in }}} \times \sqrt{\left(\frac{1}{P_{a t m}}\right)^{2} \operatorname{err}\left(P_{a t m}\right)^{2}+\left(\frac{1}{T_{\text {in }}}\right)^{2} \operatorname{err}\left(T_{i n}\right)^{2}}
$$

e

$$
\operatorname{err}(U)=\sqrt{\frac{2 \Delta P}{\rho}} \times \sqrt{\left(\frac{1}{2 \Delta P}\right)^{2} \operatorname{err}(\Delta P)^{2}+\left(\frac{1}{2 \rho}\right)^{2} \operatorname{err}(\rho)^{2}}
$$

em que $\operatorname{err}(\rho), \operatorname{err}(U), \operatorname{err}\left(P_{a t m}\right), \operatorname{err}(T)$ e $\operatorname{err}(\Delta P)$ são respectivamente a incerteza nas medidas de densidade do ar, da velocidade do túnel, e nos sensores de pressão atmosférica, temperatura e pressão diferencial.

Para o caso das condições médias de pressão atmosférica em São Carlos $\left(P_{a t m} \approx\right.$ $92,08 \mathrm{kPa})$ e a uma temperatura de $T_{i n}=30{ }^{\circ} \mathrm{C}\left(R^{*}=287 \mathrm{~J} \mathrm{~kg}^{-1} \mathrm{~K}^{-1}\right)$, a incerteza na velocidade é apresentada na Fig. 13.

Apesar de apresentar uma incerteza muito grande na estimativa de baixas velocidades, isto não invalida o controle utilizado, um vez que a maioria das aplicações no LANT acontecem a velocidades maiores que $5 \mathrm{~m} / \mathrm{s}$. Nesta configuração de experimentos, a incerteza na medida de velocidade é estável em $2 \%$. 


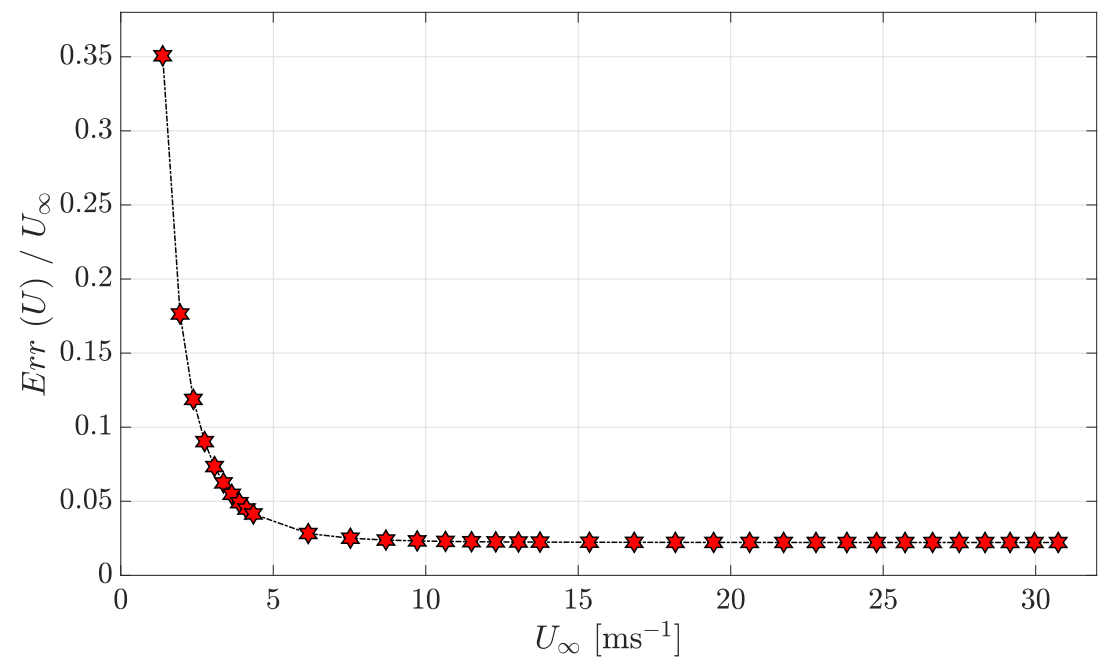

Figura 13 - Incerteza na estimativa da velocidade no LANT.

\subsection{Anemometria à fio quente}

A anemometria à fio quente (Hot Wire Anemometry - HWA) é usada há muito tempo como uma ferramenta fundamental na pesquisa experimental em mecânica de fluídos, principalmente em aerodinâmica. Embora consista em uma técnica pontual, é largamente utilizada por sua alta sensibilidade a mudanças de velocidade e excelente resposta em frequência, permitindo um estudo detalhado da turbulência. Esta seção é baseada nos textos de Perry (1982) e Bruun (1995), as principais referências no assunto.

A técnica se baseia no principio de transferência convectiva de calor, expondo um pequeno filamento aquecido, o sensor, Fig. 14, a um escoamento de um fluido, sendo a taxa de transferência dependente da velocidade do escoamento. Assim, é possível estabelecer uma relação entre a tensão de saída do aparelho e a velocidade do fluido.

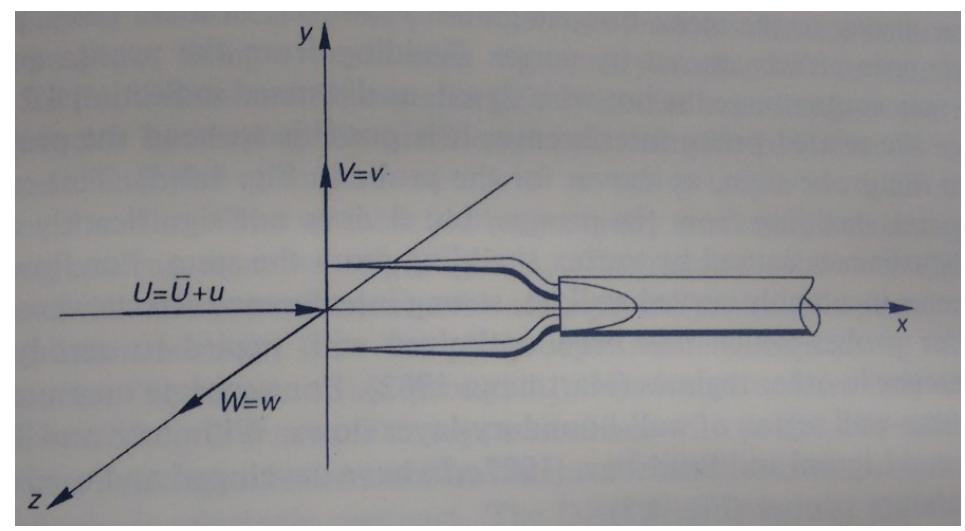

Figura 14 - Uma sonda 1D com o fio posicionado paralelamente ao escoamento médio, retirado de Bruun (1995).

Tipicamente para o ar os sensores utilizados são constituídos de filamentos de tungstênio com comprimento de 1,2 mm e diâmetro de $5 \mu \mathrm{m}$. No estudo da turbulência, as 
sondas mais utilizadas são as miniaturizadas, com filamentos de 1,2 mm de comprimento e, as normais, com filamentos de $3 \mathrm{~mm}$. Neste trabalho, todas as medidas foram feitas com sondas de camada limite, conforme a Fig. 15.

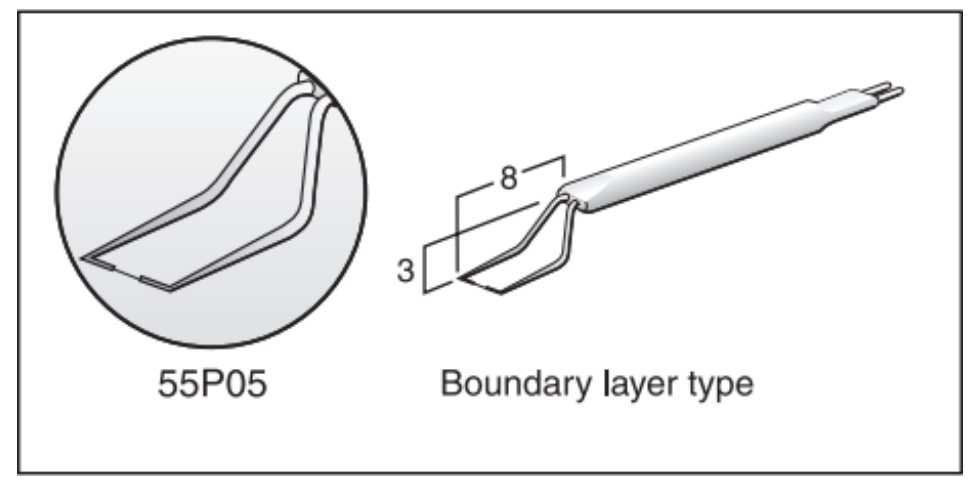

Figura 15 - Sonda de camada limite.

\subsubsection{Modos de operação}

Basicamente, a técnica de HWA opera em 2 modos: (1) à corrente constante (Constant Current Anemometry - CCA) e, (2) à temperatura constante (Constant Temperature Anemometry - CTA). No modo CCA, a corrente no sistema é mantida constante, e a resistência do fio é monitorada através da queda de tensão no sensor; no modo CTA, a temperatura no fio/sensor é mantida constante, e a corrente elétrica fornecida pelo sistema varia de acordo com a velocidade do escoamento. Embora ambos os modos sejam equivalentes nas respostas e suas razões sinal-ruído (signal-to-noise ratio), anemômetros em modo CCA são pouco utilizados, pois este apresenta a característica de queimar o filamento com certa facilidade. A tabela 3 compara as principais características dos modos de anemometria. Em todas as medidas feitas neste trabalho, foram utilizados anemômetros em modo CTA.

\subsubsection{Modo de temperatura constante - CTA}

No modo CTA, o circuito típico do anemômetro é constituído por uma ponte de Wheatstone, um amplificador de retroalimentação (feedback) e um sub-circuito de testes, como pode ser visto na Fig. 16. Quando a velocidade do escoamento é alterada, no modo CTA há um desbalanceamento da ponte que é amplificado pelo circuito de retroalimentação e comparado com uma tensão de referência (offset); assim, a corrente é aumentada ou diminuída para reequilibrar a ponte.

Define-se a relação de ponte, como a razão entre as resistências

$$
B_{\text {ratio }}=\frac{R_{1}}{R_{2}}
$$




\begin{tabular}{ccc} 
& Modo CTA & Modo CCA \\
\hline \hline Princípio de & A resistência e a & Corrente que circula \\
funcionamento & $\begin{array}{c}\text { temperatura do sensor } \\
\text { são mantidas } \\
\text { constantes }\end{array}$ & $\begin{array}{c}\text { no sensor é mantida } \\
\text { constante }\end{array}$ \\
& & \\
\hline
\end{tabular}

Facilidade no uso

Vantagens

Alta resposta em

frequência

Alta resposta em

frequência

Baixo ruído

Dificuldade no uso

Desvantagens Circuito complexo Resposta diminui com

a velocidade

Risco de queima no

sensor

Tabela 3 - Comparação entre modos CTA e CCA.

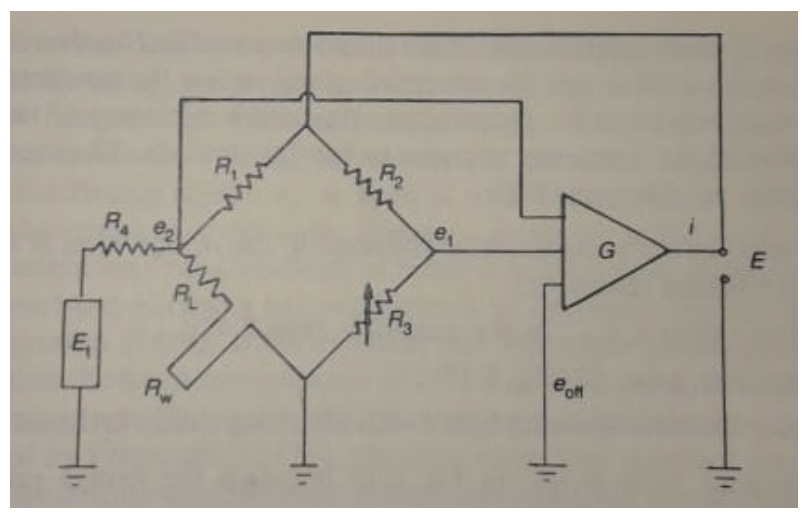

Figura 16 - Circuito básico anemômetro em modo CTA, retirado de Bruun (1995).

No equilíbrio,

$$
\frac{R_{1}}{\left(R_{w}+R_{L}\right)}=\frac{R_{2}}{R_{3}}
$$

em que $R_{3}, R_{L}$ e $R_{w}$ são respectivamente as resistências de ajuste, dos cabos de conexão e do sensor. Tipicamente, relação de ponte é 20 : 1 e a resistência de ajuste é dada pela Eq.3.7, onde $\alpha$ é chamada taxa de sobreaquecimento (overheat). Para o ar, é comumente 
utilizado $\alpha=0,8$ (BRUUN, 1995) e

$$
R_{3}=R_{w}(1+\alpha)
$$

\subsubsection{Modelo térmico do anemômetro à fio quente}

Conforme descrito anteriormente, a técnica de HWA é baseada na transferência de calor convectiva de um elemento sensor aquecido, sendo a configuração mais comum sensores de fio cilíndricos. Assim, a taxa de transferência de calor de um fio aquecido colocado em um escoamento de fluido, depende das propriedades do ambiente (por exemplo, a densidade do fluido, $\rho$, a viscosidade, $\mu$, a condutividade térmica, $k$, etc.) e das propriedades do escoamento (velocidade, $\mathbf{V}$, temperatura, $T_{a}$, pressão, $P$, etc.). Uma descrição detalhada do modelo térmico da técnica de HWA é apresentado em Bruun (1995).

Considerando um elemento sensor finito exposto a um escoamento de fluido, o balanço de energia do elemento pode ser escrito como

$$
d \dot{Q}_{e}=d \dot{Q}_{f c}+d \dot{Q}_{c}+d \dot{Q}_{r}+d \dot{Q}_{s}
$$

em que $d \dot{Q}_{e}$ é a taxa de geração de calor elétrico, $d \dot{Q}_{f c}$ é a taxa de transferência de calor por convecção forçada, $d \dot{Q}_{c}$ é a taxa de transferência de calor por condução, $d \dot{Q}_{r}$ é a taxa de transferência de calor por radiação, e $d \dot{Q}_{s}$ é a taxa de acumulo de energia no fio.

Por simplificação, considere que as perdas de calor por radiação e condução sejam desprezíveis, e que o sistema se encontra em regime, ou seja, não há acúmulo de calor no sensor, logo, a Eq.3.8 se torna

$$
d \dot{Q}_{e}=d \dot{Q}_{f c}
$$

Estas quantidades podem ser modeladas como

$$
d \dot{Q}_{e}=\frac{I^{2} \chi_{w}}{A_{w}} d x
$$

$\mathrm{e}$

$$
d \dot{Q}_{f c}=\pi d h\left(T_{w}-T_{a}\right) d x
$$

em que $I$ é a corrente que passa no fio, $\chi_{w}$ é a resistividade do material, $A_{w}$ é a área de seção transversal do fio, $d$ é o diâmetro do fio, $h$ é o coeficiente de transferência de calor entre o fio e o escoamento, $T_{w}$ é a temperatura do fio, e $T_{a}$ é a temperatura do fluido. 
Portanto, da equação de balanço de energia tem-se

$$
\frac{I^{2} \chi_{w}}{A_{w}}=\pi d h\left(T_{w}-T_{a}\right)
$$

A resistividade de um material, a temperatura constante, é definida como a resistência por unidade de comprimento e por unidade de área transversal. Assim,

$$
\chi_{w}=\frac{R_{w} A_{w}}{l}
$$

em que $R_{w}$ é a resistência e $l$ é o comprimento do fio.

Logo, a Eq.3.12 torna-se

$$
I^{2} R_{w}=\pi d h l\left(T_{w}-T_{a}\right) .
$$

O número de Nusselt, $N u$, é a grandeza adimensional que relaciona as taxas de transferência de calor convectiva e condutiva, sendo dado por

$$
N u=\frac{\text { Taxa de transferência de calor convectiva }}{\text { Taxa de transferência de calor condutiva }}=\frac{h d}{k},
$$

em que $k$ é a condutividade térmica do fluido. Substituindo na Eq.3.14, obtém-se

$$
I^{2} R_{w}=\pi l k N u\left(T_{w}-T_{a}\right)
$$

A resistência elétrica de um fio condutor em função da temperatura geralmente é modelada na forma

$$
R_{w}=R_{0}\left(1+\alpha_{0}\left(T_{w}-T_{0}\right)\right)
$$

em que $R_{0}$ é a resistência do fio em uma temperatura de referência, $\alpha_{0}$ o coeficiente de resistividade na temperatura de referência.

Assim, substituindo a Eq. 3.17 na Eq. 3.16, obtém-se

$$
\frac{I^{2} R_{w}}{R_{w}-R_{a}}=\frac{\pi l k}{\alpha_{0} R_{0}} N u
$$

em que $R_{a}$ é a resistência do fio na temperatura do fluido.

Segundo Bruun (1975), o número de Nusselt é geralmente expresso na forma

$$
N u\left(\frac{T_{m}}{T_{a}}\right)^{a}=A+B R e^{n}
$$


em que $A, B, a$ e $n$ são constantes, $T_{a}$ é a temperatura do fluido e $T_{m}$ é a média aritmética da temperatura do fluido e a temperatura do fio.

Combinando-se as equações 3.18 e 3.19, pode-se escrever a relação entre a tensão do anemômetro e a velocidade do escoamento, conhecida como Lei de King,

$$
\frac{E_{w}^{2}}{R_{w}}=\left(A+B U^{n}\right)\left(T_{w}-T_{a}\right)
$$

Quando o escoamento possui temperatura constante, a Lei de King é simplificada para

$$
E_{w}^{2}=\left(A+B U^{n}\right)
$$

Esta equação geralmente é expressa em termos da tensão de resposta do anemômetro, $E$,

$$
E=\frac{R_{1}+R_{L}+R w}{R_{w}} E_{w},
$$

em que $R_{1}, R_{w} R_{L}$ são as resistências da sonda, do fio e do cabo de conexão, respectivamente.

\subsubsection{Calibração}

Como demonstrado na seção anterior, para se utilizar a técnica de HWA é necessário correlacionar a velocidade do escoamento com o sinal de saída do anemômetro. Isto é geralmente feito através da calibração do instrumento. Existem diversas equações propostas para a modelar a resposta de uma sonda de anemômetro, envolvendo leis de potência, curvas spline, curvas polinomiais e utilização de adimensionais como os números de Nusselt e Reynolds. Entretanto, Bruun (1995) mostra que as melhores resultados são obtidos pela Lei de King, Eq. 3.21, que para o anemômetro em modo CTA assume a forma

$$
E^{2}=A+B U_{e}^{n}
$$

em que $U_{e}$ é a velocidade efetiva do escoamento.

Para uma sonda simples, unidirecional, a calibração portanto consiste em determinar as constantes $A, B$ e $n$ da Eq. 3.23. Invertendo esta equação, obtém-se a relação entre a tensão medida e a velocidade do escoamento,

$$
U_{e}=\left(\frac{E^{2}-A}{B}\right)^{1 / n}
$$

A calibração é geralmente executada antes de cada experimento e pode ser realizada de diferentes formas, por exemplo, utilizando estações especiais ou em um escoamento em 
que a direção e a magnitude da velocidade sejam conhecidos. No LANT, isto é obtido posicionando a sonda próximo ao tubo de Pitot da câmara de ensaios, sendo adquiridos pelo menos 5 dados de $E \times U_{e}$, espaçados entre as velocidades máxima e mínima do experimento. Após as medições, as constantes são determinadas utilizando o método de mínimos quadrados. A Fig. 17 apresenta as curvas típicas obtidas no processo de calibração.

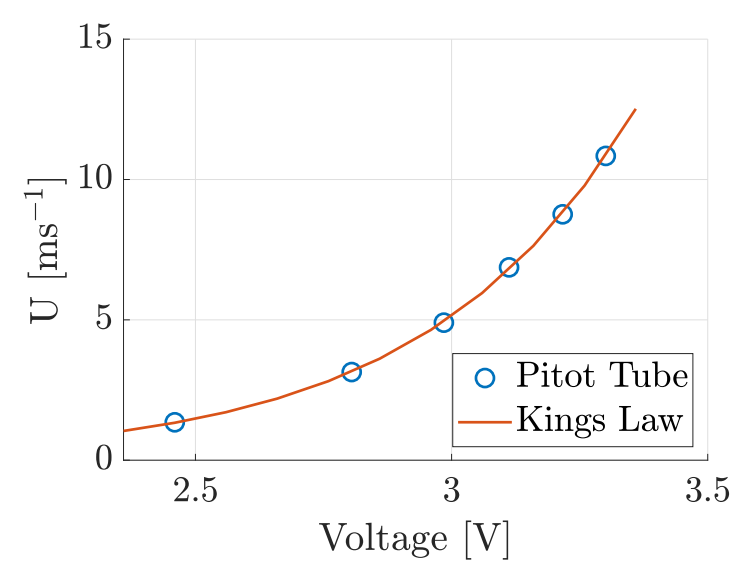

(a) Curva $E \times U_{e}$

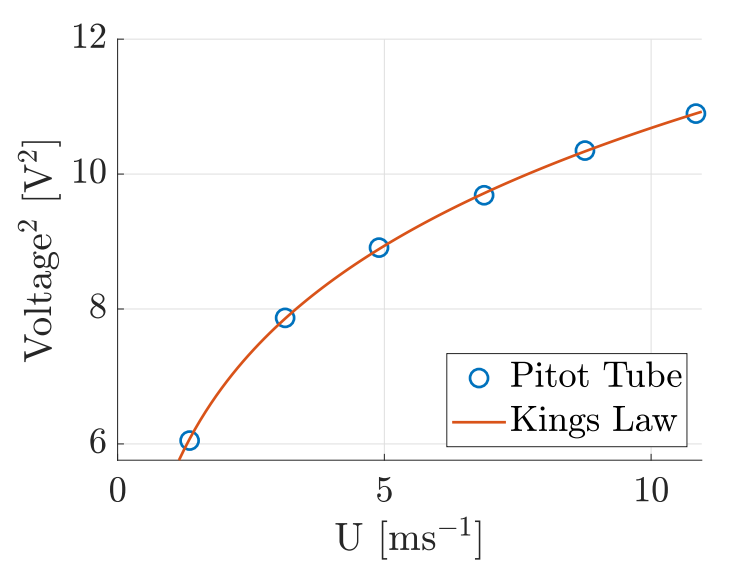

(b) Curva $U_{e} \times E^{2}$

Figura 17 - Curvas típicas de calibração da técnica de HWA.

Em experimentos com medições em faixas de velocidade muito amplas, com valores muito baixos e muito altos, o recomendado é dividir a calibração das constantes para sub-faixas de velocidade para o aumento da sensibilidade do sensor (BRUUN, 1995). Embora este método de calibração seja bastante acurado, ele apresenta problemas para velocidades menores do que $3 \mathrm{~m} / \mathrm{s}$. Isto ocorre pois o tubo de Pitot, que trabalha medindo a diferença de pressão $\Delta P$, possui dificuldades em medir corretamente a pressão nesta faixa de velocidades, que é da ordem de $1 \mathrm{mmH}_{2} \mathrm{O}(9,8 \mathrm{~Pa})$. Para este caso, há outras técnicas de calibração disponíveis (BRUUN, 1995).

Quando as aplicações consideram um ampla intervalo de velocidades, podem ocorrer alterações na temperatura do fluido $T_{a}$ com o tempo. Neste caso, estas mudanças de temperatura devem ser incorporadas ao modelo da Lei de King, Eq.3.21. Assim, a calibração deve ser executada considerando o modelo

$$
E^{2}=\left.f\left(U_{e}, T_{a}\right)\right|_{T_{w}=\text { constante }}=A^{*}+B^{*} U^{n}
$$

em que

$$
A^{*}=A_{1}+A_{2} T_{a}
$$




$$
B^{*}=B_{1}+B_{2} T_{a}
$$

ou ainda,

$$
E^{2}=\frac{\left(R_{1}+R_{L}+R_{w}\right)^{2}}{R_{w}}\left(T_{w}-T_{a}\right)\left(A+B U_{e}^{n}\right)
$$

\subsubsection{Equipamentos disponíveis}

O laboratório do grupo de transição e turbulência está completamente operacional para a execução de experimentos com a técnica de HWA. A infraestrutura conta com quatro anemômetros de modo CTA, sendo três do modelo DISA 55D05, reparados pelo técnico Luis Roberto Contri Lopes do Departamento de Física da UFSCar e um construído pelo ex-doutorando do grupo Igor Braga de Paula, alimentados por uma bateria de $12 \mathrm{~V}$ através de um regulador de tensão de construção própria. Possui um conjunto de sondas DANTEC, contando com uma sonda geral modelo 55P01, uma sonda para camada limite modelo 55P05 e uma sonda perpendicular modelo 55P04, conforme a Fig. 18. O sistema de aquisição é baseado em equipamentos da National Instruments: (1) o sinal AC é adquirido por uma placa PXI-4498 de 16 canais analógicos e resolução de 24 bits, alocada em um chassi PXI-1042Q; e (2) o sinal DC é adquirido por um módulo NI-9234 de 4 canais analógicos e resolução de 24 bits, alocados em um chassi NI-cDAQ-9184. Embora o módulo NI-9234 possua acoplamento AC/DC, ele não pode ser utilizado para adquirir o sinal AC pois possui impedância de entrada muito baixa $(50 \Omega)$. Como o sinal do HWA é de baixa potência, esta impedância de entrada causa interferência no sinal. Para efeito de comparação, a impedância de entrada das placas PXI-4498 é de 10 M $\Omega$. A aquisição dos dados de voltagem é controlada por um programa escrito em Labview, gerando arquivos separados com os dados de voltagem AC e DC.

Para reparação e manutenção de sondas, o laboratório conta com um sistema de micromanipulação, Fig. 19, que possibilita a solda entre os fios de tungstênio e a haste da sonda. Este sistema é constituído por um micromanipulador para a movimentação dos eletrodos e fio, microscópio e fonte para realização de solda capacitiva.

A movimentação das sondas na seção de testes do túnel de vento é feita por um sistema de posicionamento em 3 dimensões. A construção deste equipamento foi parte deste projeto de mestrado e sua descrição detalhada é apresentada na Seção 3.3. 


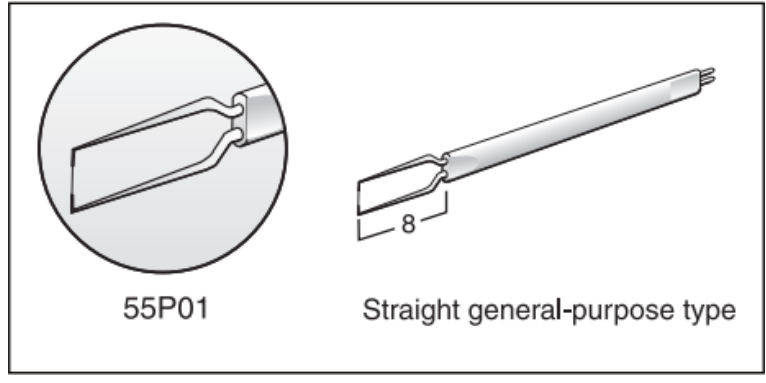

(a) Modelo 55P01 - sonda de aplicações gerais

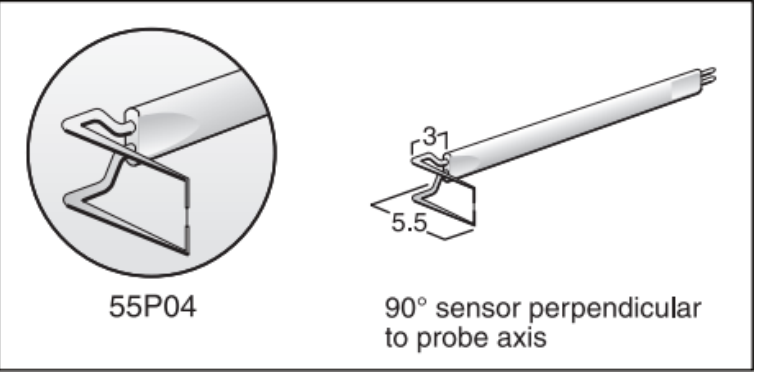

(b) Modelo 55P04 - sonda perpendicular

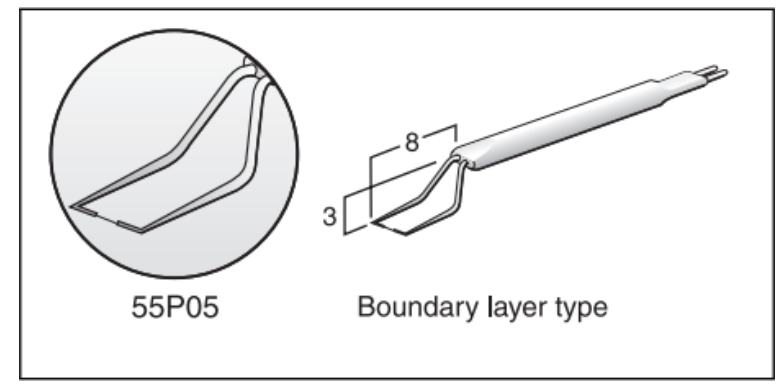

(c) 55P05 - sonda para camada limite

Figura 18 - Conjunto de sondas disponíveis, retirado de Jorgensen (2002).

\subsubsection{Procedimento experimental}

A execução dos experimentos de HWA é dividida em duas fases: (1) a calibração do sistema e (2) a medição da velocidade do fluido. Porém, antes de realizar a calibração e o experimento de anemometria, algumas etapas de configuração do equipamento devem ser executadas, tais como: (1) seleção do modo de operação de operação do anemômetro (CTA ou CCA) - o grupo opera apenas com o modo CTA; (2) seleção dos anemômetros modelos DISA ou fabricação própria; (3) seleção da relação de ponte - $1: 1$ ou 10 : 1 para os anemômetros DISA e 20 : 1 para o de fabricação própria; (4) seleção da sonda - camada limite ou aplicações gerais; (5) escolha da taxa de overheat; (6) aferição da resistência fria do fio, $R_{0}$; (7) seleção da resistência $R_{3}$, conforme Eq.3.7; e (8) balanceamento da ponte. A tabela 4 resume as etapas de configuração do anemômetro.

Nos experimentos executados neste trabalho: (1) o anemômetro opera em modo CTA; (2) o aparelho selecionado foi o DISA, conforme a Sec. 3.2.6; (3) a ponte é de $10: 1$; (4) a sonda escolhida é de camada limite e (5) a taxa de overheat é fixa em 0,8. A aferição da resistência do fio é feita após o reparo da sonda, quando necessário, e a escolha da resistência $R_{3}$ é feita de acordo com a resistência da sonda; o balanceamento da ponte é feito antes da execução de cada experimento.

\subsubsection{Calibração}

Conforme discutido na Sec. 3.2.3 deste capítulo, a calibração tem por objetivo correlacionar a voltagem de saída do anemômetro com a velocidade do escoamento. Após a 


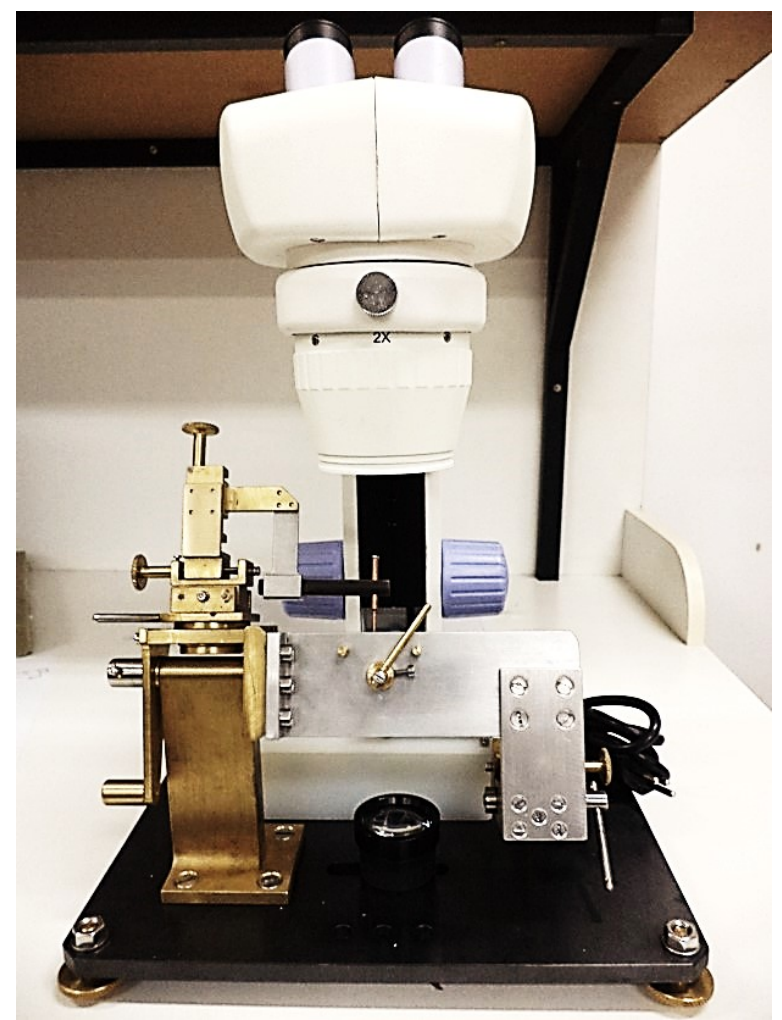

Figura 19 - Sistema para reparação de sondas de anemômetro

\section{Etapa \\ Etapa}

2

3

4

5

6

7

8

\section{Atividade}

$$
\text { Selecionar modo de operação - CTA ou CCA }
$$

Selecionar anemômetro - DISA ou fabricação própria

Selecionar relação de ponte - $1: 1,10: 1$ ou $20: 1$

Selecionar sonda - camada limite ou aplicação geral

Selecionar taxa de overheat - $\alpha$

Aferir resistência à frio do fio sensor $-R_{0}$

Selecionar a resistência - $R_{3}$

Balancear a ponte

Tabela 4 - Etapas de configuração do anemômetro.

configuração do equipamento, conforme a seção anterior, a calibração é feita anteriormente a execução de cada experimento, seguindo as etapas: (1) seleção da taxa de amostragem e tempo de aquisição; (2) seleção das velocidades do escoamento na execução do experimento; (3) aquisição entre 5 e 8 grupos de dados de $E$ e $U_{e}$, cobrindo o intervalo de velocidades do experimento e (4) determinação das constantes experimentais pelo método de mínimos quadrados. A tabela 5 apresenta um resumo das etapas de calibração. 


\section{Etapa Atividade}

\begin{tabular}{cc}
\hline \hline 1 & $\begin{array}{r}\text { Selecionar taxa de amostragem e tempo de } \\
\text { aquisição }\end{array}$ \\
2 & Selecionar intervalo de velocidades \\
3 & Adquirir sinais de $E$ e $U_{e}$ \\
4 & Determinar as constantes experimentais pelo \\
& método de mínimos quadrados \\
\hline
\end{tabular}

Tabela 5 - Etapas de calibração do anemômetro.

Os experimentos executados neste trabalho utilizam uma taxa de amostragem de 25 $\mathrm{kS} / \mathrm{s}$ (kilo-amostras/segundo) e tempo de aquisição de 31 s; o intervalo de velocidades varia de acordo com o experimento, podendo ser fixo para medições na camada limite ou varia de $10 \mathrm{~m} / \mathrm{s}$ até $25 \mathrm{~m} / \mathrm{s}$ para medidas do nível de turbulência. As constantes experimentais, retiradas da Eq.3.23, são calculadas por um script de mínimos quadrados não linear no Matlab. A convergência do método é dada para que $R^{2}$ seja maior que 0,999.

\subsubsection{Velocidade do Escoamento}

Após a calibração do anemômetro, o passo seguinte é realizar o experimento para medir a velocidade média $\left(U_{\text {mean }}\right)$ e a flutuação $\left(u_{r m s}\right)$ do escoamento. Utilizando o sistema de posicionamento, Sec.3.3, a sonda é posicionada dentro da câmara de ensaios e os valores de tensão são adquiridos segundo as configurações de calibração, ou seja, taxa de aquisição de $25 \mathrm{kS} / \mathrm{s}$ e tempo $31 \mathrm{~s}$. Este processo é repetido para diversas posições automaticamente, dependendo do tipo de experimento. Os dados adquiridos são tratados no Matlab, sendo a velocidade média calculada utilizando a Eq.3.24 e, partindo do dados de calibração, a flutuação é calculada da relação

$$
U=f(E),
$$

em que $U$ é a velocidade do escoamento e $E$ é a tensão de saída do anemômetro.

Assim,

$$
\delta U=\frac{\partial U}{\partial E} \delta E
$$

em que a derivada pode ser calculada diretamente da curva de calibração, simplificando o 
processo. Portanto,

$$
u_{r m s}=\frac{\partial U}{\partial E} E_{r m s}
$$

Assim é possível, por exemplo, calcular o nível de turbulência do escoamento como

$$
T u \%=100 \frac{u_{r m s}}{U_{\text {mean }}},
$$

sendo a incerteza na medida dada por

$$
\operatorname{err}(T u \%)=\sqrt{\left(\frac{100}{U_{\text {mean }}}\right)^{2} \operatorname{err}\left(u_{r m s}\right)^{2}+\left(\frac{100 u_{r m s}}{U_{\text {mean }}^{2}}\right)^{2} \operatorname{err}\left(U_{\text {mean }}\right)^{2}}
$$

em que $\operatorname{err}\left(u_{r m s}\right)$ e $\operatorname{err}\left(U_{\text {mean }}\right)$ são respectivamente as incertezas nas medições da variação da velocidade e da velocidade média.

\subsubsection{Seleção Anemômetro}

O grupo de pesquisa apresenta um bom estoque de aparelhos de anemometria, conforme a Sec.3.2.4. Entretanto, muitos deles são antigos e modificados (aparelhos DISA do final dos anos 60) e o outro foi construído exclusivamente pelo grupo. Dado a este fato, não é possível comparar os aparelhos apenas pelas especificações técnicas, sendo necessária a execução de um experimento controlado para comparar estatisticamente a resposta dos aparelhos. A comparação foi feita através da exposição dos aparelhos a um escoamento de $10 \mathrm{~m} / \mathrm{s}$, utilizando as mesmas sonda e taxa de overheat. Durante o experimento, foram adquiridos dados de tensão AC e DC 200 vezes para cada aparelho, com duração de 31 s; sendo que a temperatura do escoamento foi mantida constante. A tabela 6 apresenta o resumo dos dados de tensão DC de cada aparelho.

\begin{tabular}{cccc} 
Aparelho & $\begin{array}{c}\text { Tensão } \\
\text { Média } \\
(\mathbf{V})\end{array}$ & $\begin{array}{c}\text { Variação } \\
(\mathbf{V})\end{array}$ & $\begin{array}{c}\text { \% de } \\
\text { Variação }\end{array}$ \\
\hline \hline DISA 01 & 1,797 & 0,002 & 0,12 \\
DISA 02 & 1,908 & 0,107 & 5,61 \\
DISA 03 & 1,479 & 0,035 & 2,36 \\
Próprio & 5,109 & 0,003 & 0,05 \\
& & & \\
\hline
\end{tabular}

Tabela 6 - Variação do sinal de saída dos diversos anemômetros. 
Como pode ser observado na tabela 6 , os aparelhos DISA operam com um tensão menor que o aparelho de construção própria, devido a diferenças dos circuitos, e os anemômetros DISA 01 e de construção própria apresentam uma incerteza similar na medida da tensão DC média. Os aparelhos DISA 02 e DISA 03 apresentam uma tendência de queda da saída e tensão ao longo do tempo, como pode ser visto na Fig. 20, enquanto os demais aparelhos oscilam em torno da média. Isto ocorre devido a idade e as modificações feitas ao circuitos ao longo dos anos. Por este motivo, não foram utilizados neste trabalho.

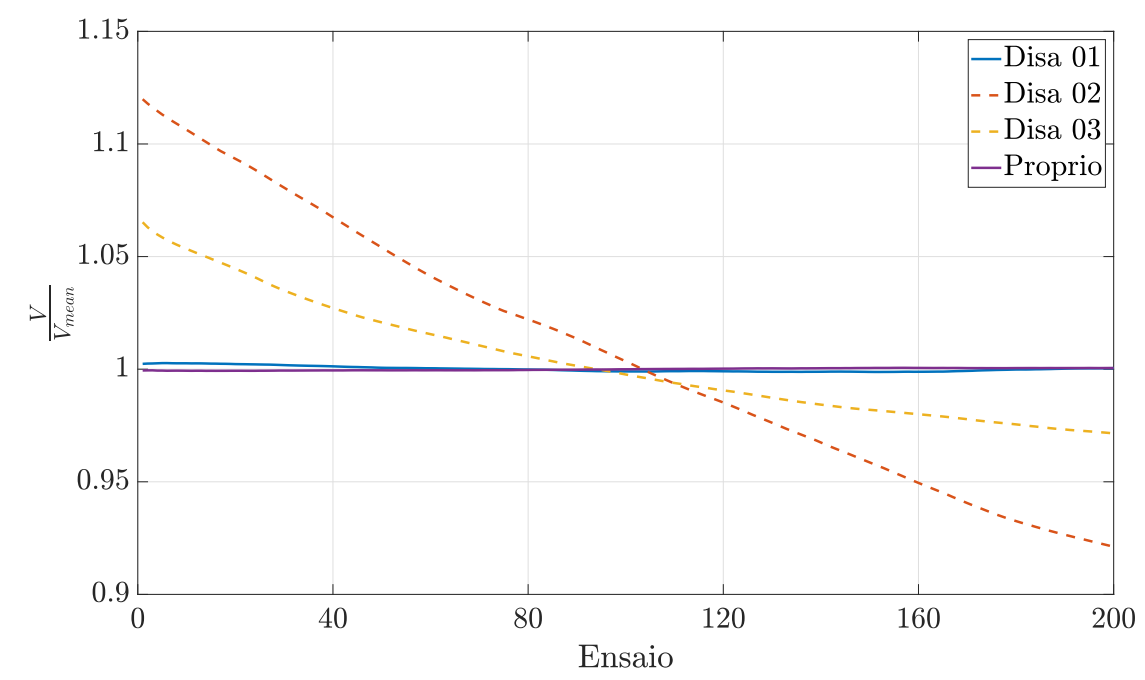

Figura 20 - Resposta dos anemômetros para cada tomada de dados.

Além de avaliar a variação da resposta a tensão média de saída do aparelho, é necessário comparar a variação do sinal AC, apresentado na tabela 7. Novamente, os aparelhos DISA 01 e de construção própria apresentam resultados semelhantes, embora os aparelhos DISA 02 e DISA 03 sejam melhores.

\begin{tabular}{ccc} 
Aparelho & $V_{r m s}(\mathbf{V})$ & $\begin{array}{c}\text { Variação } \\
V_{r m s}(\mathbf{V})\end{array}$ \\
\hline \hline Disa 01 & $1,2 \mathrm{e}-3$ & $5,7 \mathrm{e}-5$ \\
Disa 02 & $0,8 \mathrm{e}-3$ & $2,5 \mathrm{e}-5$ \\
Disa 03 & $0,6 \mathrm{e}-3$ & $3,2 \mathrm{e}-5$ \\
Próprio & $1,6 \mathrm{e}-3$ & $9,7 \mathrm{e}-5$ \\
\hline
\end{tabular}

Tabela 7 - Variação do sinal de saída dos diversos anemômetros.

Outra comparação possível é entre os espectros de sinal, conforme a Fig. 21. Nela, observa-se que ambos os aparelhos apresentam espectro de sinal muito semelhante, diferindo basicamente por um fator constante, e apresentando níveis de ruído equivalente. 


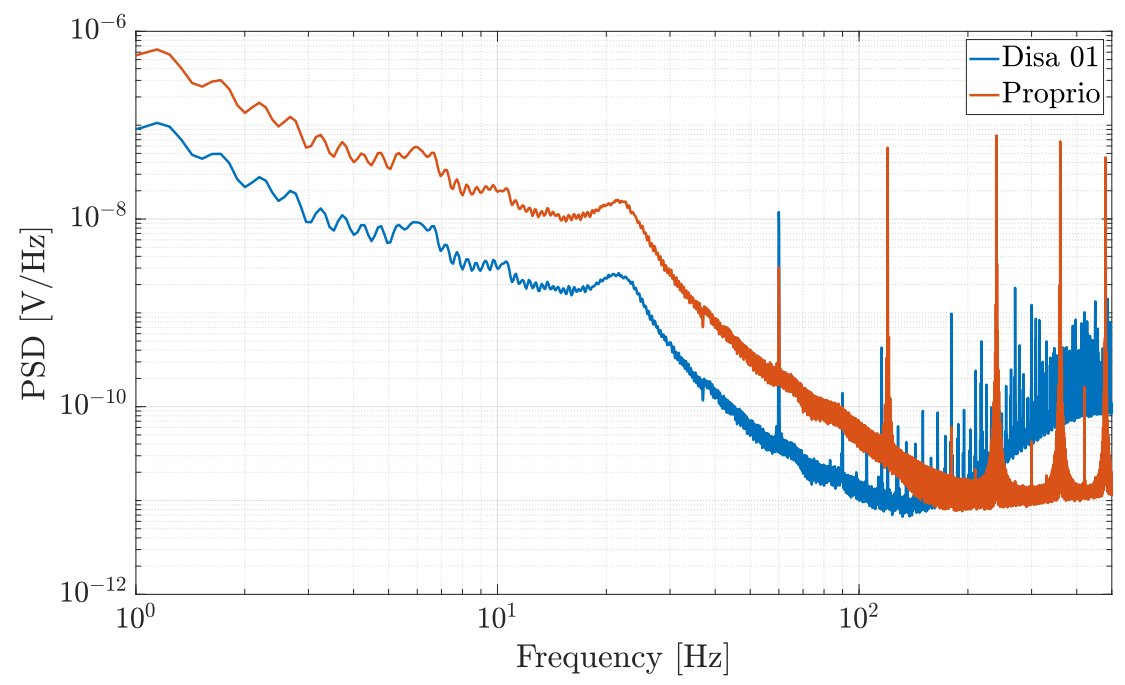

Figura 21 - Espectro dos anemômetros DISA 01 e Próprio.

Pelo exposto acima, os anemômetros DISA 01 e de construção própria são equivalentes em termos de qualidade da medida, ou seja, ambos aparelhos poderiam ser utilizados nos experimentos deste trabalho. Logo, a escolha recaiu sobre critérios subjetivos como a facilidade de uso. Assim, o anemômetro utilizado no trabalho é o DISA 01, assumindo uma incerteza de $0,2 \%$ na voltagem média e $5 \%$ no valor rms (root mean square).

\subsection{Sistema de Posicionamento}

Por se tratar de uma técnica pontual, conforme a Seção3.2, a utilização da anemometria à fio quente necessita de um sistema de posicionamento e movimentação de sondas. Esta seção descreve o projeto e construção do sistema de posicionamento utilizado neste trabalho sobre turbulência e instabilidade da camada limite. O posicionador de sondas foi projetado para atender os seguintes requerimentos: (1) ter alcance de pelo menos $50 \%$ do volume total da câmara de ensaios e pelo menos $75 \%$ de sua área útil; (2) resolução de mínima de 0,1 mm por direção; (3) apresentar frequências de vibração fora da região utilizada em experimentos; e (4) ser de fácil vedação.

O projeto original, elaborado por Juan Carlos Serrano Rico, ex-doutorando do grupo de pesquisa, adotou como solução uma combinação de estrutura de alumínio e aço, com face de acrílico, movimentado por um fuso de esferas propelidos por motores de passo e controlados por computador. Um croqui do projeto pode ser visto na Fig.22. As modificações e redesenho do projeto foram feitas com o auxílio de Juan Carlos Serrano Rico, a quem agradeço pela presteza e paciência nas discussões.

Conforme a Fig.22, a estrutura principal é constituída de perfis modulares de alumínio, fornecidos pela FAMAK, com seção reta de dimensões $45 \times 45 \mathrm{~mm}$ e $60 \times 60$ $\mathrm{mm}$; optou-se por guias de alumínio, pois se trata de um material leve e resistente e de 


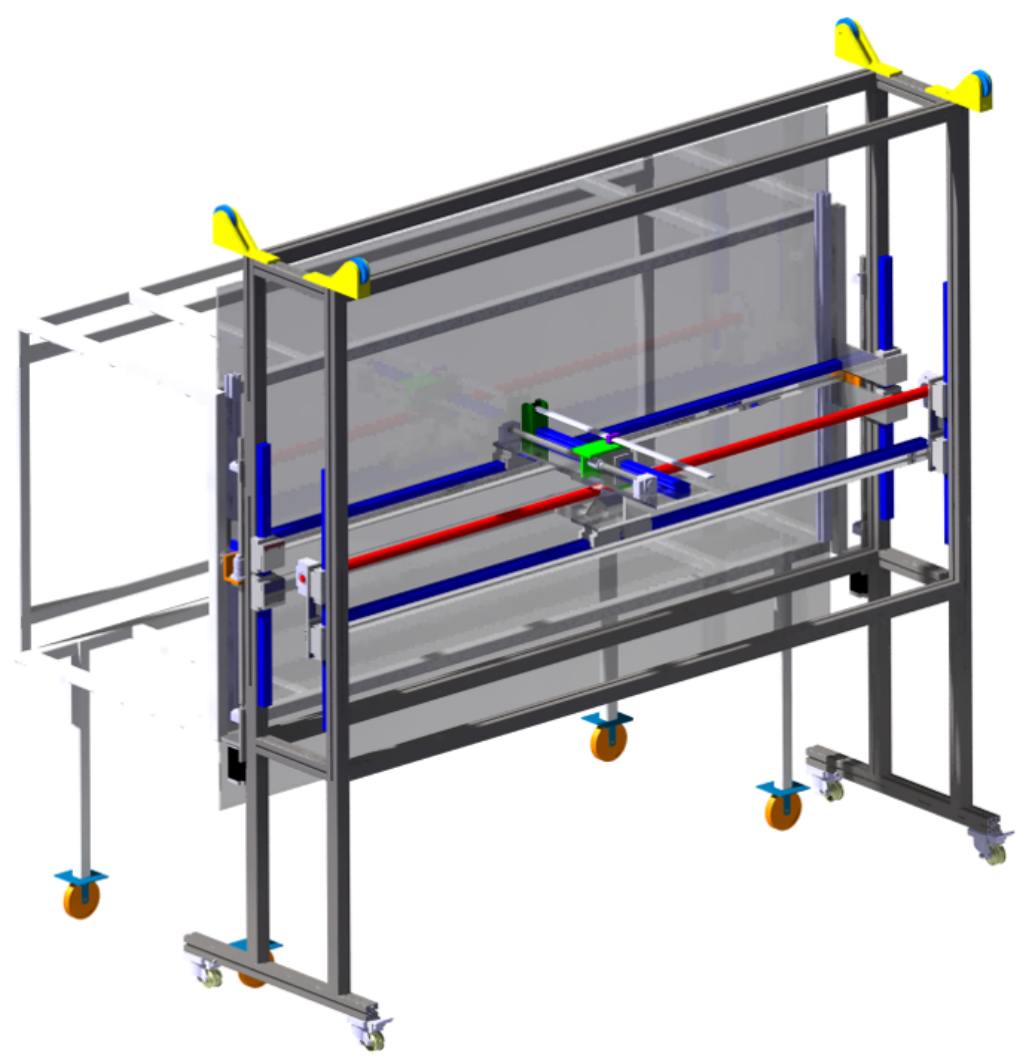

Figura 22 - Croqui do sistema de posicionamento, elaborado por Juan Carlos Serrano Rico.

fácil montagem, não precisando de soldas. Esta estrutura, com dimensões de $3000 \mathrm{~mm} \times$ $3000 \mathrm{~mm} \times 500 \mathrm{~mm}$, é montada em uma base de alumínio com rodas, para movimentação, e sapatas com amortecimento, para fixação na execução dos experimentos. As peças de acoplamento entre as seções de movimento são usinadas em aço SAE 1020, com espessura de $10 \mathrm{~mm}$. A face frontal do posicionador, que entra em contato com a câmara de ensaios, é feita em acrílico de dimensões $2890 \mathrm{~mm} \times 2050 \times \mathrm{mm}$ e $10 \mathrm{~mm}$ de espessura. Esta face frontal de acrílico é sustentada por um quadro de alumínio, tendo um corte de $25 \mathrm{~mm}$ de espessura e $2450 \mathrm{~mm}$ de comprimento para a movimentação de uma haste na direção horizontal, sendo vedada por cerdas, conforme Fig.23.

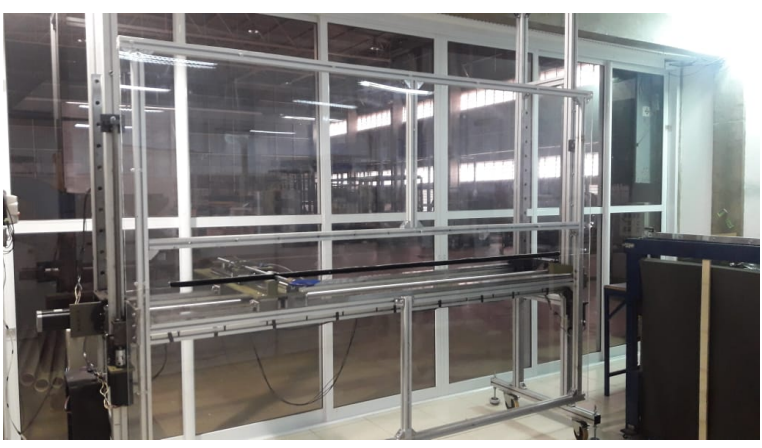

(a) Frente do posicionador

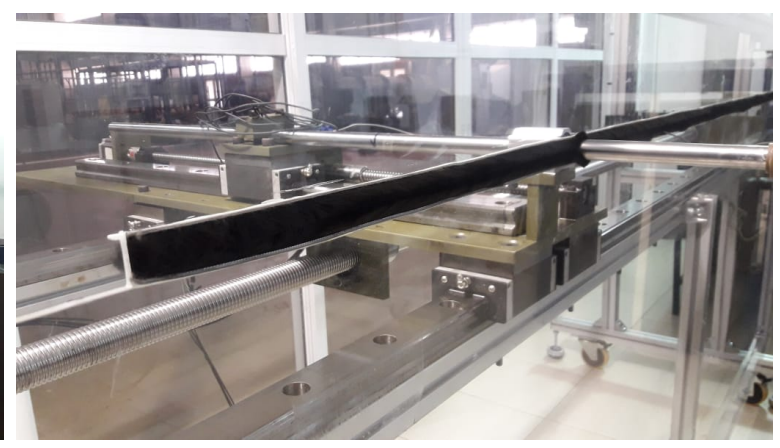

(b) Detalhe vedação

Figura 23 - Face frontal de acrílico do posicionador. 


\subsubsection{Movimento vertical e horizontal}

O projeto do posicionador prevê que toda a estrutura de acrílico, que está em contato com a câmara de ensaios, se movimente verticalmente, ajudando na vedação de ar. Este movimento é feito por meio de dois fusos de esferas, fornecidos pela Kalatec, com diâmetro de $25 \mathrm{~mm}$ e $1000 \mathrm{~mm}$ de comprimento, sendo propelidos por motores de passo KTC-HT34-487. Para garantir o alinhamento do movimento, a estrutura do acrílico é presa a duplas de guias lineares em faces opostas, por meio de patins, em ambos os lados da estrutura. Foram escolhidos 2 motores de passo de grande potência para eliminar a necessidade de utilização de contrapesos. Os motores são controlados por drivers STR-8, regulados para 200 passos por volta. Com estas características, e considerando que os eixos apresentam um passo de $5 \mathrm{~mm}$ por volta (incerteza de $5 \mathrm{~mm} / 3000 \mathrm{~mm}$ ), a resolução mínima do sistema para movimento vertical é de $0,025 \mathrm{~mm}$ por passo e curso total de 830 mm. O eixo vertical equivale à direção $z$, de envergadura (spanwise) do escoamento.

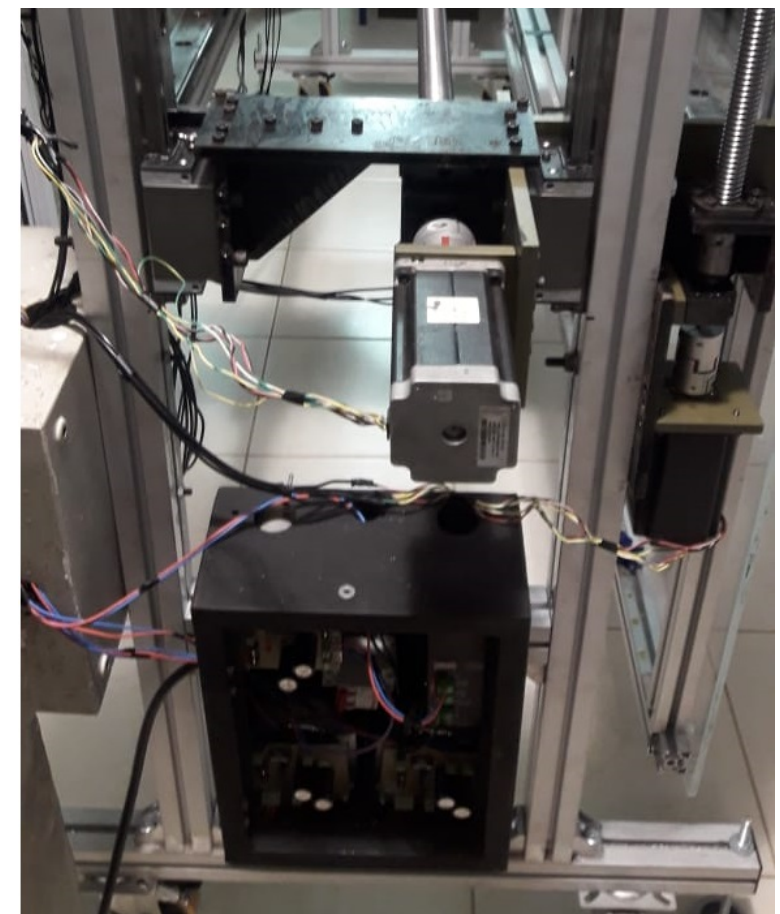

(a) Detalhe motor de passo horizontal e aco-(b) Detalhe do acoplamento com patins vertiplamento com patins verticais.

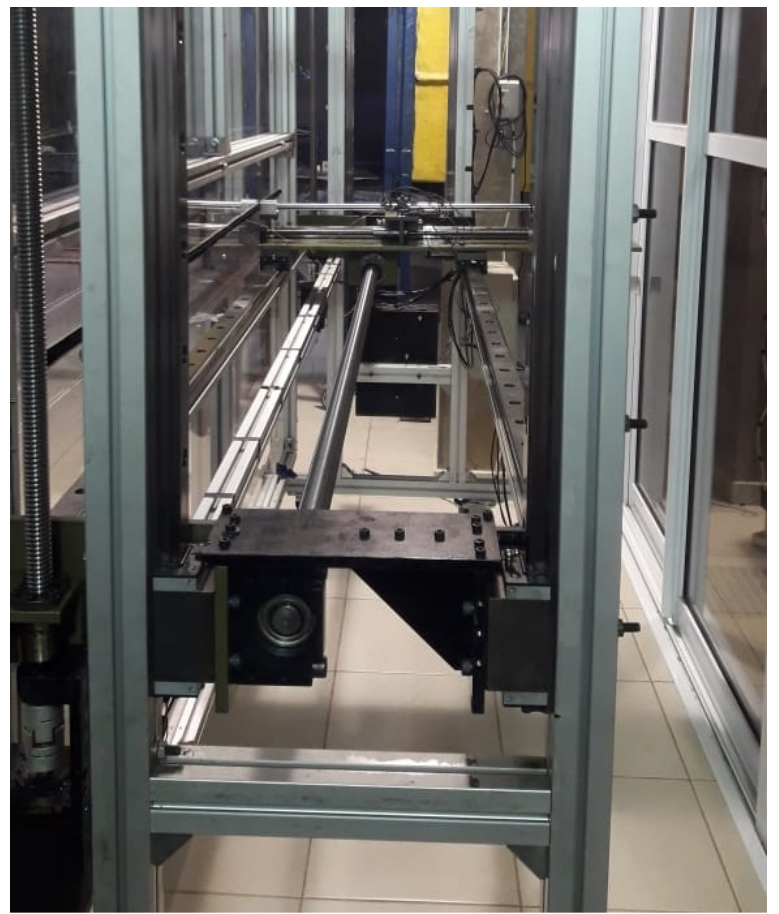

cais, lado esquerdo.

Figura 24 - Acoplamento horizontal-vertical.

O movimento horizontal, de modo similar ao vertical, é feito por meio de um fuso de esferas, com diâmetro de $40 \mathrm{~mm}$ e $3000 \mathrm{~mm}$ de comprimento, propelido por um motor de passo KTC-HT34-487 e controlado pelo drivers STR-8 . O eixo horizontal é preso ao eixo vertical por duas mesas de acoplamento, ligadas a estrutura de sustentação da face frontal de acrílico, conforme a Fig.24; também conta com duas guias lineares para nivelamento da mesa principal. O movimento horizontal foi configurado com as mesmas especificações do vertical, ou seja, 200 passos por volta e resolução mínima de 0,025 mm por passo, 
com curso total de $2400 \mathrm{~mm}$. O eixo horizontal é equivalente à direção $x$, streamwise, do escoamento.

\subsubsection{Mesa}

A mesa é o componente principal do sistema de posicionamento, uma vez que ela sustentará a haste da sonda e o sistema de movimentação. Ela é construída em aço SAE 1020 usinado de $10 \mathrm{~mm}$ de espessura, com dimensões de $1100 \mathrm{~mm} \times 250 \mathrm{~mm}$; contendo o fuso de esferas, guia linear e patim para alinhamento e movimentação da haste e o motor de passo KTC-HT23-401. O patim é ligado ao eixo de esferas por meio de uma peça usinada, que também é responsável por prender a haste a estrutura. Por sua vez, a mesa é unida ao eixo horizontal por meio de uma castanha de esferas e quatro patins ligados a duas guias lineares paralelas. Estas guias são também responsáveis por manter todo o sistema nivelado, conforme a Fig.25. O fuso de esferas é de $15 \mathrm{~mm}$ de diâmetro e comprimento de $900 \mathrm{~mm}$, possuindo um curso de $720 \mathrm{~mm}$ e mesmas características dos demais eixos. Entretanto, o motor de passo, controlado por um driver programável ST10-Si, foi regulado para 400 passos por volta, o que garante uma resolução mínima de 0,0125 mm para o que equivale a direção $y$, cross-stream, do escoamento.

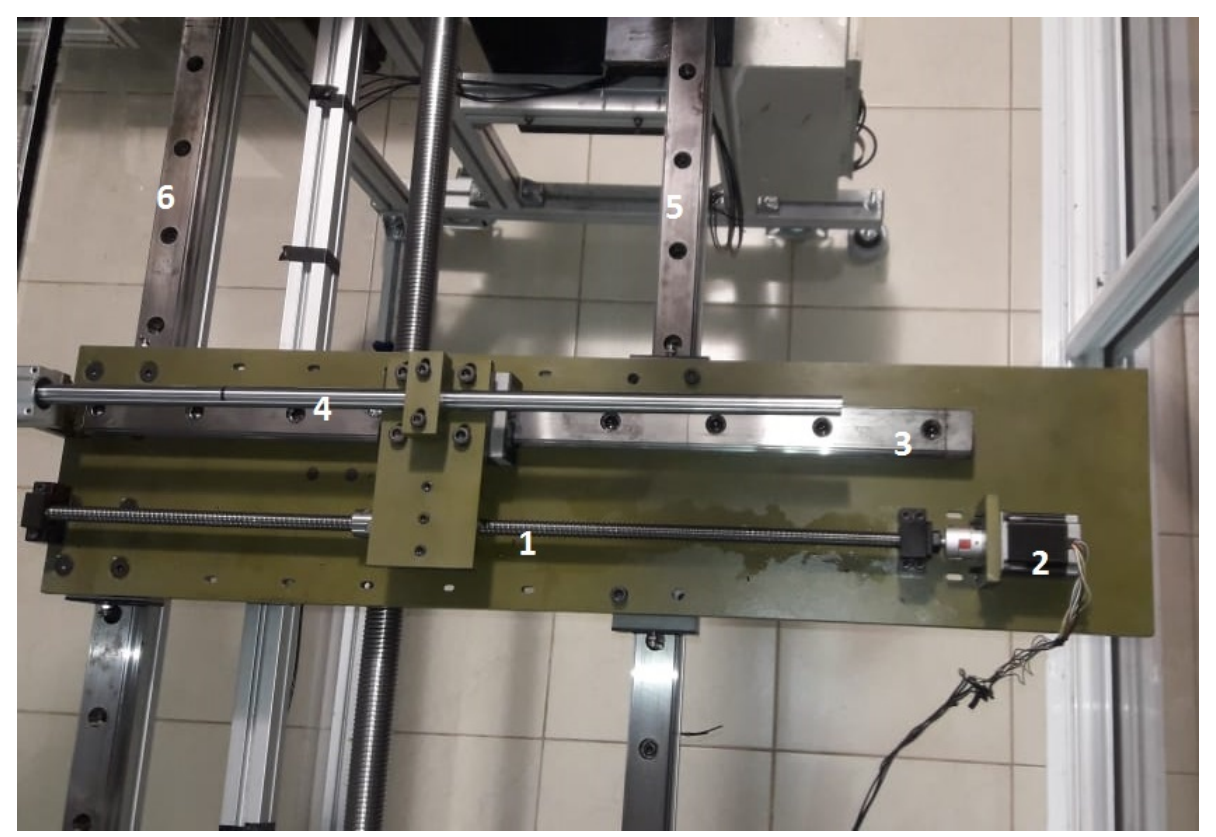

Figura 25 - Detalhes mesa: (1) eixo de esferas; (2) motor de passo; (3) guia linear, (4) haste; (5) e (6) guias horizontais.

\subsubsection{Haste}

O projeto de uma haste funcional para a movimentação da sonda para adentrar a câmara de ensaios, apresenta uma série de desafios, tais como: (1) garantir que a sonda entre e saia da câmara de ensaios sem grandes dificuldades; (2) não apresente frequências 
de vibração natural que prejudiquem o experimento, e (3) causem pouca perturbação no escoamento na região próxima a sonda, de modo que não interfira nas medições.

Para resolver este problema optou-se por construir a haste em 2 partes: (1) cilindro de aço preso ao patim de movimento e apoiado em um rolamento linear de esferas (bucha de esferas); e (2) uma asa feita em impressão 3D presa ao cilindro de aço mecanicamente.

Conforme a Fig.25, a haste é presa mecanicamente à mesa, sendo o movimento de entrada na câmara de ensaios promovida pelo eixo de esferas preso ao patim. Quando o sistema da haste adentra a câmara de ensaios, a parte cilíndrica passa a desprender vórtices devido à instabilidade de von Kárman (PLATZER, 2013), que por sua vez excita a vibração do cilindro de aço. Deste modo, é de grande importância que esta frequência de desprendimento de vórtices não interfira nos experimentos. A relação entre a frequência de desprendimento de vórtices, a velocidade do escoamento e o diâmetro do cilindro é dada pelo número de Strouhal $(S t)$,

$$
S t=\frac{f d}{U}
$$

em que $f$ é a frequência de desprendimento de vórtices, $d$ é o diâmetro do cilindro e $U$ é a velocidade do escoamento. Utilizando como referência o trabalho de Fey, König e Eckelmann (1998), a relação entre o número St e o Re do escoamento é dada por:

$$
S t=S t *+\frac{m}{\sqrt{R e}}
$$

onde os valores de $S t *$ e $m$ são tabelados. A Fig.26 apresenta os valores de frequência de desprendimento de vórtices da haste cilíndrica do posicionador, sendo que estas devem ser evitadas em experimentos de HWA para impedir contaminação dos dados.

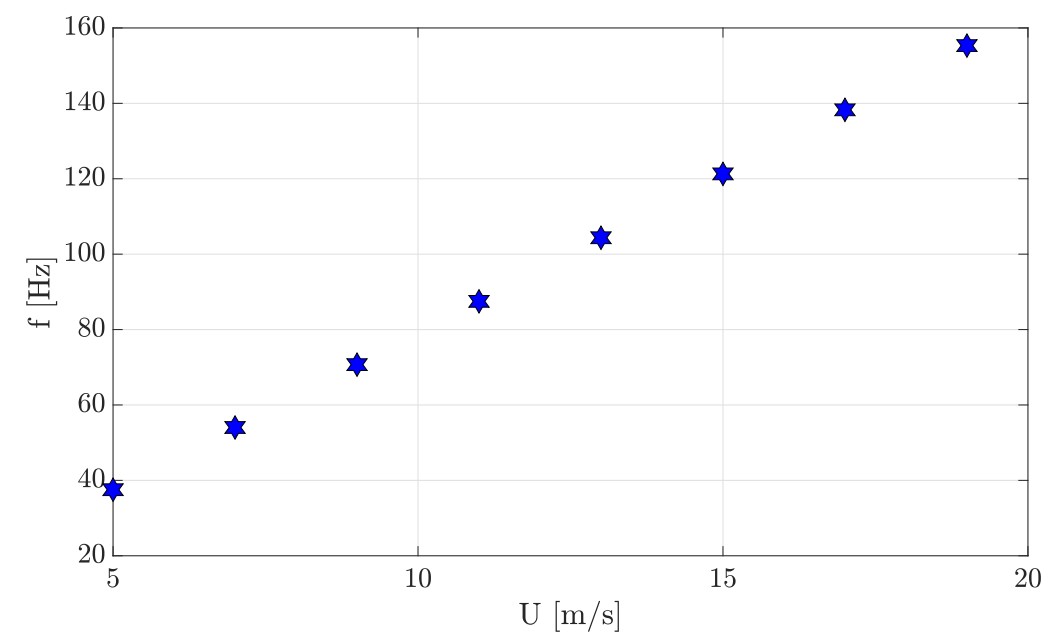

Figura 26 - Frequências de desprendimento de vórtices da haste cilíndrica do posicionador, em relação à velocidade do escoamento. 
Com o objetivo de reduzir a pertubação produzida pela sonda do anemômetro, foi construída uma seção da haste com formato aerodinâmico de uma asa. Para facilitar a sua construção, o perfil aerodinâmico escolhido foi de um aerofólio NACA de 2 dígitos, seguindo os critérios: (1) asa afilada linearmente com envergadura de $350 \mathrm{~mm}$; (2) corda da seção maior com máximo de 150 mm e (3) corda da seção menor com mínimo de 3,5 mm. Para avaliar a adequação dos perfis, foi também calculado o arrasto gerado pela haste utilizando o software XFoil (DRELA, 1989).

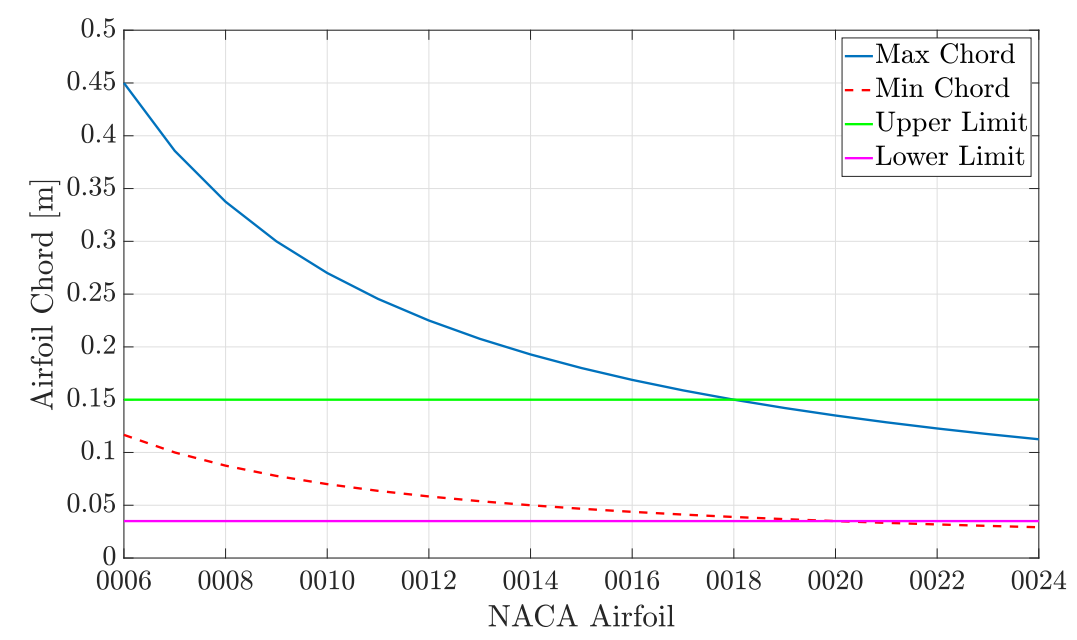

(a) Limites para corda máxima e mínima

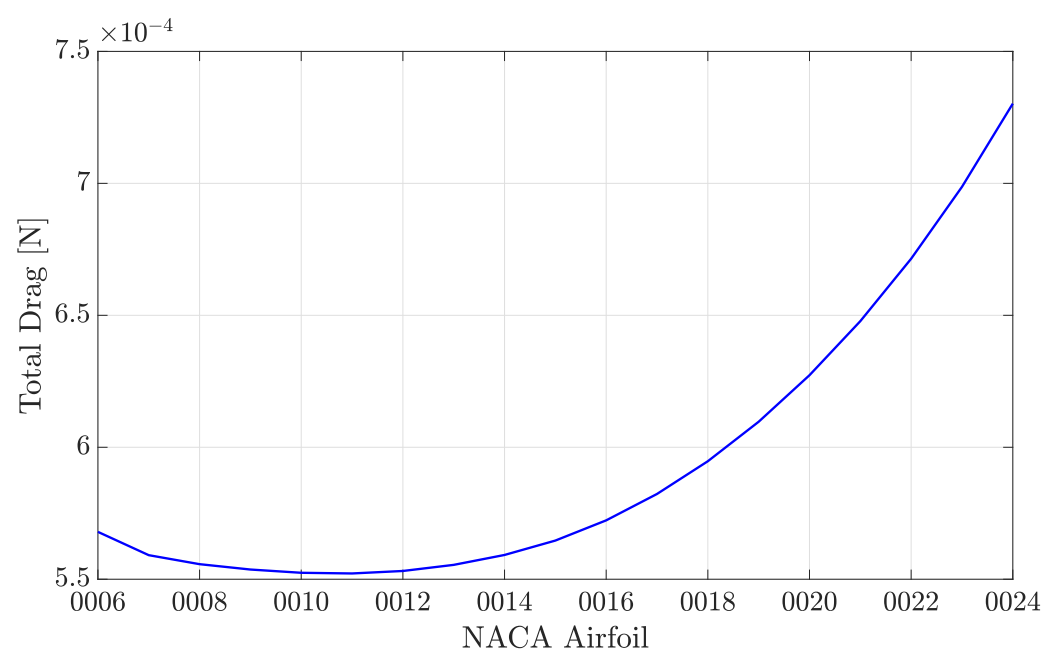

(b) Arrasto total da haste

Figura 27 - Seleção do perfil aerodinâmico.

A Fig.27 mostra os aerofólios que satisfazem as condições estabelecidas. Analisando este estudo, chega-se a conclusão que o aerofólio NACA0018 seria o perfil adequado, pois ele satisfaz as condições de tamanho e também apresenta o menor arrasto total, dentre os que atendem as especificações. Para atender as várias condições experimentais, foram construídas 2 asas: (1) com envergadura de $350 \mathrm{~mm}$ para experimentos na camada limite da placa plana e, (2) com envergadura de $100 \mathrm{~mm}$ para experimentos de qualidade do 
escoamento, conforme a Fig.28.
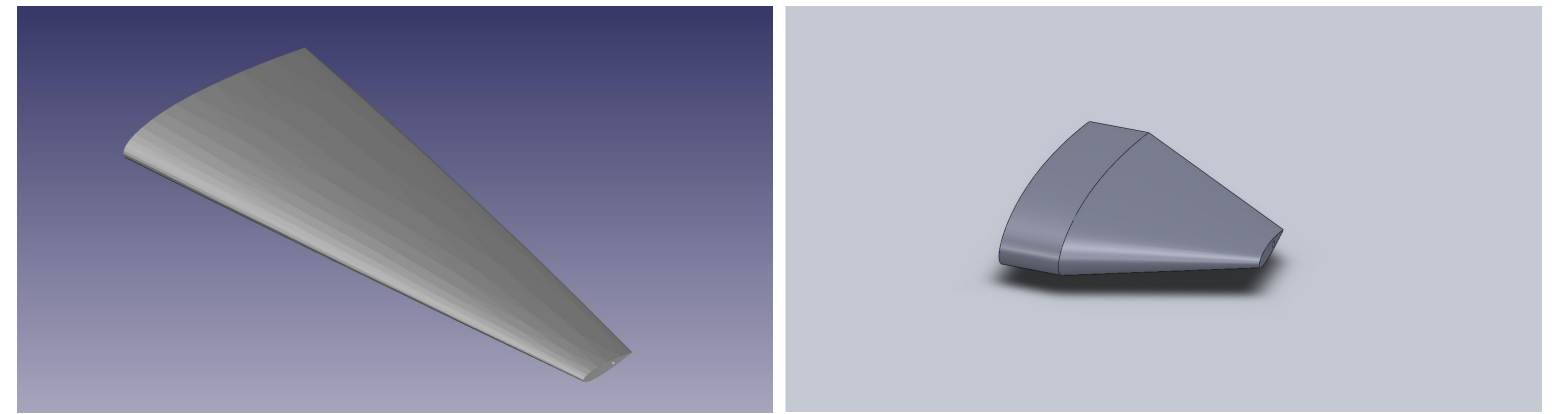

(a) Haste maior para experimentos de camada (b) Haste menor para experimentos de qualilimite na placa plana dade de escoamento

Figura 28 - Projeto de hastes aerodinâmicas para experimentos de HWA. 


\section{CARACTERIZAÇÃO DO ESCOAMENTO DO LANT}

Os resultados deste trabalho serão divididos em dois capítulos: (1) neste serão apresentados os dados de qualificação do túnel de vento; e (2) no próximo capítulo serão apresentados os resultados da execução de um experimento piloto de medição de ondas Tollmien-Schlichting artificiais em uma placa plana.

Nas próximas seções serão apresentadas as principais características do LANT, tais como, a variação da temperatura com o tempo, a uniformidade do escoamento, o nível de turbulência; bem como comparações com outros túneis de referência no Brasil e no mundo. Ao final será apresentada uma pequena análise sobre os efeitos da velocidade de rotação do ventilador nos níveis de turbulência.A caracterização do LANT se baseia em três trabalhos principais: (1) a caracterização do túnel Klebanoff-Saric, da Texas $A \& M$ University (HUNT et al., 2010); (2) o túnel MTL (Minimum Turbulence Level or Marten Theodore Landahl), do KTH Royal Institute of Technology (LINDGREN; JOHANSSON, 2002) e (3) o túnel NDF (National Diagnostic Facility), do Illinois Institute of Technology (NAGIB et al., 1994).

\subsection{Aspectos Térmicos}

Apesar de ter uma grande influência na resposta da técnica de HWA, conforme Sec.3.2.3, a caracterização térmica dos túneis de vento não é muito detalhada. Embora Saric e Reshotko (1998) descrevam que as flutuações de temperatura devam ser minimizadas, poucos trabalhos apresentam tal detalhamento, tais como Lindgren e Johansson (2002) e Nagib et al. (1994).

O objetivo desta seção é verificar quantitativamente a variação da temperatura do túnel em função da velocidade do escoamento e do tempo, e não elaborar um modelo térmico do LANT, embora se saiba que as principais fontes de calor do túnel são: (1) o motor que propulsiona o ventilador, (2) a perda de carga nas estruturas de redução de turbulência (telas, colmeia e guias de curva) e (3) o atrito do ar com as paredes. Diferentemente dos túneis MTL e NDF, o LANT não possui sistema de refrigeração do escoamento. Por simplificação, foi medida a variação da temperatura na linha central da câmara de ensaios, próximo à entrada. Embora incompleta, esta é uma medida relevante, pois permite estimar o tempo necessário para a temperatura se estabilizar para uma faixa de $\pm 0,5^{\circ} \mathrm{C}$. 
O procedimento para medição de temperatura foi posicionar um sensor DS18B20 no centro da seção transversal da câmara de ensaios, utilizando-se do sistema de posicionamento, a uma distância de $400 \mathrm{~mm}$ da entrada, para medir a temperatura interna $\left(T_{i n}\right)$; e utilizar um sensor BMP 280 para medir a temperatura externa $\left(T_{\text {out }}\right)$. A aquisição foi feita a cada $4 \mathrm{~s}$, automaticamente por software em Labview, durante pelo menos 250 minutos. As velocidades escolhidas foram $10 \mathrm{~m} / \mathrm{s}, 20 \mathrm{~m} / \mathrm{s}$ e $30 \mathrm{~m} / \mathrm{s}$. Os resultados são apresentados na Fig.29.

Para $10 \mathrm{~m} / \mathrm{s}$, após o salto inicial conforme Fig.30, a temperatura interna do túnel cresce a uma taxa média de $0,01^{\circ} \mathrm{C} / \mathrm{min}$. Do ponto de vista prático, isso significa que para experimentos em HWA, deve-se esperar pelo menos 30 minutos antes de se iniciar as medições; garantindo assim uma varição menor que $1{ }^{\circ} \mathrm{C} /$ hora na temperatura interna do túnel. Desta forma, não seriam necessários os ajustes de temperatura para experimentos com HWA.

Por outro lado, conforme a Fig.29 (b) e (c), para velocidades mais altas, $20 \mathrm{~m} / \mathrm{s}$ e $30 \mathrm{~m} / \mathrm{s}$, a temperatura interna do túnel apresenta uma taxa de crescimento muito maior que a temperatura externa. Isto provoca dificuldades para encontrar o tempo necessário para estabilização da temperatura. Neste caso, é melhor avaliar a taxa de crescimento da diferença entre as temperaturas e determinar o tempo necessário para que a taxa de crescimento seja menor que $1 / 60{ }^{\circ} \mathrm{C} /$ minuto. A Fig.31 apresenta esta taxa.

Um modelo que descreve, razoavelmente, o comportamento assintótico desta diferença, é o modelo de potência,

$$
T_{\text {in }}-T_{\text {out }}=a t^{b}+c
$$

em que $a, b$ e $c$ são constantes e $t$ é o tempo medido em minutos. Os parâmetros para o modelo são apresentados na tabela 8.

\begin{tabular}{ccc} 
& $20 \mathrm{~m} / \mathrm{s}$ & $30 \mathrm{~m} / \mathrm{s}$ \\
\hline \hline $\mathrm{a}$ & $-89,42$ & $-46,02$ \\
$\mathrm{~b}$ & $-0,7786$ & $-0,6497$ \\
$\mathrm{c}$ & 9,122 & 19,44 \\
& & \\
\hline
\end{tabular}

Tabela 8 - Parâmetros experimentais do modelo de aquecimento.

Assim, é possível estimar o tempo de espera necessário para a estabilização da temperatura do túnel, de acordo com a faixa de interesse, bastando derivar a Eq.4.1 e igualar a taxa de crescimento da temperatura. Por exemplo, para uma taxa de aquecimento 


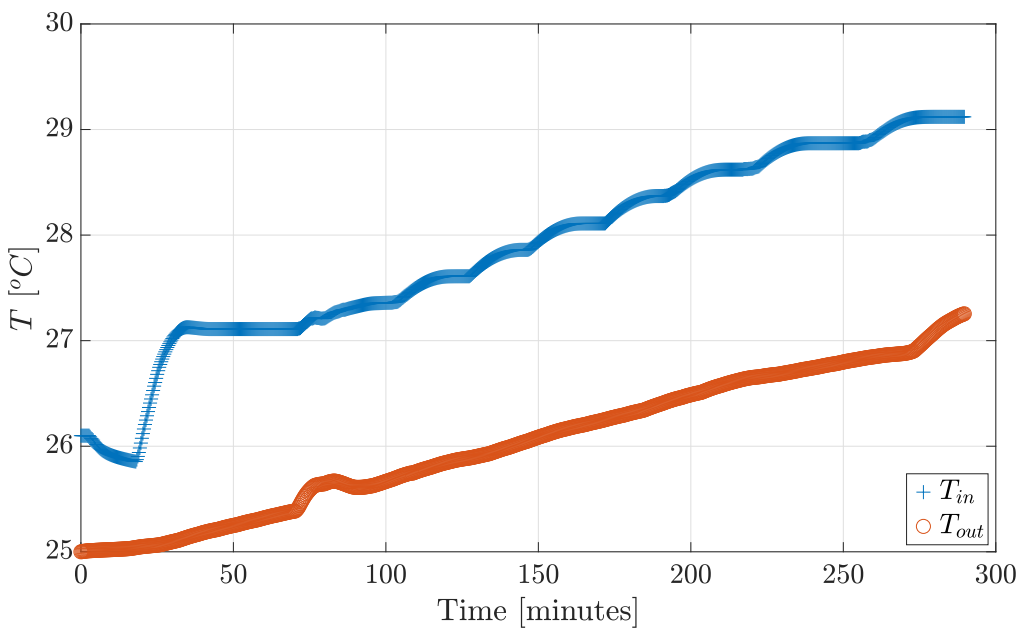

(a) $U_{\infty}=10 \mathrm{~m} / \mathrm{s}$

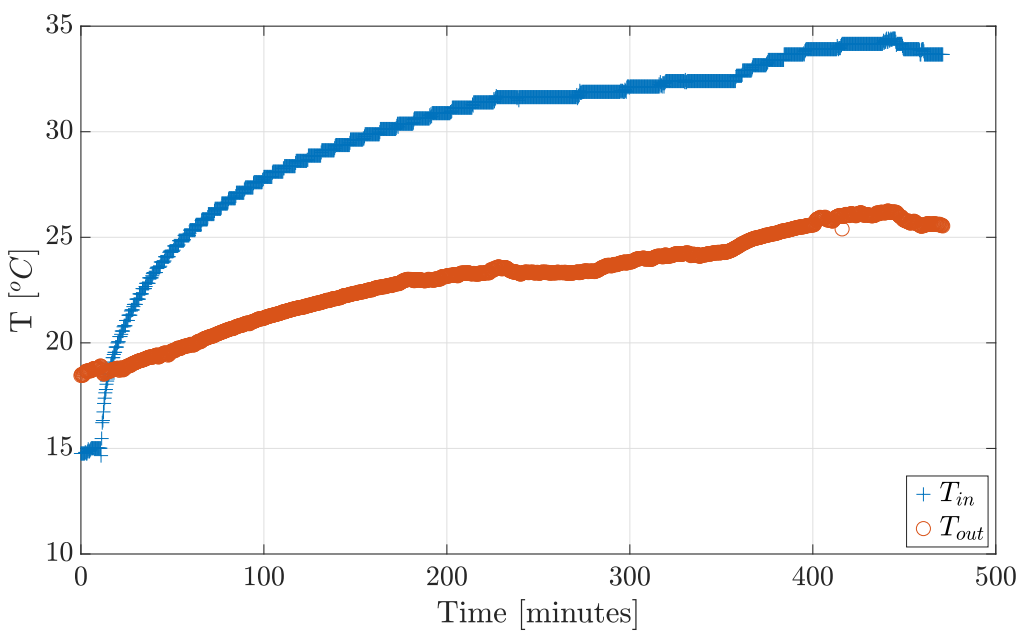

(b) $U_{\infty}=20 \mathrm{~m} / \mathrm{s}$

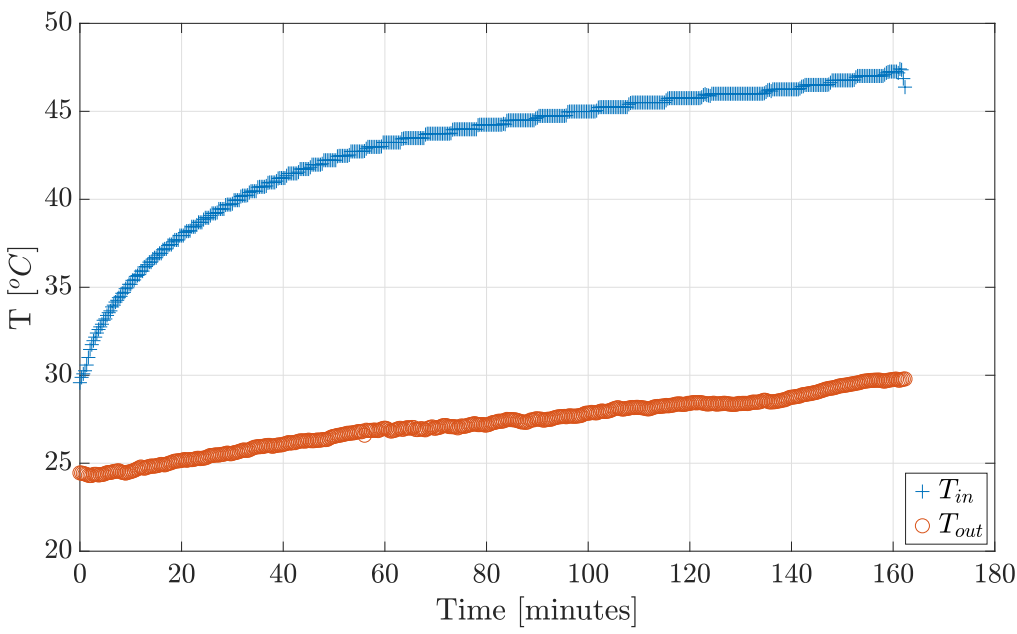

(c) $U_{\infty}=30 \mathrm{~m} / \mathrm{s}$

Figura 29 - Variação da temperatura na câmara de ensaios. 


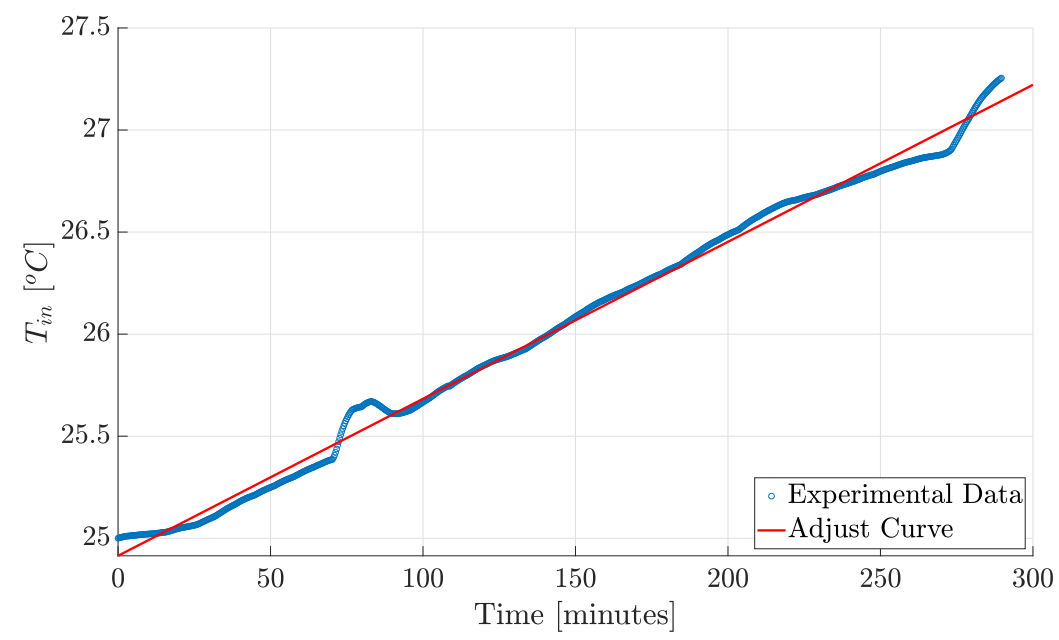

Figura 30 - Evolução da temperatura interna para $10 \mathrm{~m} / \mathrm{s}$.

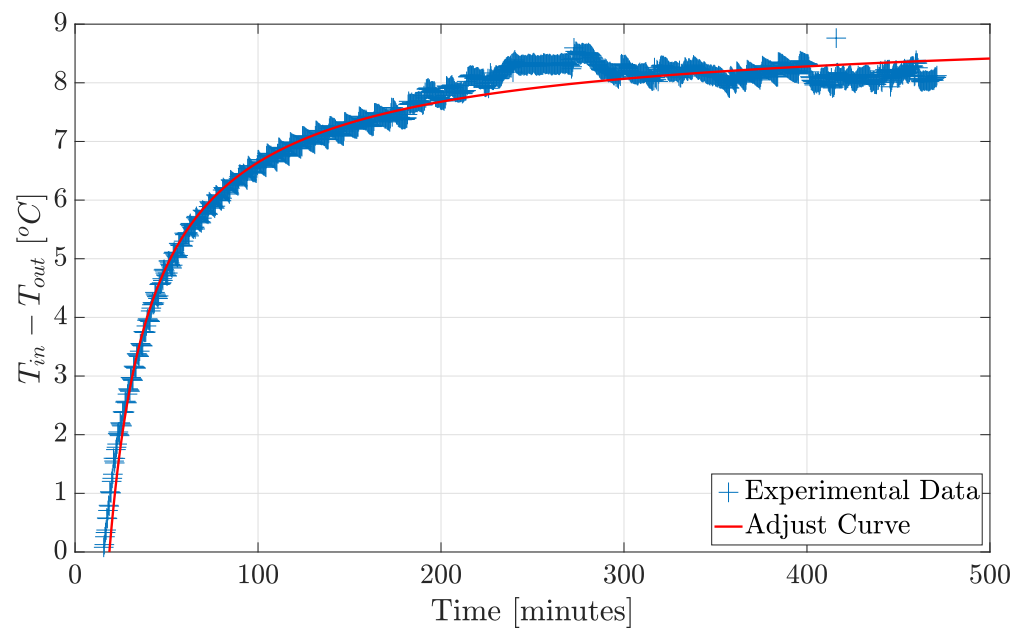

(a) $U_{\infty}=20 \mathrm{~m} / \mathrm{s}$

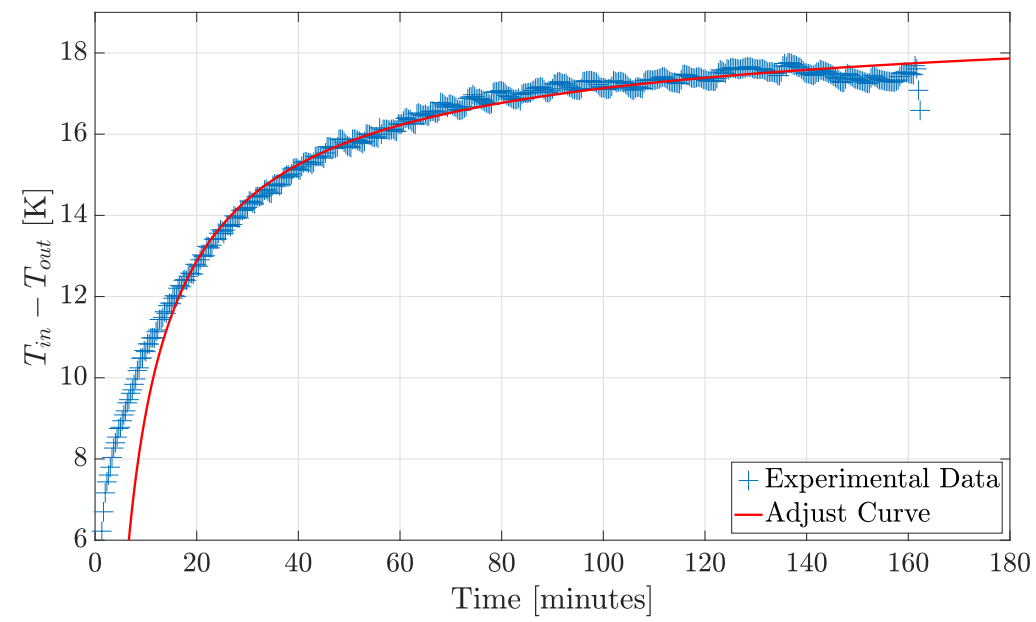

(b) $U_{\infty}=30 \mathrm{~m} / \mathrm{s}$

Figura 31 - Diferenças entre as temperaturas interna e externa do túnel. 
de $1{ }^{\circ} \mathrm{C} /$ hora, na velocidade de $20 \mathrm{~m} / \mathrm{s}$ são necessários 108 minutos, enquanto que para 30 m/s, são necessários 93 minutos.

Com estes dados e a duração estimada do experimento de anemometria, é possível determinar o tempo necessário para o túnel estabilizar a temperatura antes de se iniciar as medições.

\section{2 Área Útil}

De maneira geral, a área útil de um túnel pode ser definida como a área da câmara de ensaios em que os efeitos da camada limite das paredes podem ser desprezados (LINDGREN, 2002). Embora seja uma das características principais de túneis de vento, esta informação geralmente não é apresentada.

A forma de determinar a área útil do LANT, seria medir a camada limite das paredes no final da câmara de ensaios na menor velocidade de operação do túnel; pois a espessura da camada limite, para uma dada posição, é maior para uma velocidade menor. Para o caso do LANT, a velocidade é de $10 \mathrm{~m} / \mathrm{s}$ e a distância $2500 \mathrm{~mm}$ da entrada da câmara de ensaios.

Para medir a camada limite do LANT, foi utilizada a técnica de HWA e uma velocidade de escoamento de $10 \mathrm{~m} / \mathrm{s}$. Foram mensuradas duas posições, (1) a $500 \mathrm{~mm}$ e (2) $2500 \mathrm{~mm}$ da entrada da câmara; a resolução utilizada no posicionador foi de $1 \mathrm{~mm}$ e o tempo de aquisição foi de $31 \mathrm{~s}$ por posição.

Os resultados obtidos não foram bons, como pode ser conferido Fig. 32; pois seria esperado que a camada limite apresentasse o mesmo formato para as duas posições, fato que não ocorreu. Por se tratar de uma camada limite turbulenta, seriam necessárias várias medidas na mesmas condições para conseguirmos um perfil médio e compará-lo com a teoria, uma vez que ela não se comporta tão bem como a camada limite laminar.

Devido a necessidade de outros experimentos para complementar este trabalho e o baixo impacto relativo da medida da camada limite do túnel, optou-se por um procedimento indireto para mensurar a área útil do túnel. Assim, a área útil do LANT foi determinada pela variação do nível de turbulência em relação a do escoamento livre, ou seja, quando o nível de turbulência atingisse um determinado crescimento em relação ao escoamento livre, determina-se a área útil do LANT. Partindo do nível de turbulência normalizado pelo nível do escoamento livre, conforme Fig. 33, e adotando um critério conservador de crescimento de $10 \%$, a camada limite do LANT teria comprimento de $70 \mathrm{~mm}$ e $98 \mathrm{~mm}$ respectivamente para as distâncias de $500 \mathrm{~mm}$ e $2500 \mathrm{~mm}$ da entrada da câmara de ensaios, conforme a Fig. 34 .

Como a seção transversal da câmara de ensaios possui lados iguais, pode-se inferir 


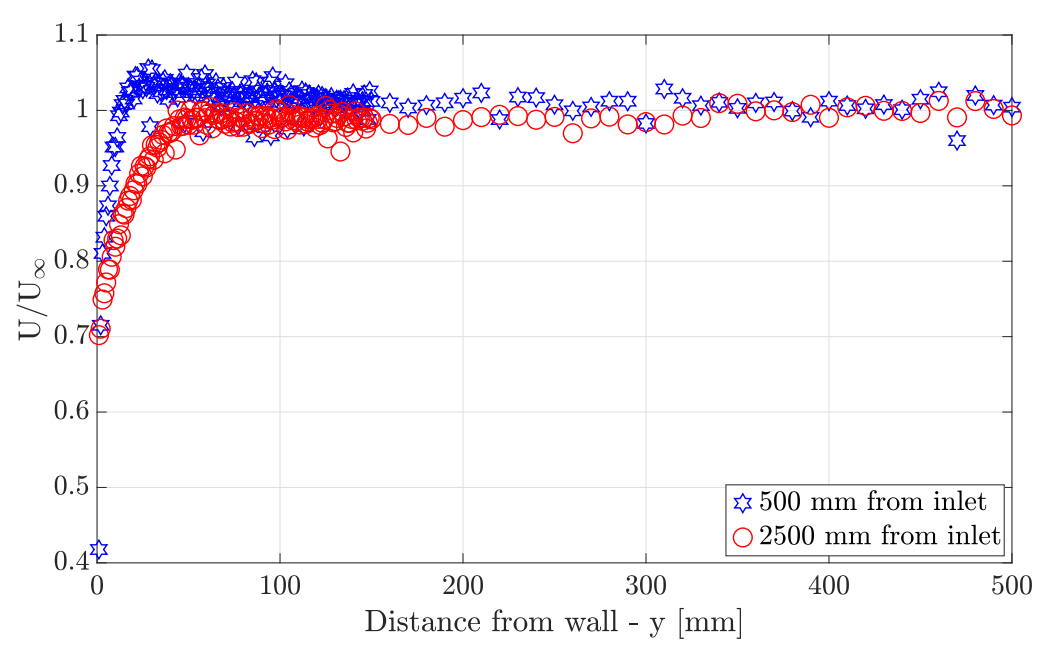

Figura 32 - Perfis de velocidade da camada limite do LANT à 10 m/s.

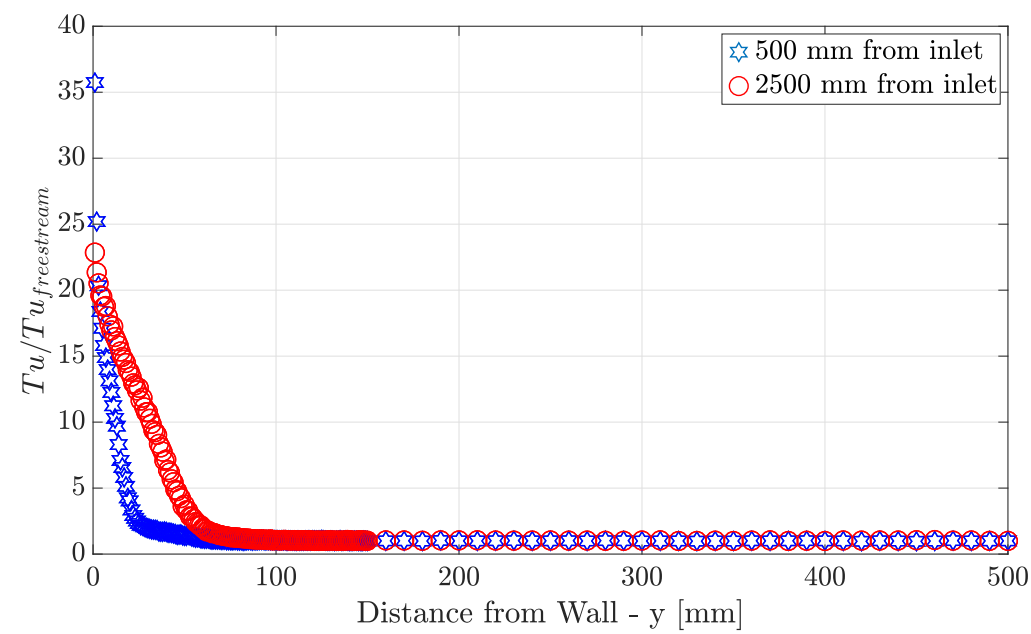

Figura 33 - Variação do nível de turbulência em relação a parede do LANT, para $10 \mathrm{~m} / \mathrm{s}$.

por simetria que a camada limite seja igual para todas elas. Assim, a área útil da câmara de ensaios à $2500 \mathrm{~mm}$ da entrada seria de $800 \mathrm{~mm} \times 800 \mathrm{~mm}$; o que corresponde a $64 \%$ de sua área total, conforme Fig. 35. Embora a área para regiões mais próximas à entrada sejam maiores, um experimento que utilize completamente a câmara de ensaios deve respeitar este limite.

Outra característica que pode ser verificada, para a distância de $2500 \mathrm{~mm}$ a partir da entrada da câmara de ensaios, é de que a camada limite do túnel pode ser dividida em três regiões: (1) uma região altamente turbulenta - variando de $1 \mathrm{~mm}$ até aproximadamente $40 \mathrm{~mm}$, (2) uma região de transição - variando de $50 \mathrm{~mm}$ até $110 \mathrm{~mm}$, e (3) uma região de escoamento livre - variando de $120 \mathrm{~mm}$ até $500 \mathrm{~mm}$. Estas três regiões podem ser vistas na Fig. 36. 


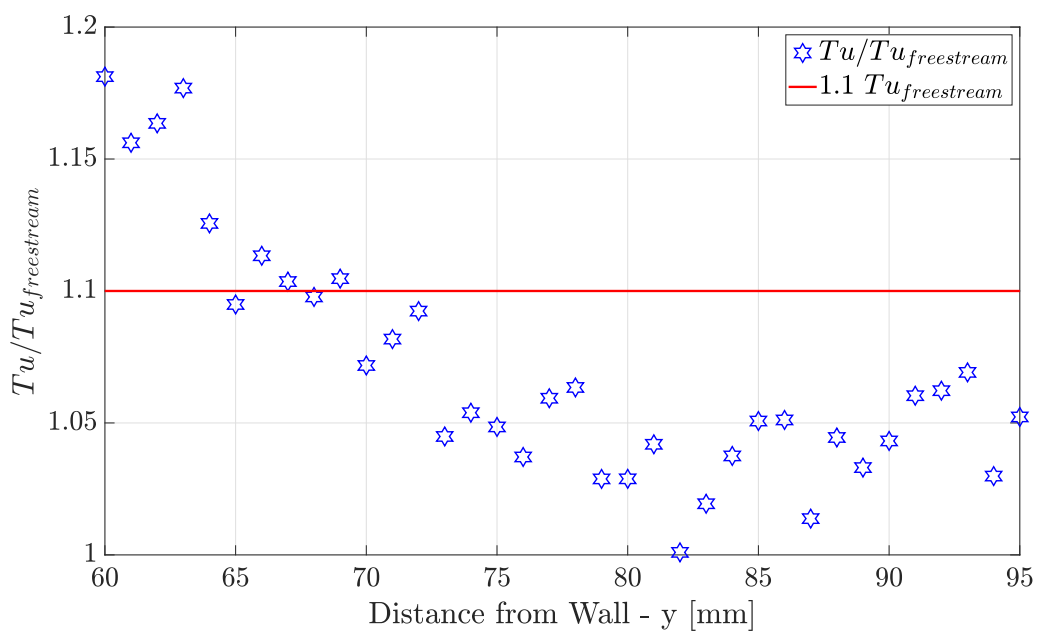

(a) $500 \mathrm{~mm}$

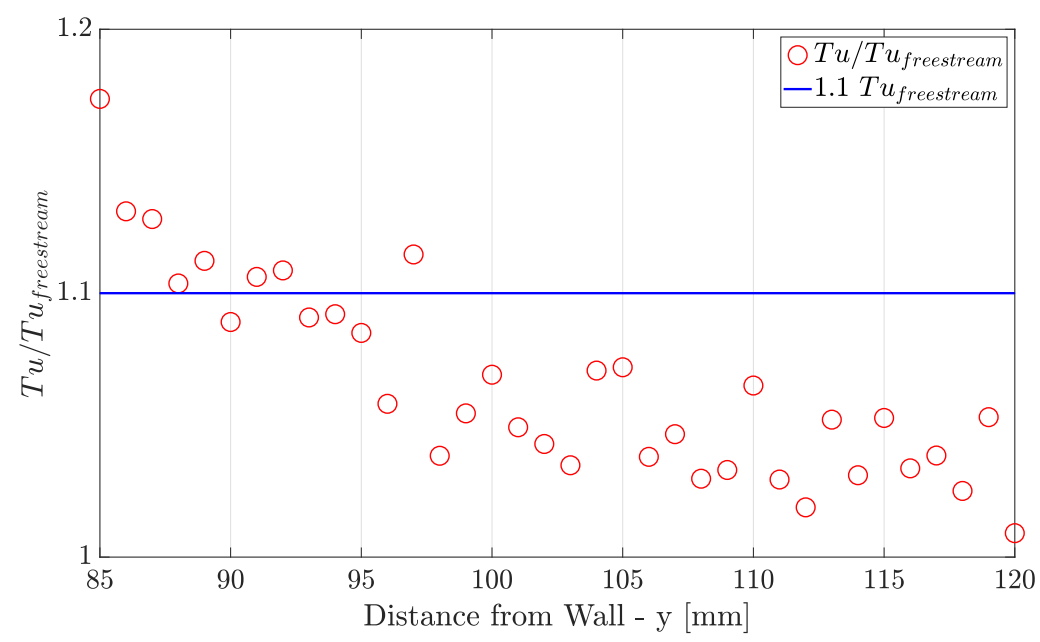

(b) $2500 \mathrm{~mm}$

Figura 34 - Critério para determinação da camada limite do LANT.

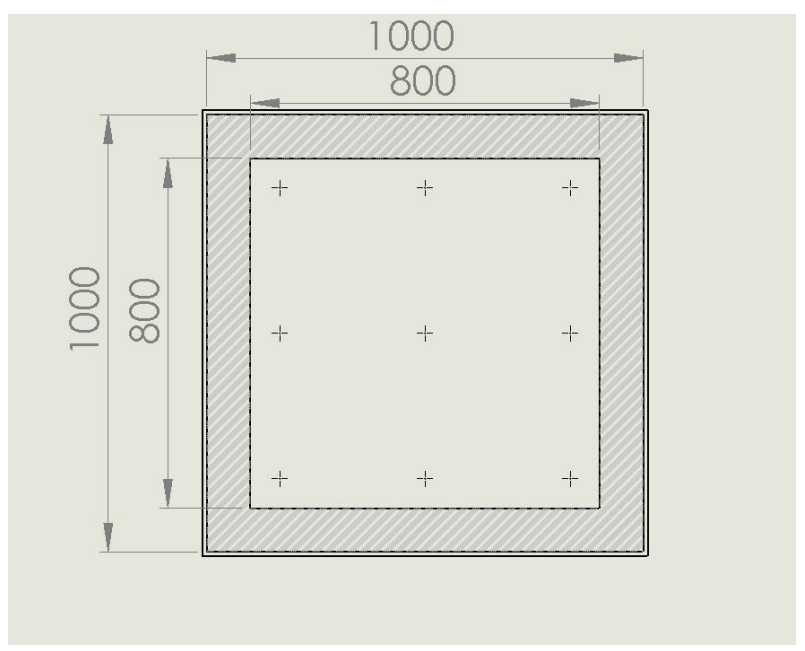

Figura 35 - Área útil da câmara de ensaios LANT 


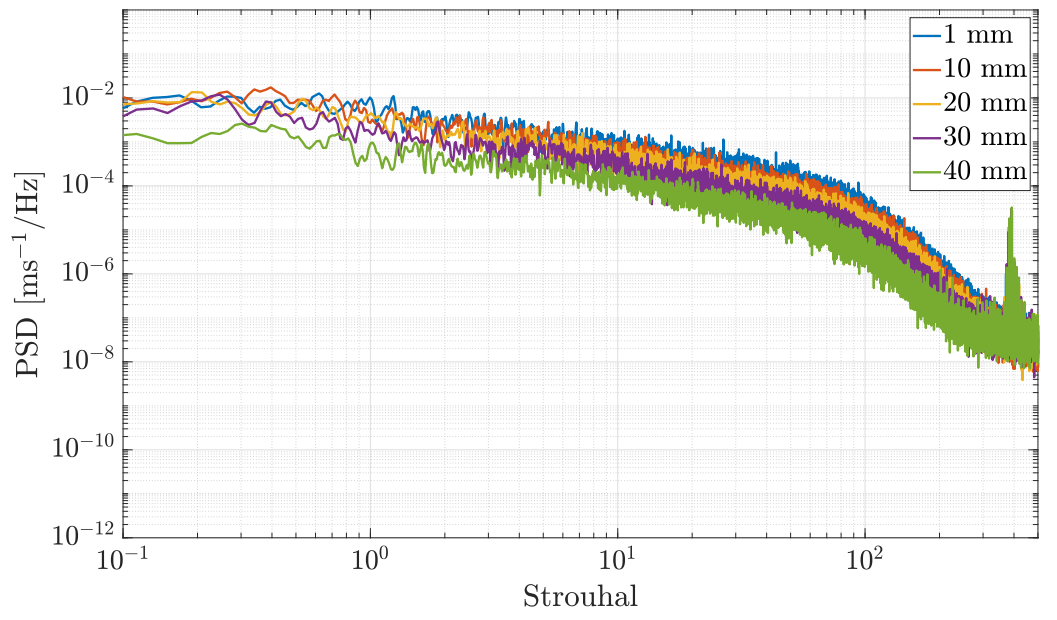

(a) Região altamente turbulenta

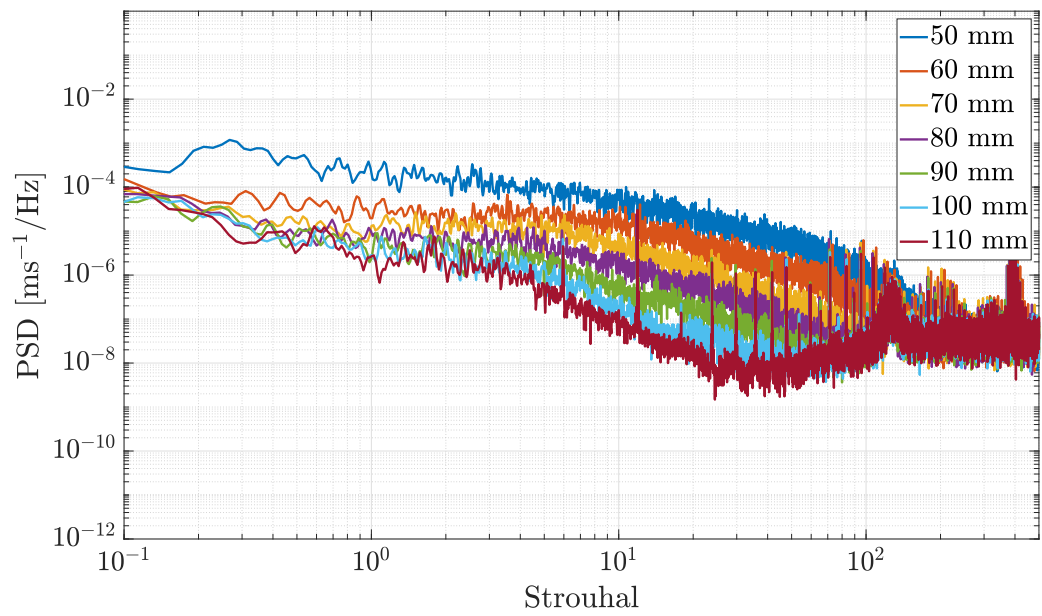

(b) Região de transição

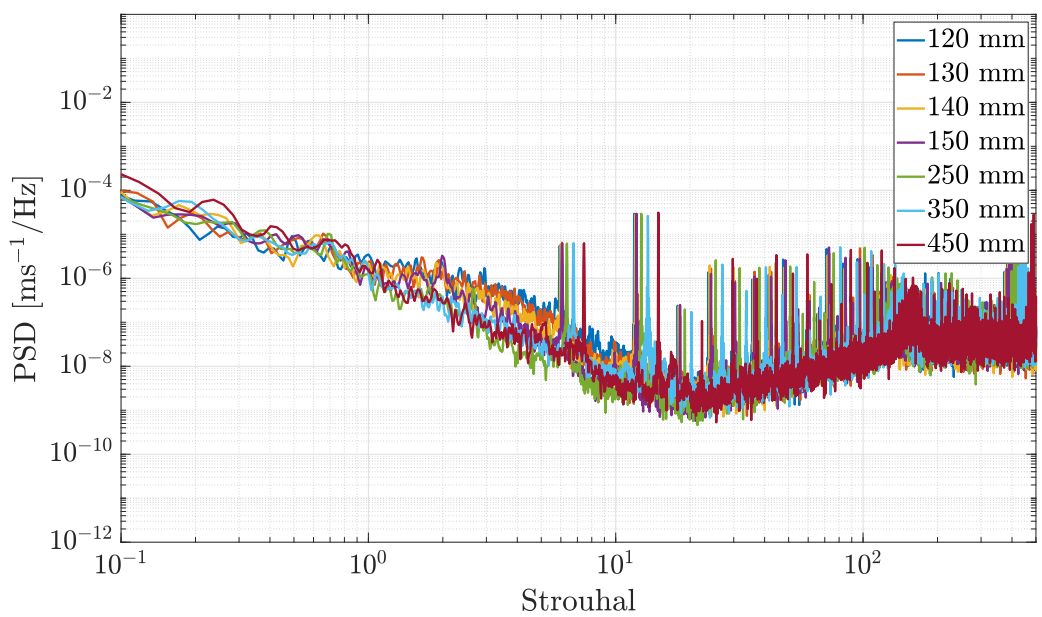

(c) Escoamento livre

Figura 36 - Regiões da camada limite LANT. 


\subsection{Uniformidade do Escoamento}

Os dispositivos utilizados para tratamento de qualidade do escoamento, descritos na Sec.3.1, não buscam apenas reduzir o nível de turbulência do LANT, mas também melhorar a uniformidade do escoamento. Um campo de velocidades altamente uniforme é necessário para a execução de experimentos bidimensionais, como por exemplo a geração de ondas TS na placa plana ou ainda o som por um aerofólio. A presença de não uniformidades muito grandes prejudica a execução de tais experimentos, uma vez que tornariam o escoamento tridimensional. O LANT foi projetado para apresentar não uniformidades menores que $1 \%$ da velocidade média do escoamento livre.

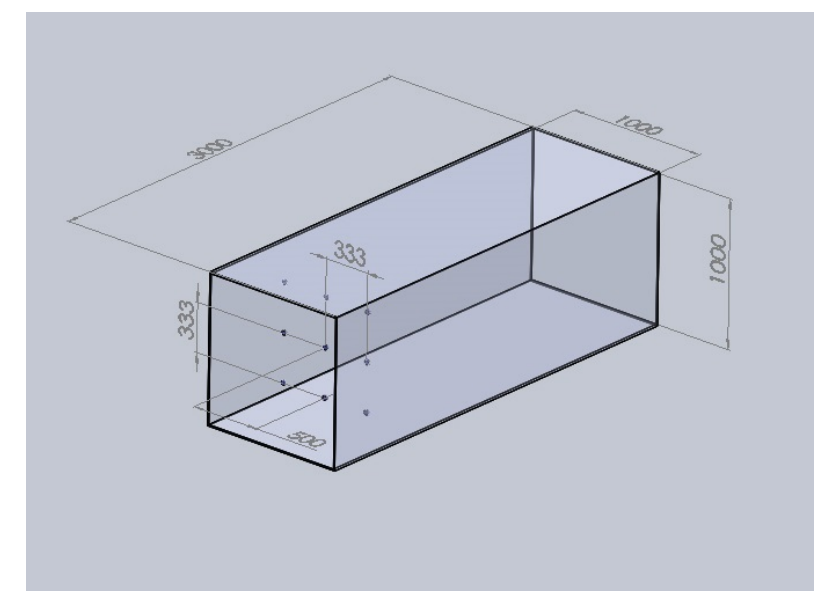

Figura 37 - Locais utilizados para aferição da uniformidade do LANT.

A medição da uniformidade do escoamento foi feita utilizando a técnica de HWA, comparando a variação da velocidade em nove pontos, utilizando o sistema de posicionamento, e englobando uma área de $666 \times 666 \mathrm{~mm}^{2}$, conforme a Fig. 37 As medidas foram tomadas, no sentido do escoamento (streamwise direction), a $500 \mathrm{~mm}$ à jusante da entrada da câmara de ensaios. Esta posição foi escolhida pois é distante o suficiente para o escoamento relaxar após as altas tensões sofridas na contração. O tempo de medição foi de 31 s para cada posição e as velocidades foram comparadas com a média de velocidade das nove posições.

Embora a técnica de HWA utilizada não seja a ideal para este tipo de medida devido a sua sensibilidade à temperatura, conforme a incerteza na tabela 9, o LANT apresenta um bom nível de uniformidade, principalmente na região central da câmara de ensaios. As não uniformidades raramente ultrapassam 1\% da velocidade na câmara, em sua região central; portanto, sendo possível considerar que as soluções adotadas foram efetivas para melhorar a qualidade do escoamento. Idealmente, estas medidas deveriam ser realizadas com um tubo de Pitot, ou ainda utilizando a técnica de velocimetria por imagens de partículas (Particle Image Velocimetry - PIV), o que será postergado para um momento futuro. 
$(500,333,-333) \quad(500,333,0) \quad(500,333,333)$

\begin{tabular}{cccc}
\hline \hline & & & \\
$10 \mathrm{~m} / \mathrm{s}$ & $0,2 \% \pm 0,9 \%$ & $-0,3 \% \pm 0,9 \%$ & $-0,2 \% \pm 0,9 \%$ \\
$15 \mathrm{~m} / \mathrm{s}$ & $0,2 \% \pm 0,9 \%$ & $-0,2 \% \pm 0,9 \%$ & $-0,3 \% \pm 0,9 \%$ \\
$20 \mathrm{~m} / \mathrm{s}$ & $-0,9 \% \pm 0,9 \%$ & $0,2 \% \pm 0,9 \%$ & $0,0 \% \pm 0,9 \%$ \\
$25 \mathrm{~m} / \mathrm{s}$ & $-1,6 \% \pm 0,9 \%$ & $1,5 \% \pm 0,9 \%$ & $-0,5 \% \pm 0,9 \%$ \\
& & & \\
& $(500,0,-333)$ & $(500,0,0)$ & $(500,0,333)$ \\
\hline \hline & & & \\
$10 \mathrm{~m} / \mathrm{s}$ & $-0,4 \% \pm 0,9 \%$ & $0,3 \% \pm 0,9 \%$ & $0,5 \% \pm 0,9 \%$ \\
$15 \mathrm{~m} / \mathrm{s}$ & $-0,1 \% \pm 0,9 \%$ & $-0,4 \% \pm 0,9 \%$ & $1,1 \% \pm 0,9 \%$ \\
$20 \mathrm{~m} / \mathrm{s}$ & $-0,3 \% \pm 0,9 \%$ & $-1,0 \% \pm 0,9 \%$ & $-0,2 \% \pm 0,9 \%$ \\
$25 \mathrm{~m} / \mathrm{s}$ & $0,4 \% \pm 0,9 \%$ & $-0,1 \% \pm 0,9 \%$ & $-0,9 \% \pm 0,9 \%$ \\
& & & \\
& $(500,-333,-333)$ & $(500,-333,0)$ & $(500,-333,333)$ \\
\hline \hline & & & \\
$10 \mathrm{~m} / \mathrm{s}$ & $-0,5 \% \pm 0,9 \%$ & $0,1 \% \pm 0,9 \%$ & $-0,3 \% \pm 0,9 \%$ \\
$15 \mathrm{~m} / \mathrm{s}$ & $0,2 \% \pm 0,9 \%$ & $-0,8 \% \pm 0,9 \%$ & $-0,4 \% \pm 0,9 \%$ \\
$20 \mathrm{~m} / \mathrm{s}$ & $1,0 \% \pm 0,9 \%$ & $0,5 \% \pm 0,9 \%$ & $0,7 \% \pm 0,9 \%$ \\
$25 \mathrm{~m} / \mathrm{s}$ & $2,4 \% \pm 0,9 \%$ & $-0,8 \% \pm 0,9 \%$ & $-0,4 \% \pm 0,9 \%$
\end{tabular}

Tabela 9 - Diferenças percentuais entre a velocidade atual e a média, para a posição (x,y,z) medida em milímetros a partir do ponto de referência, que se encontra no plano central da entrada da câmara de ensaios.

\subsection{Nível de Turbulência}

O nível de turbulência é a principal característica de um túnel de vento. Sendo o LANT um túnel para estudos de instabilidade hidrodinâmica e transição, o seu nível de turbulência determina a sua capacidade para executar estes tipos de experimentos. Saric e Reshotko (1998) dizem que o nível de perturbações no escoamento livre (freestream disturbances) modula fortemente o fenômeno a ser observado, por exemplo, se o nível de turbulência for muito alto, ele pode provocar uma transição bypass, de modo que a transição da camada limite de laminar para turbulenta ocorra a montante de sua posição em um ambiente com nível de turbulência menor do que determinado valor.

Geralmente o nível de turbulência é expresso em um percentual do escoamento livre, conforme a Eq.3.32, e a banda de filtragem utilizada para obter o resultado. Similarmente ao experimento de uniformidade, Sec.4.3, o nível de turbulência do LANT foi feito à 500 mm da entrada (inlet) da câmara de ensaios, no centro da seção transversal, utilizando o sistema de posicionamento, e para quatro velocidades: (1) $10 \mathrm{~m} / \mathrm{s}$, (2) $15 \mathrm{~m} / \mathrm{s}$, (3) $20 \mathrm{~m} / \mathrm{s}$ e (4) $25 \mathrm{~m} / \mathrm{s}$. O sistema utilizado foi descrito na Sec.3.2.6, e tempo total de aquisição de 61 s; os sinais foram então filtrados, com filtros digitais para diferentes bandas de passagem, e analisados. 


\subsubsection{Seleção de Filtro}

Por questão de facilidade, e por não possuir filtros analógicos operacionais, optou-se por utilizar scripts em Matlab para simular filtros digitais. Embora o Matlab possua uma toolbox específica para a construção de filtros digitais, com diversas opções de personalização, buscou-se avaliar apenas os filtros mais tradicionais, ou seja, (1) o filtro Butterworth, (2) o filtro Chebyshev Tipo I, (3) o filtro Chebyshev Tipo II e (4) o filtro Elíptico. A resposta destes filtros com a mesma ordem é apresentada na Fig. 38.

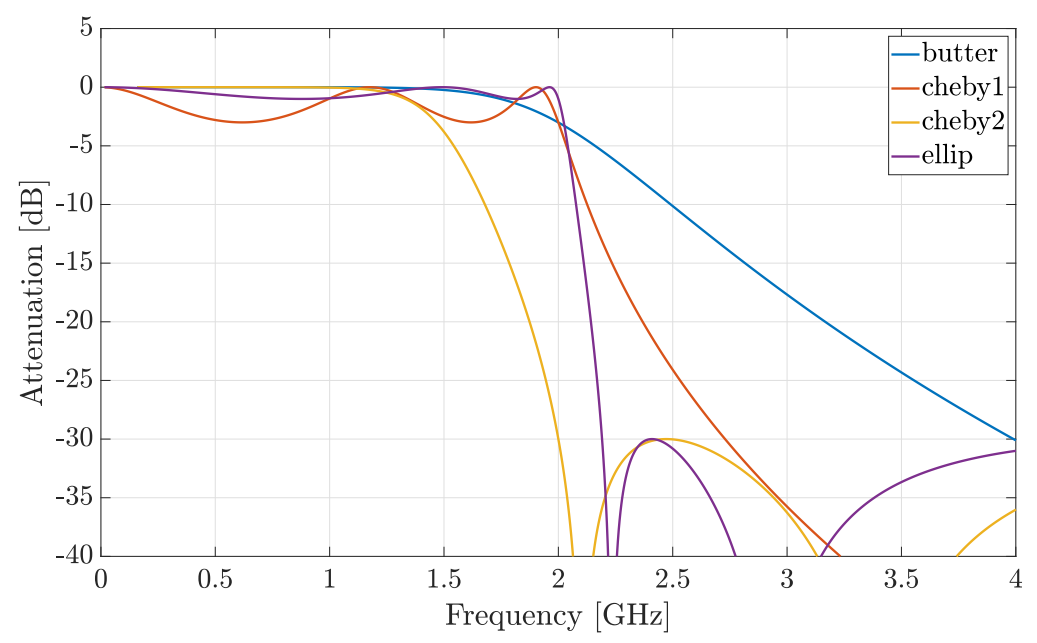

Figura 38 - Exemplo de resposta dos diferentes filtros de mesma ordem.

Analisando as repostas de cada filtro, optou-se por utilizar o Chebyshev Tipo II, pois ele apresenta uma resposta rápida e tem baixa oscilação próximo a frequência de corte. As características utilizadas nos filtro são (1) uma atenuação da banda de passagem (passband ripple) de $1 \mathrm{~dB},(2)$ uma atenuação de $150 \mathrm{~dB}$ na banda de bloqueio (stopband ripple) e (3) diferentes intervalos de banda de passagem (passband). Assim, o filtro utilizado é de ordem 202 e a resposta é dada pela Fig. 39.
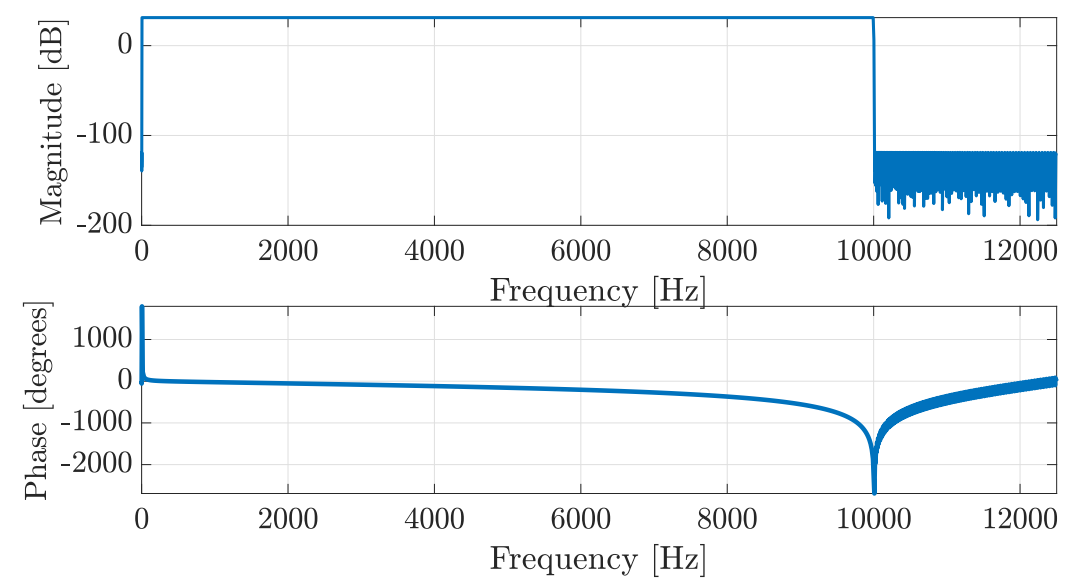

Figura 39 - Resposta do filtro passa banda Chebyshev Tipo II utilizado. 
A escolha da banda de passagem não é restritiva, embora Saric e Reshotko (1998) sugiram $0,1 \mathrm{~Hz}$ para o valor inicial a ser utilizado. Neste trabalho utilizou as bandas de passagem: (1) $1 \mathrm{~Hz}-10 \mathrm{kHz}$, (2) $4 \mathrm{~Hz}-10 \mathrm{kHz}$, (3) $8 \mathrm{~Hz}$ - $10 \mathrm{kHz}$ e (4) dinâmica. A banda dinâmica é utilizada para determinar o nível de turbulência do MTL (LINDGREN, 2002), sendo definida como

$$
f_{c}=\frac{U_{\infty}}{\lambda_{c}}
$$

em que $f_{c}$ é a frequência de corte (cutoff frequency), $U_{\infty}$ é a velocidade do escoamento livre e $\lambda_{c}$ é o comprimento de onda de corte (cutoff wavelength).

A escolha do $\lambda_{c}$ é feita de modo a manter as ondas, cujo comprimento, caibam dentro da seção transversal da câmara de ensaios. De modo a garantir estas ondas, $\lambda_{c}$ é escolhido como duas vezes o comprimento da seção transversal da câmara de ensaios, ou seja $2 \mathrm{~m}$; complementam ainda um filtro passa baixa (low pass filter) de $10 \mathrm{kHz}$. Uma comparação entre os filtros e o sinal do anemômetro é exibido na Fig. 40.

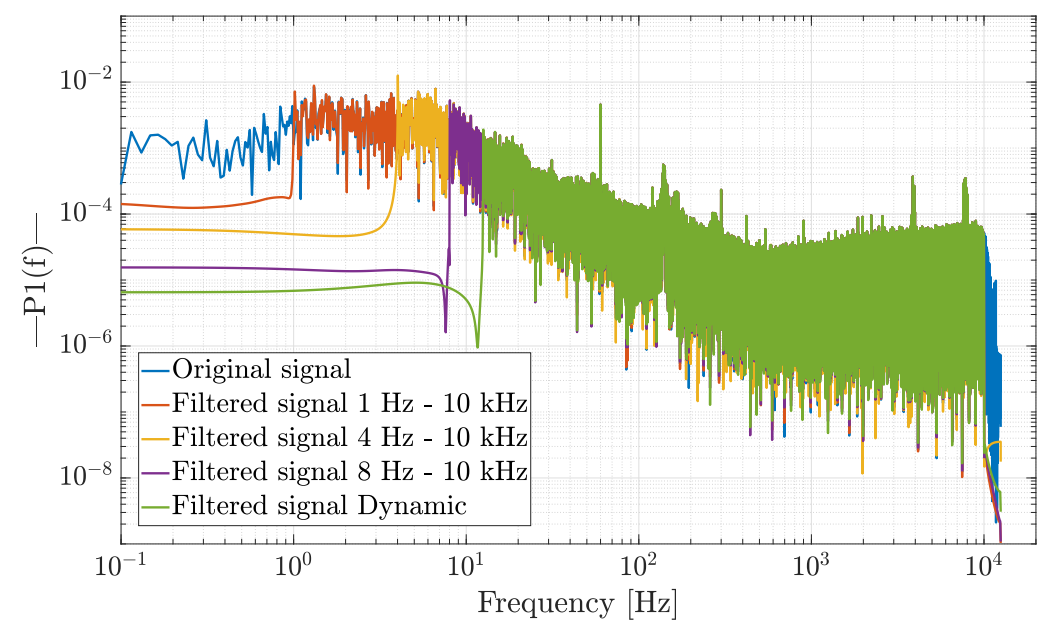

Figura 40 - Comparação entres os sinais o anemômetro para a velocidade de $25 \mathrm{~m} / \mathrm{s}$.

\subsubsection{Tempo de aquisição}

O tempo de aquisição utilizado nos experimentos de turbulência foi fixado em 61 s. Para averiguar se o tempo escolhido foi suficiente, o sinal foi dividido em intervalos menores, e foram calculados os valores rms da velocidade e foram tiradas médias de conjuntos (ensemble averages). O número de médias depende do intervalo de tempo, ou seja, intervalos menores mais médias foram realizadas. A Fig. 41 apresenta os resultados de turbulência para diferentes tempos de aquisição, nela é possível observar que não existem diferenças significativas para tempos maiores do que 10 segundos. Portanto, o tempo adotado para os experimentos de turbulência é suficiente. 


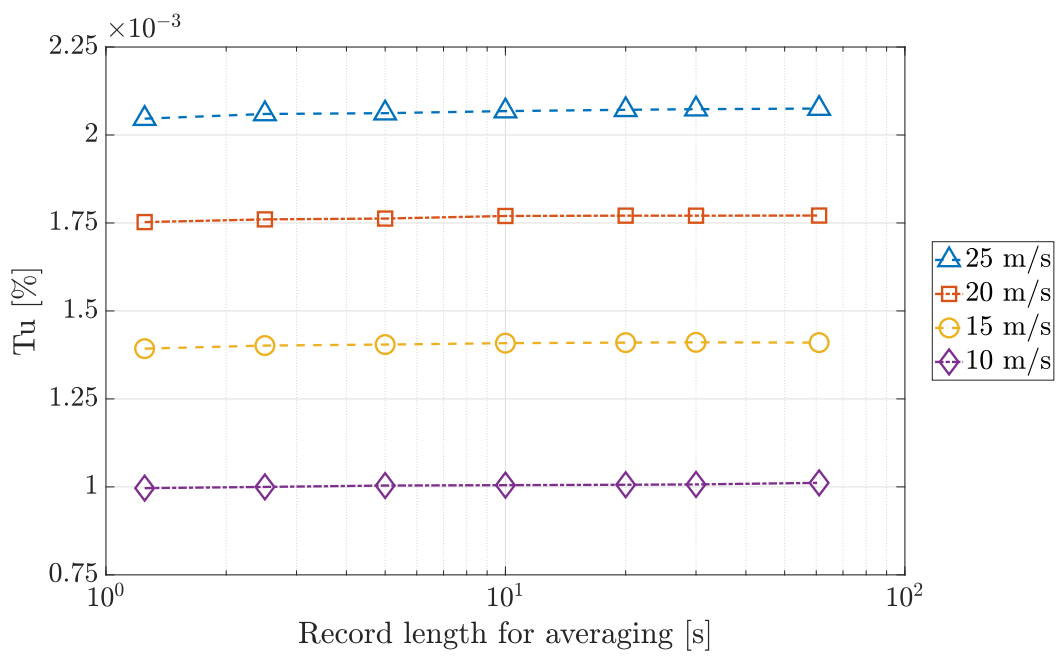

Figura 41 - Variação do nível de turbulência com o tempo de aquisição.

\subsubsection{Turbulência}

Utilizando os critérios estabelecidos nas subseções anteriores e as Eq.3.32 e Eq.3.33, a turbulência do LANT foi calculada usando um script em Matlab. Os resultados obtidos podem ser vistos na tabela 10 .

Nível de turbulência [\%]

\begin{tabular}{ccccc} 
velocidade $[\mathrm{m} / \mathrm{s}]$ & $1 \mathrm{~Hz}-10 \mathrm{kHz}$ & $4 \mathrm{~Hz}-10 \mathrm{kHz}$ & $8 \mathrm{~Hz}-10 \mathrm{kHz}$ & dinâmico \\
\hline \hline & & & & \\
$24,7 \pm 0,3$ & $0,21 \pm 0,01$ & $0,17 \pm 0,01$ & $0,106 \pm 0,007$ & $0,072 \pm 0,005$ \\
$20,1 \pm 0,3$ & $0,18 \pm 0,01$ & $0,14 \pm 0,01$ & $0,087 \pm 0,006$ & $0,072 \pm 0,005$ \\
$15,3 \pm 0,2$ & $0,14 \pm 0,01$ & $0,11 \pm 0,01$ & $0,073 \pm 0,005$ & $0,075 \pm 0,005$ \\
$10,4 \pm 0,1$ & $0,09 \pm 0,01$ & $0,08 \pm 0,01$ & $0,068 \pm 0,005$ & $0,073 \pm 0,005$
\end{tabular}

Tabela 10 - Nível de turbulência do LANT.

Embora escolha do filtro de passagem tem grande influência no nível de turbulência do LANT, conforme Fig. 42, o grupo entende que o filtro dinâmico é o mais coerente para a utilização de qualificação de túneis. Portanto, o nível de turbulência do LANT é de aproximadamente $0,07 \%$ da velocidade do escoamento livre, no intervalo de $10 \mathrm{~m} / \mathrm{s}$ até 25 $\mathrm{m} / \mathrm{s}$.

Para complementar a análise do nível de turbulência, é importante analisar o espectro de sinal e determinar a faixa de frequências presente no LANT. A Fig. 43 apresenta o espectro de frequências do LANT para diferentes velocidades, nela é possível observar que estas decrescem monotonicamente até uma região de ruído, sendo este comportamento de acordo com o sugerido por Saric e Reshotko (1998). Também é possível observar a existência de três grandes picos nas frequências de (1) $54 \mathrm{~Hz}$, (2) $140 \mathrm{~Hz}$ e 


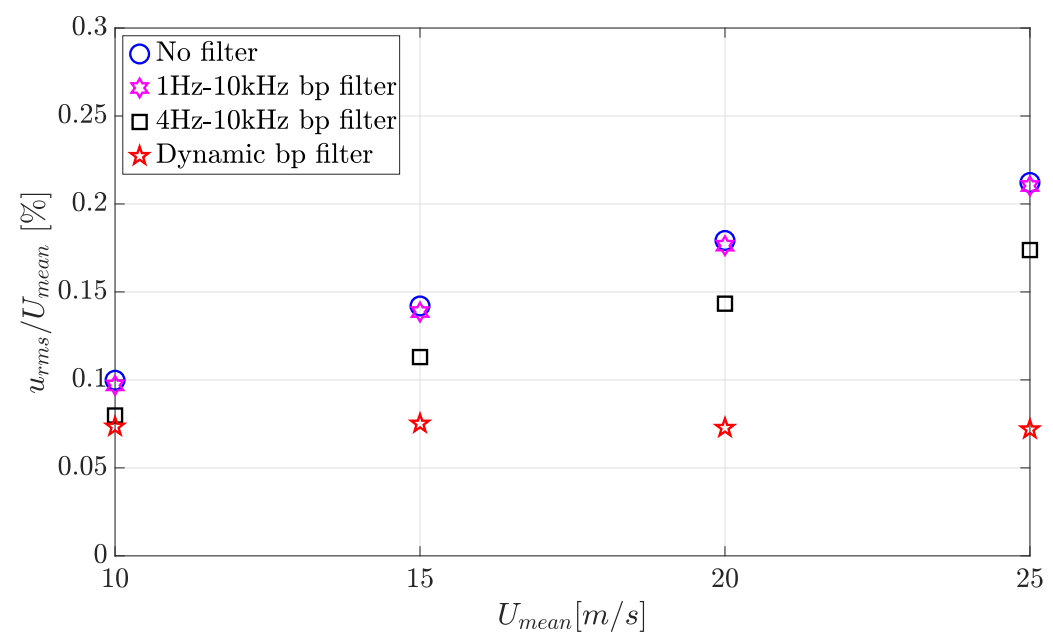

Figura 42 - Variação do nível de turbulência com o filtro escolhido.

(3) $270 \mathrm{~Hz}$, e uma série de picos menores, múltiplos de $60 \mathrm{~Hz}$. Uma vez que o grupo não dispõe rede dedicada para a aquisição de dados, controle do ventilador e sistema de posicionamento, os picos menores são originados de ruído na rede. Entretanto, os picos maiores possuem origem na vibração do conjunto asa + haste, medidos com acelerômetro conforme a Fig. 44, pois nos experimentos foi utilizada a asa de envergadura menor, uma vez que a projetada para este experimento não ficou pronta a tempo.

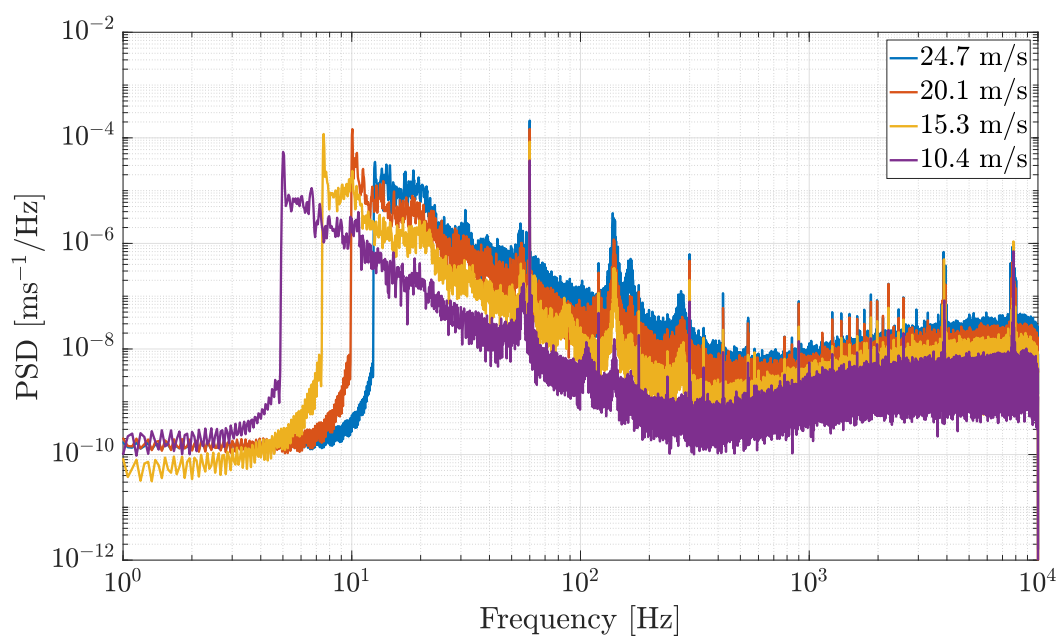

Figura 43 - Espectro de frequências do sinal obtido com HWA no LANT.

A faixa de frequências da turbulência é determinada pelo colapso do espectro pelo Strouhal, utilizando como dimensão característica $1 \mathrm{~m}$ (aresta da câmara de ensaios), Fig. 45. Nesta figura, observa-se que as frequências colapsam para o Strouhal de 0,5 até aproximadamente 300 para as velocidades mais altas, o que implica uma faixa de turbulência entre $8 \mathrm{~Hz}$ e $500 \mathrm{~Hz}$. 


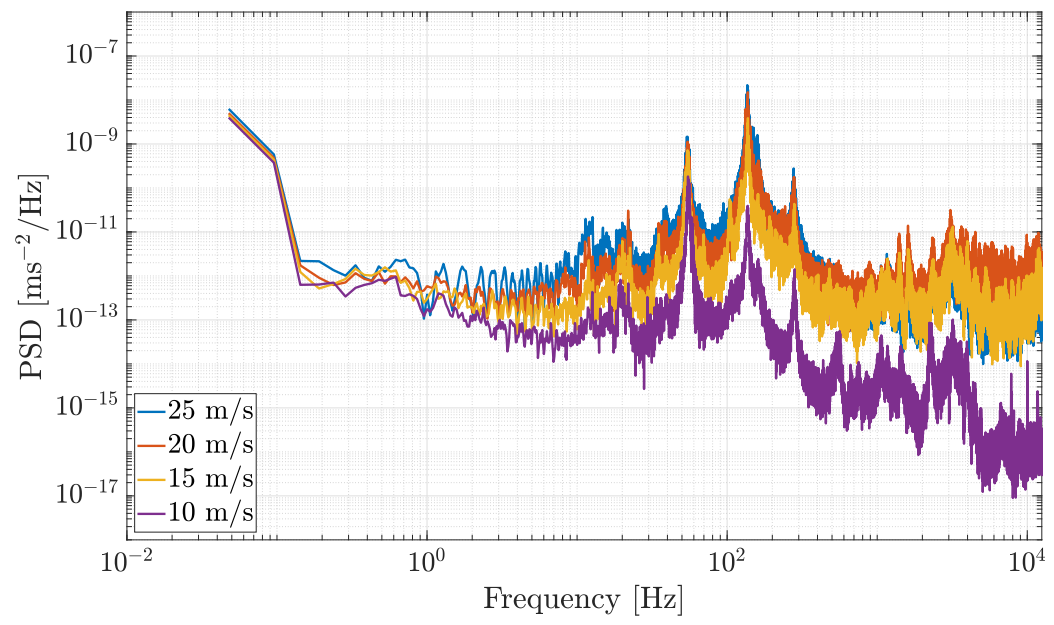

Figura 44 - Espectro de vibrações do conjunto asa + haste, medidas com acelerômetro.

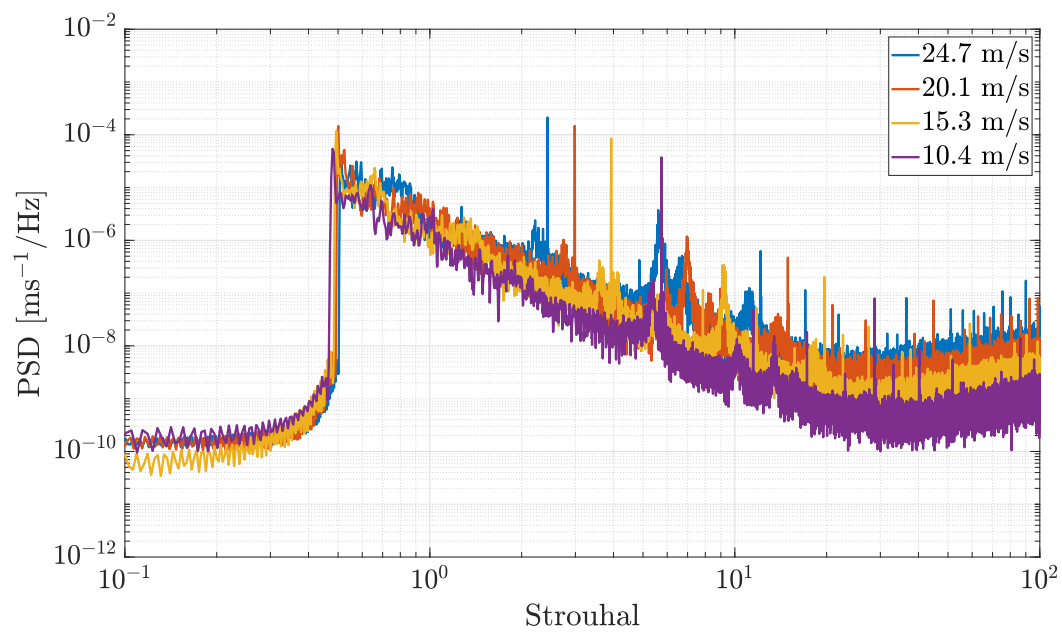

Figura 45 - Colapso do espectro de frequências obtido com as medições de HWA no LANT.

\subsubsection{Comparação com outros túneis de vento}

É interessante comparar os níveis de turbulência do LANT com o de outros túneis de vento nacionais e estrangeiros. Os equipamentos comparados são os nacionais, (1) o Túnel TA-2 do Departamento de Ciência e Tecnologia Aeroespacial - DCTA (AVELAR, 2005), (2) o túnel do Laboratório de Aerodinâmica Experimental - LAE da EESC-USP (SANTANA et al., 2010), e os internacionais, (3) Klebanoff-Saric da Universidade Texas A \& M (HUNT et al., 2010), (4) o MTL do Instituto Real de Tecnologia - KTH (LINDGREN, 2002), (5) o NDF do Instituto de Tecnologia de Illinois (NAGIB et al., 1994), (6) o Túnel de Instabilidade da Virginia Tech (REMILLIEUX et al., 2008) e o (7) túnel D5 da Universidade de Beihang (LIU et al., 2017). Os dados do nível de turbulência dos trabalhos supracitados diferem nas bandas de frequências utilizadas na medição e, quando disponíveis, as informações sobre filtros são apresentadas entre parenteses na legenda da Fig. 46. 
Como pode ser observado, o LANT possui níveis de turbulência equivalentes aos principais túneis de referência internacionais, representando um grande avanço em relação aos nacionais LAE e ao TA-2.

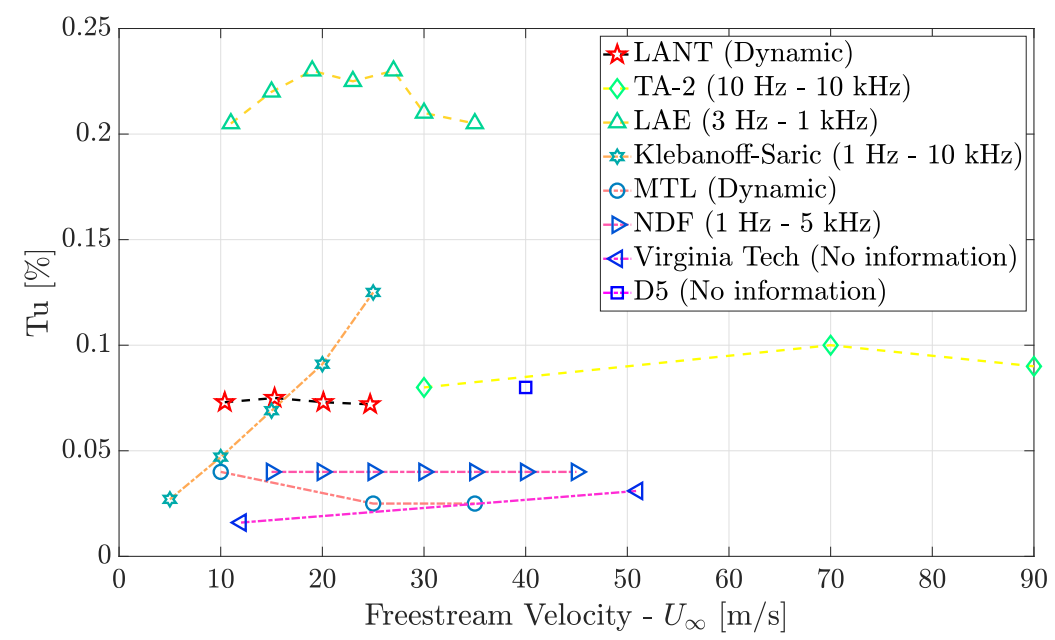

Figura 46 - Comparação entre os níveis de turbulência de diferentes túneis. Os dados entre parenteses representam os filtros passa banda utilizados, as linhas tracejadas indicam equipamentos nacionais e as linhas ponto-traço indicam equipamentos estrangeiros.

\subsection{Efeitos da Rotação do Ventilador}

Diferentemente de outros túneis, como o NDF, o ventilador do LANT possui pás fixas, ou seja, não é possível alterar o seu ângulo de ataque. Para testar a influência da velocidade de rotação do ventilador nos níveis de turbulência e ruído acústico de fundo do LANT, foi montada uma tela de pressão na saída (outlet) da câmara de ensaios. Esta tela foi construída com o mesmo material das telas de condicionamento do escoamento e foi instalada de modo a aumentar a perda de carga no circuito aerodinâmico; assim, para atingir velocidades semelhantes na câmara de ensaios, deve-se aumentar a rotação do ventilador. Nesta configuração de experimento, para atingir a mesma velocidade na câmara de ensaios, foi necessário um aumento médio de $27 \%$ na velocidade de rotação do ventilador, conforme a Fig.47.

A Fig.48 apresenta os resultados de turbulência para os casos com e sem tela de pressão na câmara de ensaios. Observa-se que o nível de turbulência apresenta um crescimento maior que o aumento da rotação do ventilador, aumentando em média $71 \%$. Esta análise sugere que se for possível melhorar a eficiência do ventilador do LANT, isto é, obter uma mesma velocidade de escoamento com rotações menores, será possível melhorar ainda mais a qualidade o escoamento, reduzindo o nível de turbulência. 


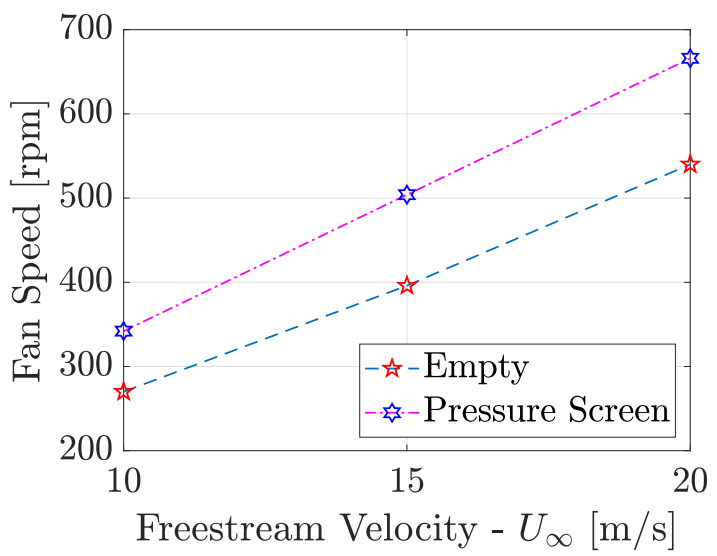

Figura 47 - Rotação do ventilador necessária para atingir velocidades semelhantes, com e sem tela de pressão.

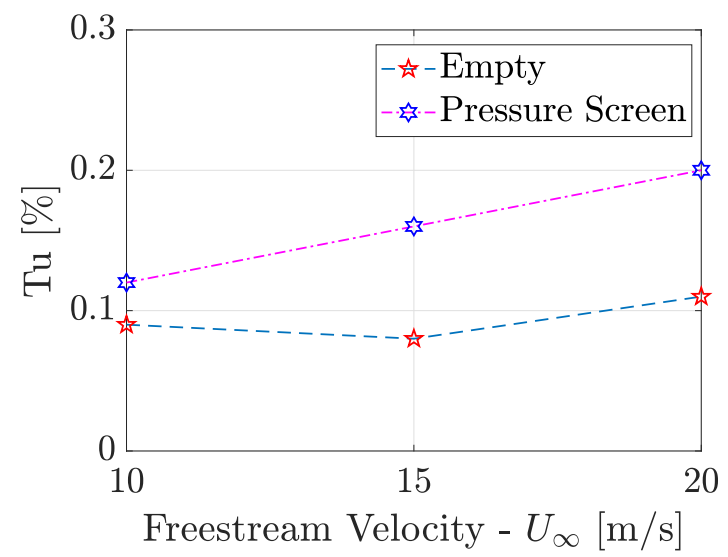

Figura 48 - Aumento no nível de turbulência, filtrado em $5 \mathrm{~Hz}$ até $20 \mathrm{kHz}$. 



\section{EXPERIMENTO PILOTO: ONDAS TOLLMIEN-SCHLICHTING}

O segundo objetivo deste trabalho é demonstrar a capacidade do LANT para realizar experimentos de transição da camada limite em uma placa plana. Para tanto, foi caracterizada a camada limite do modelo de placa plana, aferindo o seu perfil e sua transição natural, seguindo com a deteç̧ão e caracterização de uma onda TS forçada.

O modelo da placa plana, projetado por Juan Carlos Serrano Rico e apresentado na Fig. 49, é constituído de três elementos: (1) bordo de ataque em formato de superelipse, com $120 \mathrm{~mm}$ de comprimento feito em alumínio, (2) superfície plana em acrílico, com comprimento de $1800 \mathrm{~mm}$ e, (3) estrutura de flap e tab, para ajuste do gradiente de pressão, com $200 \mathrm{~mm}$ de comprimento feitos em alumínio. Assim, a parte útil da placa apresenta $1920 \mathrm{~mm}$ de comprimento e $1000 \mathrm{~mm}$ de envergadura, se estendendo ao longo da seção de testes do teto ao chão. A união entre o bordo de ataque e o corpo da placa é feito de modo a evitar o surgimento de uma cavidade, o que poderia ser prejudicial aos experimentos. A placa também possui 26 furos de $0,6 \mathrm{~mm}$ de diâmetro cada, localizados à 200 mm da junção entre o modelo e a parede da seção de testes, e espaçados ao longo da corda principal, para a medição do gradiente de pressão. Também foi adicionado um furo com $0,8 \mathrm{~mm}$ de diâmetro à $200 \mathrm{~mm}$ do bordo de ataque e na linha central da placa, para a geração de ondas TS utilizando um alto-falante de fone de ouvido.

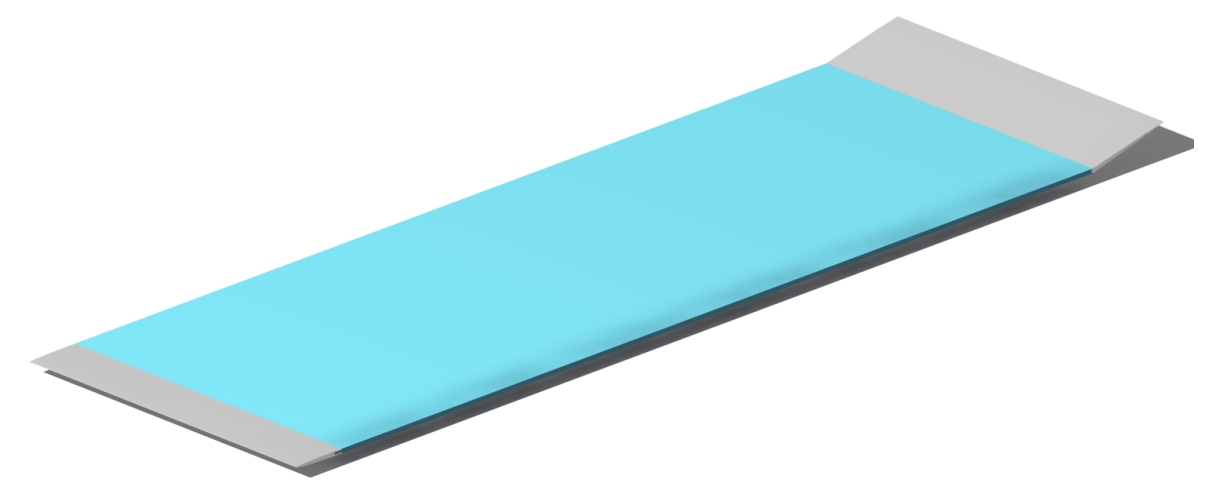

Figura 49 - Modelo utilizado para os experimentos de caracterização de ondas TS.

\subsection{Camada Limite da Placa Plana}

O conceito de camada limite, criado por Prandtl (1905), revolucionou o estudo da aerodinâmica ao estabelecer que os efeitos viscosos ficariam restritos a uma pequena camada próxima a parede para altos números de Reynolds. Este conceito implica que 
o escoamentos nesta condição podem ser divididos em duas regiões: (1) o escoamento externo (outer flow), no qual os efeitos da viscosidade podem ser desprezados e, (2) a camada limite, na qual os efeitos viscosos podem ser considerados.

A divisão do escoamento nestas duas regiões produz uma grande simplificação nas equações de Navier-Stokes (Navier-Stokes Equations - NSE), que para o caso de uma placa plana bidimensional semi-infinita assume a forma

$$
u \frac{\partial u}{\partial x}+v \frac{\partial u}{\partial y}=\nu \frac{\partial^{2} u}{\partial y^{2}}
$$

$\mathrm{e}$

$$
\frac{\partial u}{\partial x}+\frac{\partial v}{\partial y}=0
$$

com as seguintes condições de contorno

$$
\begin{aligned}
y=0: & u=0, v=0 ; \\
y \longrightarrow \infty: & u=U_{\infty} .
\end{aligned}
$$

de acordo com Schlichting e Gersten (2017).

O conjunto de equações 5.1 a 5.3 são válidas para o caso de um gradiente de pressão nulo, ou seja, $d p / d x=0$. Este sistema foi resolvido primeiramente por Blasius (1908), utilizando a função potencial $\Psi$ e a transformação de similaridade

$$
\eta=y \sqrt{\frac{U_{\infty}}{\nu x}}
$$

obtendo a equação diferencial

$$
f^{\prime \prime \prime}+f f^{\prime \prime}=0
$$

em que o apóstrofo indica diferenciação em relação a $\eta$. A Eq.5.5 é conhecida como equação de Blasius e deve satisfazer as condições de contorno

$$
\begin{aligned}
\eta=0: & f=0, f^{\prime}=0 ; \\
\eta \longrightarrow \infty: & f^{\prime}=1 .
\end{aligned}
$$

A solução da Eq.5.5 pode ser obtida numericamente e será utilizada como referência para a comparação obtidos com a medição do perfil da camada limite a partir da técnica de HWA. 


\subsubsection{Perfil da Camada Limite}

Para avaliar os instrumentos de medição e a técnica utilizada, foram realizados experimentos para a caracterização do perfil da camada limite para diferentes valores do número de Reynolds, sendo este calculado pela expressão

$$
R e_{x}=\frac{U_{\infty} x}{\nu}
$$

em que $x$ é a distância entre o bordo de ataque e a posição na placa plana. A Fig. 50 apresenta um exemplo de perfil da camada limite obtido para o modelo de placa plana ensaiado no LANT, nela é possível verificar uma excelente concordância entre os dados experimentais e a previsão da teoria para a posição $x=400 \mathrm{~mm}$ e velocidade de $18 \mathrm{~m} / \mathrm{s}$. Portanto, no LANT é possível medir uma camada limite laminar sobre uma placa plana.

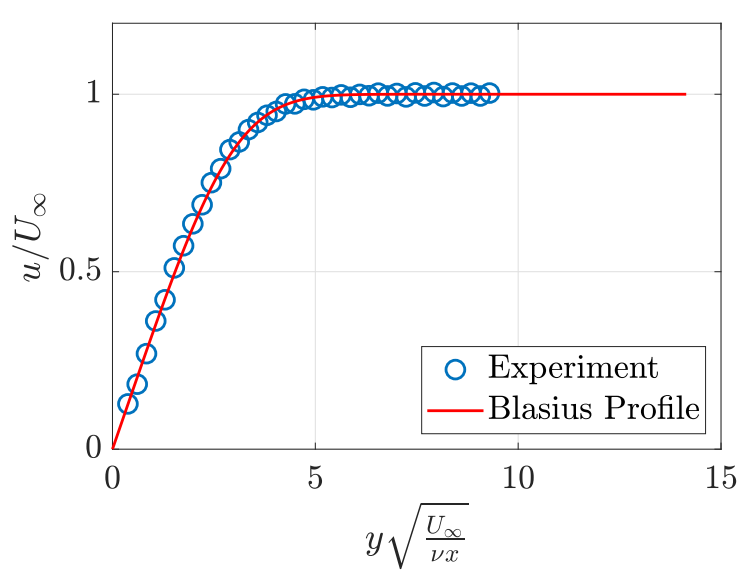

Figura 50 - Comparação entre o perfil teórico de Blasius e o perfil medido com a técnica de HWA, para $R e_{x} \approx 460.000$.

\subsubsection{Camada Limite Bidimensional}

Uma consideração importante sobre a camada limite na placa plana no LANT é determinar se ela é bidimensional. A bidimensionalidade é importante, pois ela permite a execução de experimentos 2D comparáveis à simulações numéricas. Para determinar a bidimensionalidade da camada limite, foram realizadas medidas de perfis para cinco diferentes posições de $z$ (spamvise direction), fixando-se a posição em $x$ e a velocidade do escoamento. Os resultados do perfil de velocidades é apresentado na Fig. 51, que indica um bom nível de bidimensionalidade.

\subsubsection{Transição Natural da Camada Limite}

Por fim, é importante caracterizar a transição natural da camada limite. Schubauer e Skramstad (1947) investigaram a influência do nível de turbulência na transição natural 


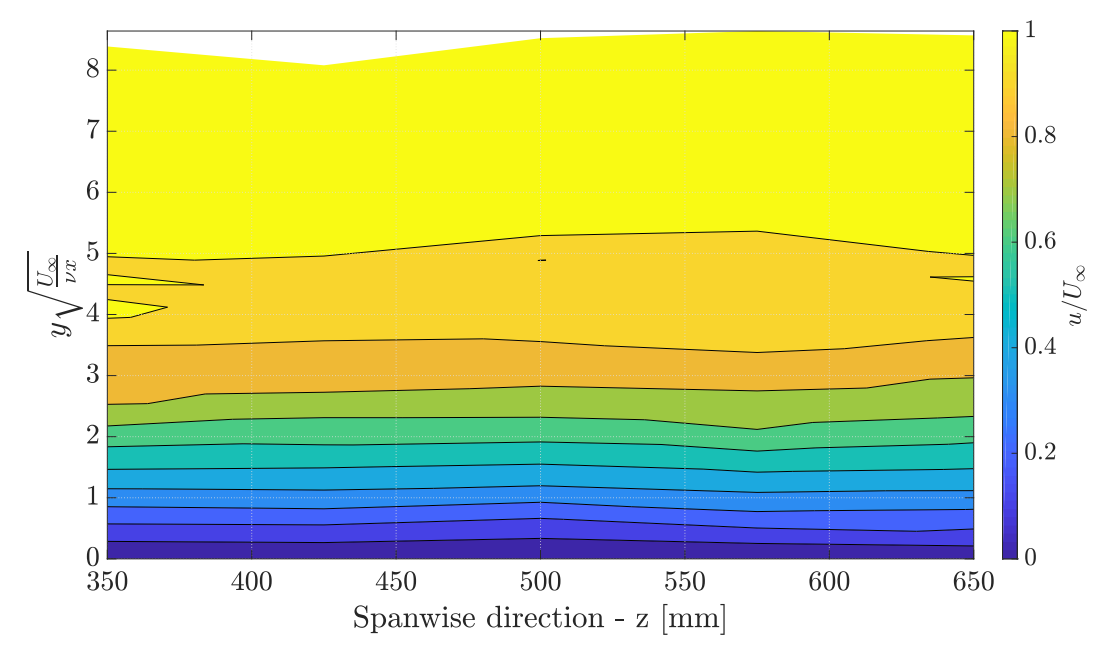

(a) Contorno do perfil de velocidades para diferentes valores de $z$.

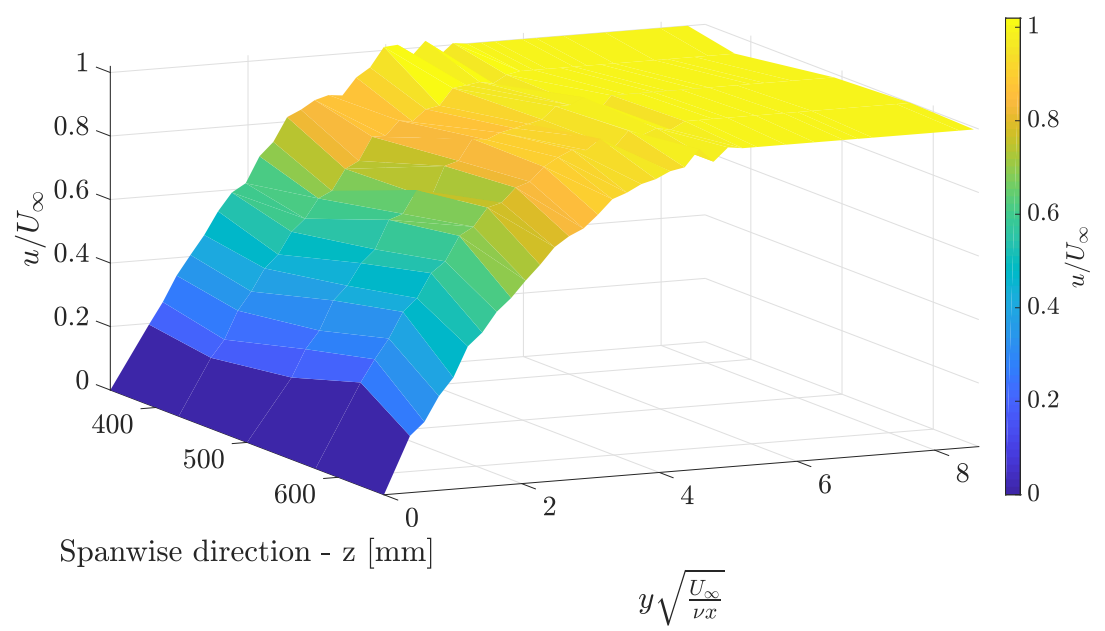

(b) Perfil de velocidades para diferentes valores de $z$.

Figura 51 - Bidimensionalidade da camada limite para $R e_{x} \approx 450.000$.

da camada limite e demonstraram que para níveis de turbulência da ordem de $0,03 \%$, na ausência de gradientes de pressão, o número de Reynolds crítico é da ordem de $3,9 \times 10^{6}$. Neste trabalho, Schubauer e Skramstad (1947) também demonstram experimentalmente que o gradiente de pressão tem grande influência na estabilidade da camada limite, sendo estas consideravelmente mais estáveis para escoamentos em que haja perda de pressão a jusante $(d p / d x<0$, escoamento acelerado) do que escoamentos com aumento de pressão $(d p / d x>0$, escoamento desacelerado $)$.

Assim, a primeira etapa foi ajustar o flap e o tap do modelo, Fig. 49, de modo a zerar o gradiente de pressão da placa plana. Os dados de pressão foram medidos utilizando um micromanômetro digital DP-Calc (incerteza de $1 \mathrm{~Pa}+0,5 \%$ do valor de leitura) em 12 pontos ao longo do modelo. Os resultados obtidos do coeficiente de pressão a $20 \mathrm{~m} / \mathrm{s}$, apresentados na Fig. 52, demonstram que o gradiente de pressão é próximo a zero sobre a placa. 


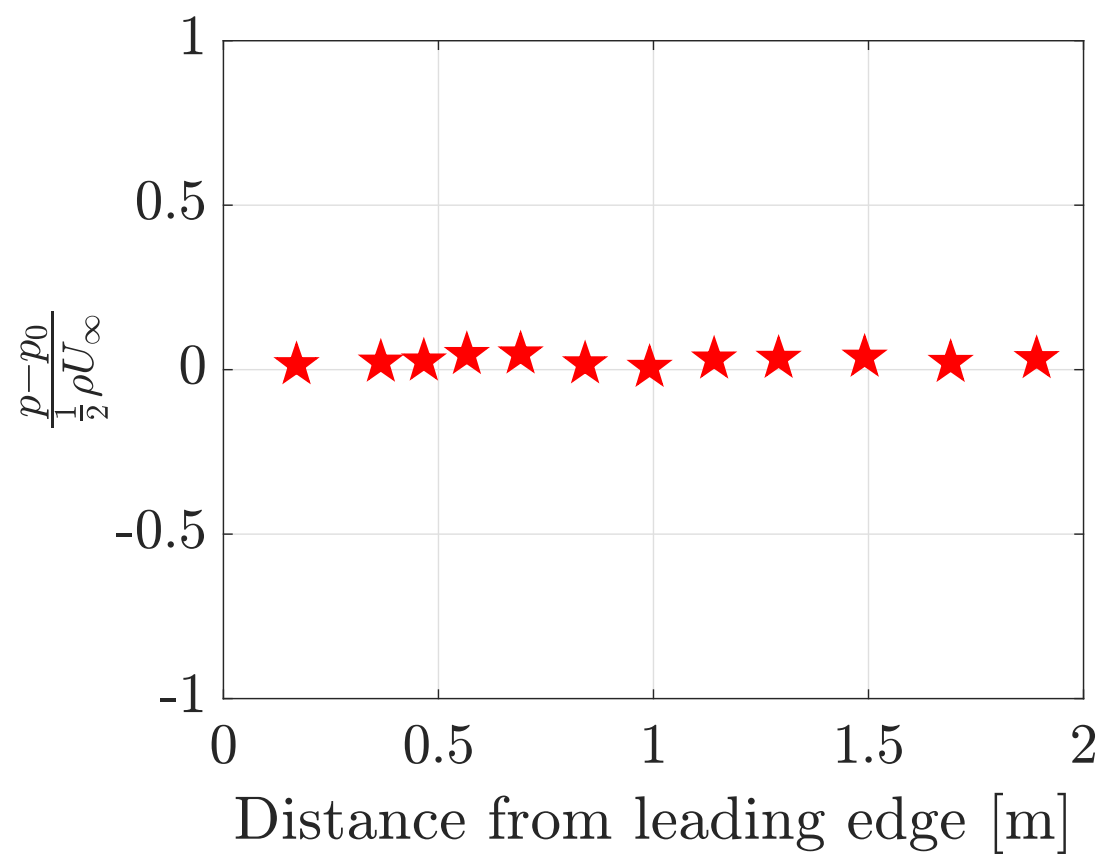

Figura 52 - Coeficiente de pressão $\left(c_{p}\right)$ sobre a placa plana.

Uma maneira de aferir a transição da camada limite é calculando a espessura de deslocamento $\delta^{*}$ (displacement thickness). De forma simples, o $\delta^{*}$ mede quanto o escoamento externo invíscido é deslocado pela perda de velocidade na camada limite de modo a manter o fluxo constante, sendo definido por

$$
\delta^{*}=\int_{0}^{\infty}\left(1-\frac{u}{U_{\infty}}\right) d y
$$

Para a camada limite laminar, a Eq. 5.8 assume a forma

$$
\delta^{*}=1,7208 \sqrt{\frac{\nu x}{U_{\infty}}}
$$

A Fig. 53 apresenta uma comparação entre a previsão da teoria e medição experimental para diferentes valores de $x$ e de $U_{\infty}$, sendo possível observar que os valores experimentais apresentam boa concordância para números de Reynolds menores que $2,5.10^{6}$. Para valores maiores há uma grande divergência entre o valor previsto pela teoria laminar e o medido experimentalmente, indicando uma mudança no perfil da camada limite.

Schubauer e Klebanoff (1955) demonstram que na região de transição há uma forte queda no valor do fator de forma $H$ (shape factor), diminuindo de um valor aproximado de 2,59 na região laminar para um valor aproximado de 1,4 na região turbulenta. $O$ fator 


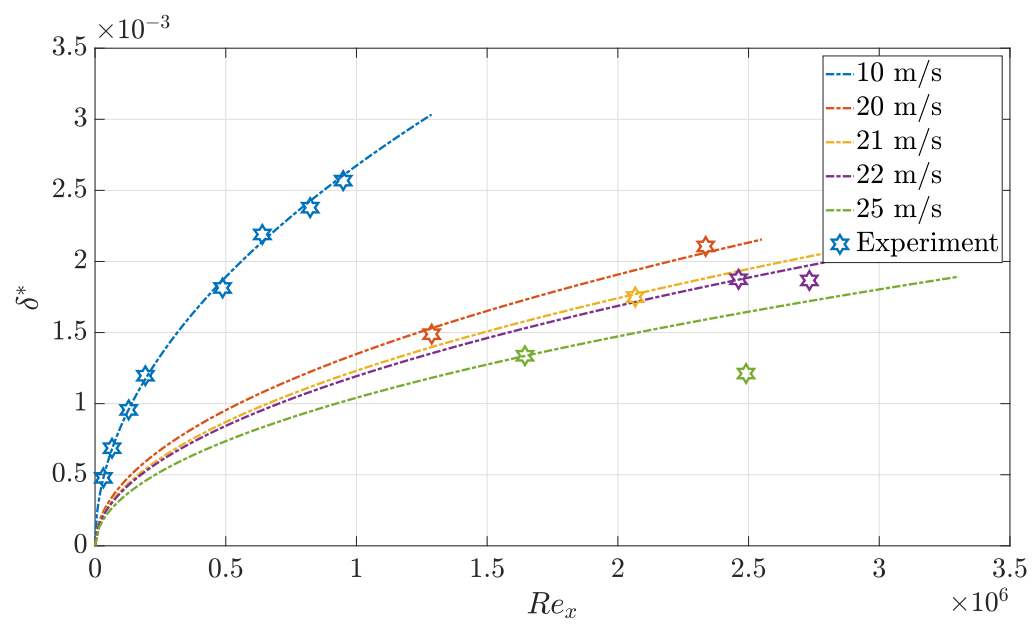

Figura 53 - Comparação entre os valores de $\delta^{*}$ medidos e a teoria de Blasius para diferentes valores de $x$ e $U_{\infty}$. As linha traço-ponto indicam a previsão teórica para os valores de $\delta^{*}$ em cada velocidade.

de forma é definido como a razão

$$
H=\frac{\delta^{*}}{\Theta}
$$

em que $\Theta$ é a espessura de momentum (momentum thickness), sendo dada por

$$
\Theta=\int_{0}^{\infty} \frac{u}{U_{\infty}}\left(1-\frac{u}{U_{\infty}}\right) d y
$$

Similarmente ao caso do $\delta^{*}$, para a camada limite laminar, $\Theta$ assume a forma

$$
\Theta=0,664 \sqrt{\frac{\nu x}{U_{\infty}}} .
$$

Comparando os valores teórico e experimental de $H$, Fig. 54, pode-se afirmar a partir do fator de forma que a camada limite na placa plana começa a transicionar para $R e>2,5 \times 10^{6}$.

Por motivo de segurança, pois o modelo, que é feito em acrílico, começou a vibrar para velocidades maiores que $25 \mathrm{~m} / \mathrm{s}$, não foi possível atingir a camada limite completamente turbulenta e determinar o número de Reynolds crítico. Entretanto, a Fig. 55 demonstra claramente uma mudança no perfil da camada limite. 


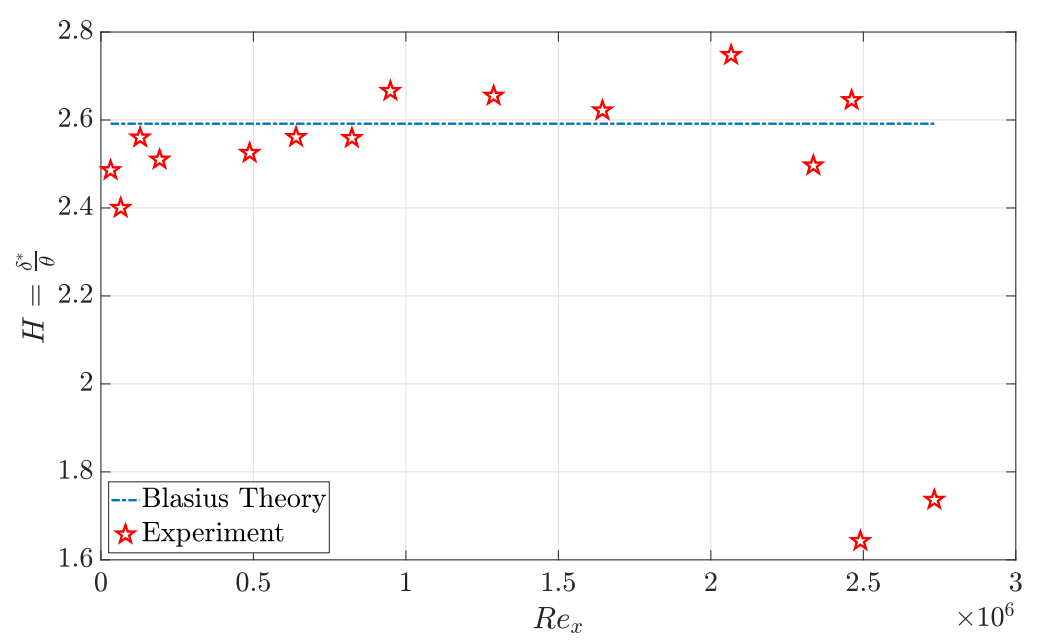

Figura 54 - Varição do fator de forma $H$ com o número de Reynolds; a linha tracejada indica a previsão teórica para a camada limite laminar.

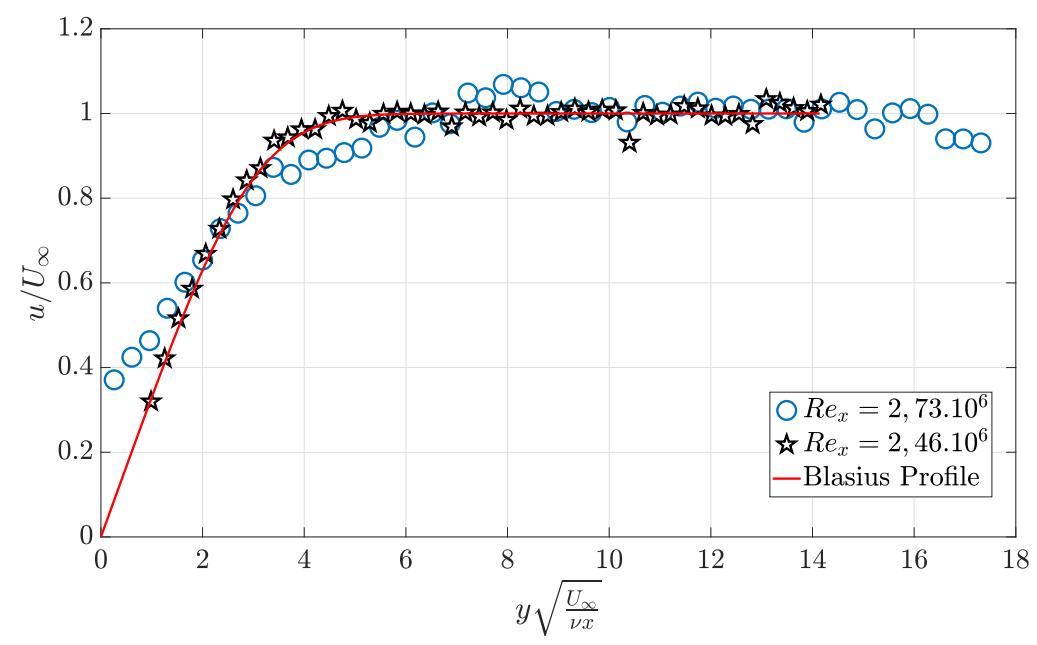

Figura 55 - Varição do fator de forma $H$ com o número de Reynolds.

\subsection{Ondas Tollmien-Schlichting}

A teoria da estabilidade hidrodinâmica linear baseia-se na utilização das equações linearizadas de Navier-Stokes (LNSE) para avaliar a estabilidade de escoamentos sob pequenas perturbações (método das pequenas perturbações - method of small perturbations). Para o caso de um escoamento bidimensional, incompressível e assumindo que o escoamento base é função apenas de $y$, ou seja, $U=U(y)$ e as demais componentes da velocidade nulas, $V=W=0$, as LNSE podem ser escritas como

$$
\begin{gathered}
\frac{\partial u^{\prime}}{\partial t}+U \frac{\partial u^{\prime}}{\partial x}+v^{\prime} \frac{d U}{d y}+\frac{1}{\rho} \frac{\partial p^{\prime}}{\partial x}=\nu\left(\frac{\partial^{2}}{\partial x^{2}}+\frac{\partial^{2}}{\partial y^{2}}\right) u^{\prime} \\
\frac{\partial v^{\prime}}{\partial t}+U \frac{\partial v^{\prime}}{\partial x}+\frac{1}{\rho} \frac{\partial p^{\prime}}{\partial y}=\nu\left(\frac{\partial^{2}}{\partial x^{2}}+\frac{\partial^{2}}{\partial y^{2}}\right) v^{\prime}
\end{gathered}
$$


e

$$
\frac{\partial u^{\prime}}{\partial x}+\frac{\partial v^{\prime}}{\partial y}=0
$$

em que $u^{\prime}, v^{\prime}$ e $p^{\prime}$ são as perturbações no campo de velocidades e de pressão, respectivamente.

Assumindo uma perturbação senoidal, o conjunto de equações 5.13 à 5.15 pode ser integrado utilizando a função potencial

$$
\Psi(x, y, t)=\phi(y) e^{i(\alpha x-\omega t)}
$$

em que $\alpha$ e $\omega$ são, respectivamente, o número de onda $(\alpha=2 \pi / \lambda)$ e a frequência da perturbação.

As perturbações na velocidade estão relacionadas com a função potencial na forma

$$
u^{\prime}=\frac{\partial \Psi}{\partial y}=\phi^{\prime}(y) e^{i(\alpha x-\omega t)}
$$

$\mathrm{e}$

$$
v^{\prime}=-\frac{\partial \Psi}{\partial x}=-i \alpha \phi(y) e^{i(\alpha x-\omega t)} .
$$

Assim, o conjunto de equações 5.13 à 5.15 se transforma em

$$
(\alpha U-\omega)\left(\phi^{\prime \prime}-\alpha^{2} \phi\right)-\alpha U^{\prime \prime} \phi=-\frac{i}{R e}\left(\phi^{\prime \prime \prime \prime}-2 \alpha^{2} \phi^{\prime \prime}+\alpha^{4} \phi\right)
$$

A Eq.5.19 é uma equação diferencial adimensional de autovalores, conhecida por equação de Orr-Sommerfeld, em homenagem aos trabalhos de Orr (1909a), Orr (1909b) e Sommerfeld (1908), sobre a estabilidade de escoamentos viscosos.

Para o escoamento da camada limite sobre uma placa plana com ângulo de incidência zero, a equação de Orr-Sommerfeld deve satisfazer as condições de que as pertubações devem ser nulas na parede e para grandes distâncias da parede, ou seja,

$$
\begin{array}{rlll}
y=0: & u^{\prime}=v^{\prime}=0: & \phi=0, & \phi^{\prime}=0, \\
y=\infty: & u^{\prime}=v^{\prime}=0: & \phi=0, & \phi^{\prime}=0 .
\end{array}
$$

O conjunto de equações 5.19 e 5.20 para a placa plana foi primeiramente resolvido por Tollmien (1929) e Schlichting (1933), que, respectivamente, investigaram a instabilidade da camada limite e calcularam as taxas de amplificação dos modos instáveis. Em homenagem ao trabalho de ambos, o primeiro modo instável da camada limite laminar ficou conhecido como ondas Tollmien-Schlichting (TS), sendo comprovado experimentalmente 
por Schubauer e Skramstad (1947). Embora neste trabalho a perturbação seja gerada por uma fonte pontual (alto-falante) e não seja exatamente 2D, os resultados serão comparados com a solução da equação de Orr-Sommerfeld apresentada na Eq.5.19.

\subsubsection{Ondas Tollmien-Schlichting Naturais}

Seguindo o trabalho de Schubauer e Skramstad (1947), foi mensurada a onda TS gerada naturalmente na placa plana. Primeiramente foi necessário avaliar uma perturbação de frequência aproximada de $10 \mathrm{~Hz}$ dentro da camada limite. O espectro de frequências para a posição $\eta=1$, utilizando a Eq.5.4, é apresentado na Fig. 56 para diferentes valores de $R e_{\delta^{*}}$, mostrando a existência de um modo próximo a $10 \mathrm{~Hz}$. Embora esta perturbação ocorra para todas as velocidades medidas, ela sempre se encontra na região estável do diagrama de instabilidade, conforme a Fig. 57, não sendo portanto uma onda TS natural.

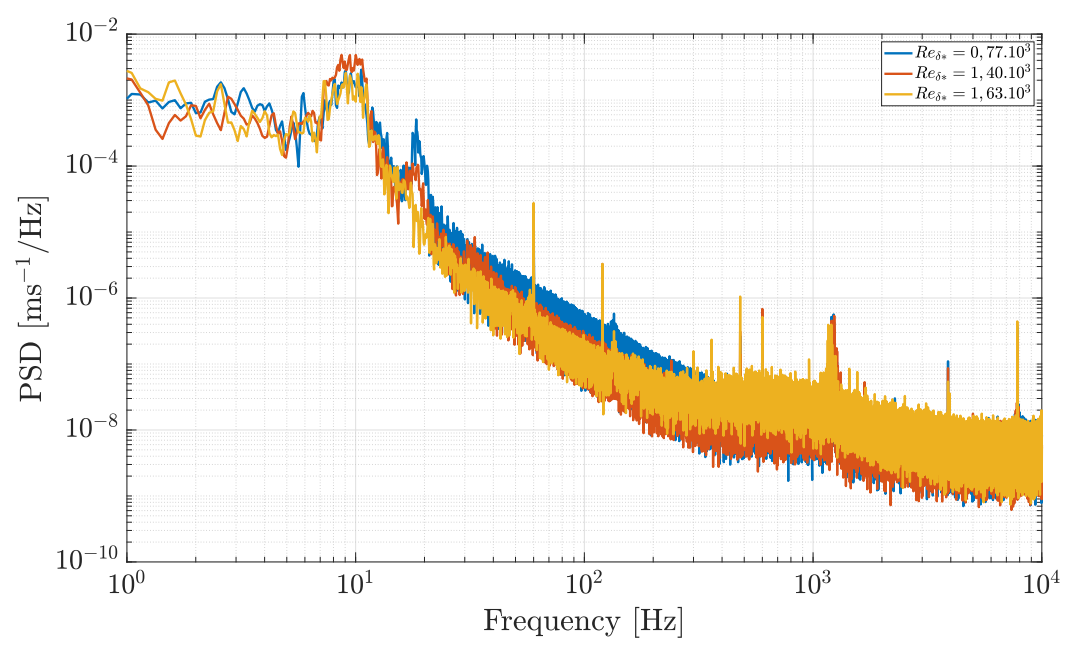

Figura 56 - Espectro frequências na camada limite para a posição $\eta=1$ para diferentes valores de $R e_{\delta^{*}}$, medidos a $10 \mathrm{~m} / \mathrm{s}$.

A provável origem deste modo é um sub-harmônico de uma onda sonora de $20 \mathrm{~Hz}$, uma vez que para a velocidade do som de aproximadamente $340 \mathrm{~m} / \mathrm{s}$ o comprimento de onda é de $17 \mathrm{~m}$, que é o comprimento total do LANT. Esta hipótese é possível de ser verificada utilizando a técnica com 2 sondas de HWA, conforme descrito por Reshotko e Saric (1997); entretanto, hoje, não há equipamento disponível para realizar tal teste no LANT, de modo que tal teste, portanto, será postergado para um momento futuro.

Para a medição da onda TS natural, a camada limite laminar foi mensurada para duas velocidades, $10 \mathrm{~m} / \mathrm{s}$ e $20 \mathrm{~m} / \mathrm{s}$, e duas posições, $1000 \mathrm{~mm}$ e $1500 \mathrm{~mm}$ do bordo de ataque. Utilizando o diagrama de instabilidade, as regiões de frequências instáveis para estas posições e velocidades são apresentadas na tabela 11.

$\mathrm{Na}$ velocidade de $10 \mathrm{~m} / \mathrm{s}$, Fig. 58 (a), o espectro de sinal, filtrado para a banda 15 $\mathrm{Hz}$ à $95 \mathrm{~Hz}$, não apresenta frequências típicas da onda TS natural; o pico de $60 \mathrm{~Hz}$ possui 


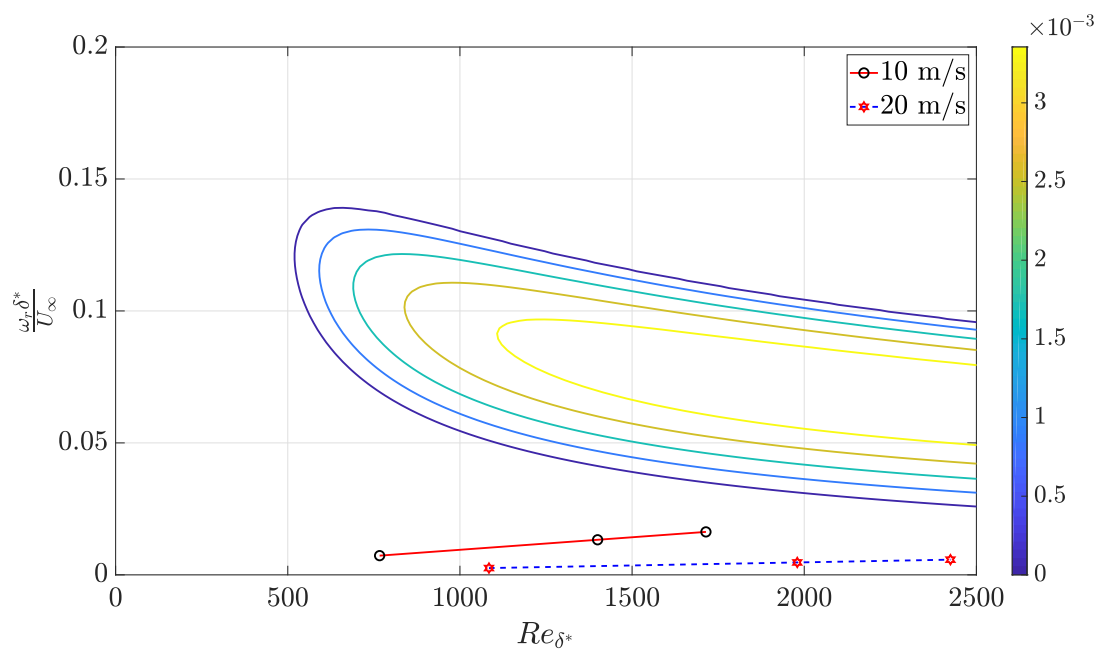

Figura 57 - Diagrama de instabilidade para a perturbação de $10 \mathrm{~Hz}$, medida nas velocidades de escoamento de $10 \mathrm{~m} / \mathrm{s}$ e $20 \mathrm{~m} / \mathrm{s}$.

\begin{tabular}{cccc} 
& \multicolumn{2}{c}{ frequência $[\mathrm{Hz}]$} \\
\hline \hline velocidade $[\mathrm{m} / \mathrm{s}]$ & distância $[\mathrm{mm}]$ & branch 1 & branch 2 \\
\hline 10 & 1000 & 30 & 90 \\
& 1500 & 22 & 68 \\
20 & 1000 & 70 & 220 \\
& 1500 & 50 & 165 \\
\hline
\end{tabular}

Tabela 11 - Regiões de frequências instáveis para as posições $1000 \mathrm{~mm}$ e $1500 \mathrm{~mm}$ do bordo de ataque, para as velocidades de $10 \mathrm{~m} / \mathrm{s}$ e $20 \mathrm{~m} / \mathrm{s}$.

origem no ruído de sinal da rede. As ondas TS naturais não foram detectas nessa região, pois elas devem ser muito pequenas, uma vez que estes pontos são muito distantes da região de transição $\left(R e_{x} \approx 9,5 \times 10^{5}\right)$, que ocorre em aproximadamente $R e_{x}=2,5 \times 10^{6}$. Já para o caso de $20 \mathrm{~m} / \mathrm{s}$, Fig. 58 (b), o espectro de sinal, filtrado para a banda $45 \mathrm{~Hz}$ à $225 \mathrm{~Hz}$, apresenta um pico centrado na frequência de $113 \mathrm{~Hz}$ para a distância de $1500 \mathrm{~mm}$. Este pico se encontra na região de instabilidade de ondas TS e pode representar uma onda TS natural. Entretanto, não se pode afirmar que seja uma onda TS natural, pois seriam necessários experimentos em distâncias maiores para verificação da amplificação destas frequências. Dada a quantidade de trabalho a ser realizada na época, os esforços foram direcionados a geração e detecção de ondas TS artificiais, embora tenha-se demonstrado que é possível detectar ondas TS naturais no LANT. 


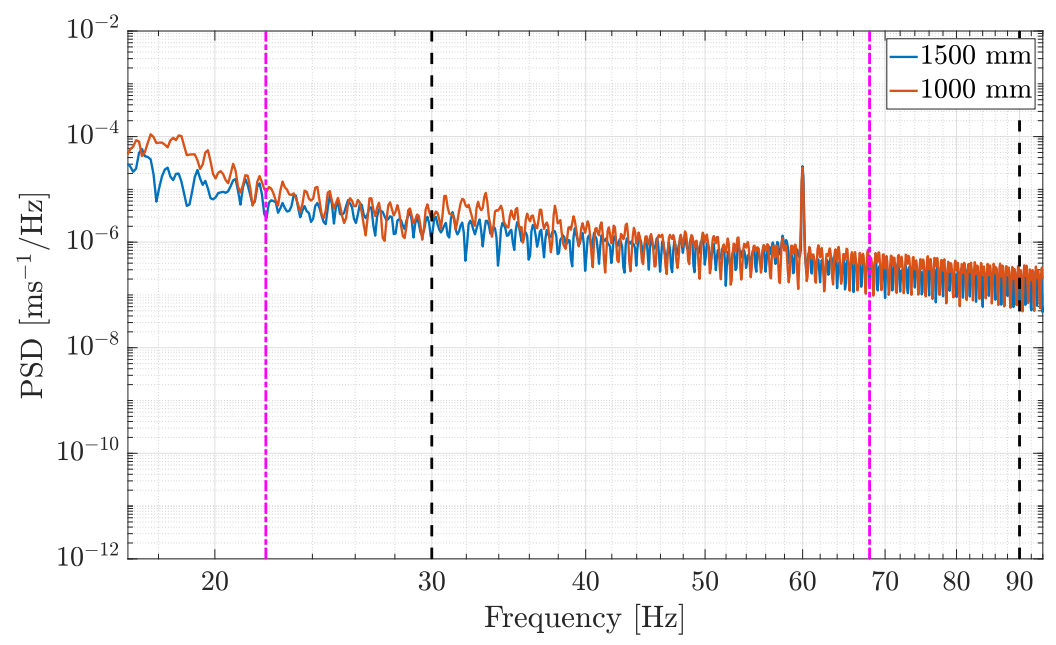

(a) $U_{\infty}=10 \mathrm{~m} / \mathrm{s}$.

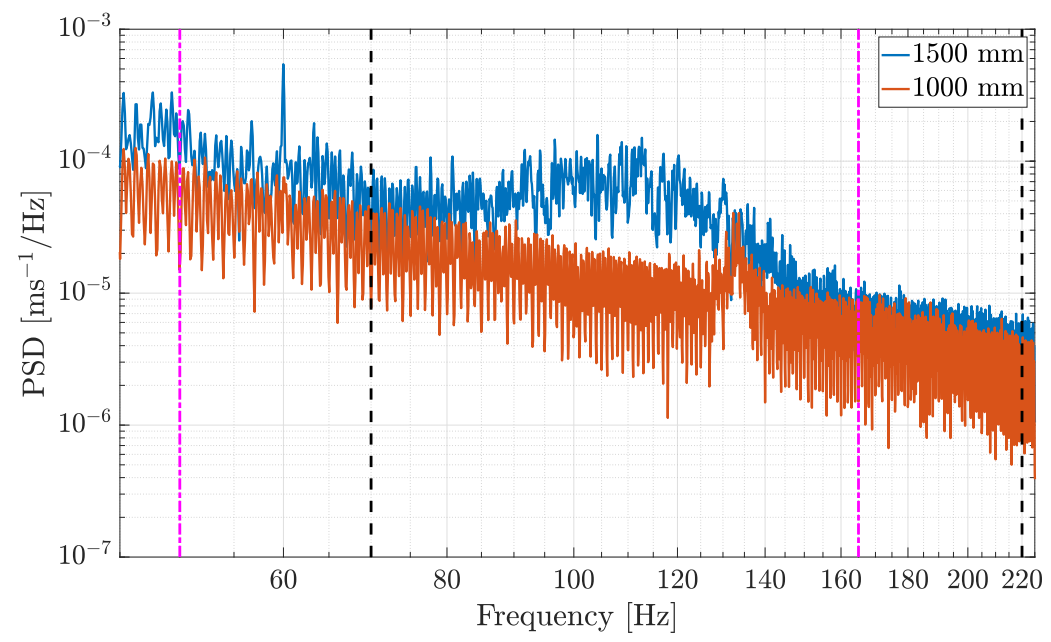

(b) $U_{\infty}=20 \mathrm{~m} / \mathrm{s}$.

Figura 58 - Espectro de frequências para a posição $\eta=1$ para as distâncias de $1000 \mathrm{~mm}$ e $1500 \mathrm{~mm}$ do bordo de ataque. As linhas tracejadas indicam os limites de frequências instáveis para a posição $1000 \mathrm{~mm}$ e as linhas traço-ponto indicam os limites das frequências instáveis para a posição $1500 \mathrm{~mm}$.

\subsubsection{Ondas Tollmien-Schlichting Artificiais}

A geração de ondas TS artificiais foi executado utilizando condições similares ao trabalho de Medeiros (2004), em que uma perturbação contínua de $200 \mathrm{~Hz}$ é inserida no escoamento de $18 \mathrm{~m} / \mathrm{s}$ à uma distância de $200 \mathrm{~mm}$ do bordo de ataque, conforme o modelo descrito no início desta seção. O diagrama de instabilidade da perturbação artificial 2D, calculado utilizando um programa de resolução (solver) da equação de Orr-Sommerfeld desenvolvido por Juniper, Hanifi e Theofilis (2014) e adaptado com a ajuda de Marlon Mathias, é apresentado na Fig. 59. 


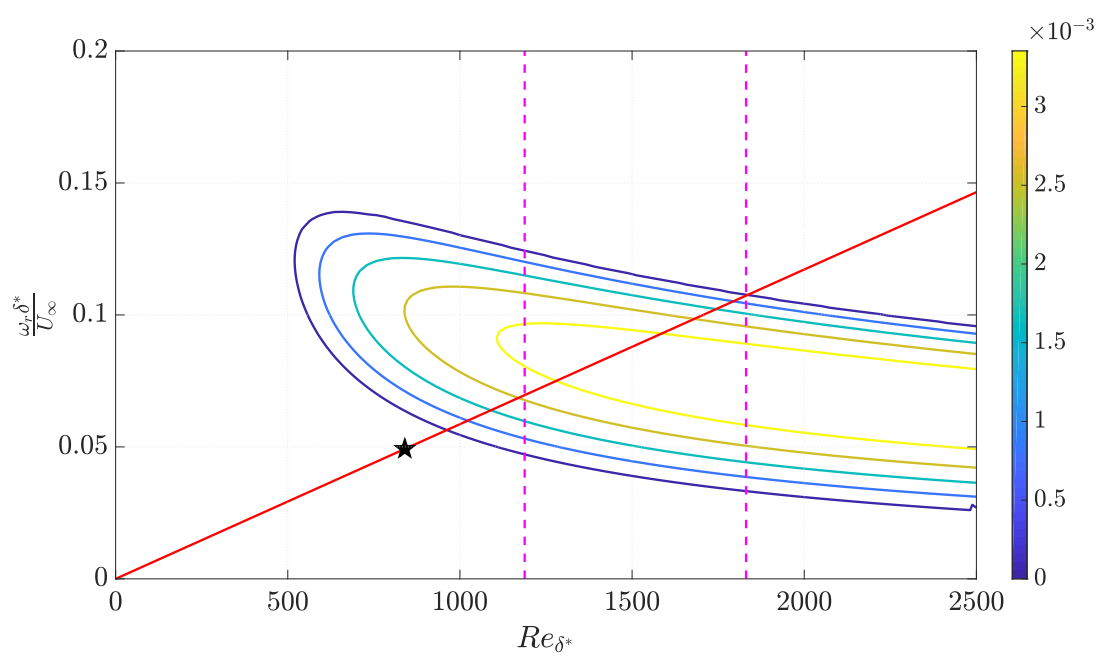

Figura 59 - Diagrama de instabilidade para ondas TS, a linha sólida vermelha demonstra o caminho de evolução da onda 2D. A estrela indica a posição da fonte de excitação e as linhas tracejadas indicam a primeira e a última estação de medição.

\subsubsection{Autofunção}

O experimento para a medição da onda TS foi feito utilizando um alto-falante de fone de ouvido alimentado por um gerador de onda Agilent 33500B Series. A intensidade da perturbação foi ajustada em 1,5 V pico a pico e as medições foram feitas a cada $50 \mathrm{~mm}$, partindo de $200 \mathrm{~mm}$ da fonte até a distância de $750 \mathrm{~mm}$. Os dados foram adquiridos com espaçamento de $0,15 \mathrm{~mm}$, tratados utilizando um filtro passa-banda entre 90 e $420 \mathrm{~Hz}$ Chebyshev Tipo II, transformados em intervalos menores (sampling), foram calculados os valores rms da velocidade de perturbação e foram tiradas médias de conjuntos (ensemble averages).

A Fig. 60 apresenta o perfil de velocidades da perturbação $u^{\prime}$ medida em rms, para a distância de $200 \mathrm{~mm}$ da fonte de perturbação. Neste ponto, a perturbação apresenta valor máximo de aproximadamente $0,22 \%$ da velocidade do escoamento livre. 


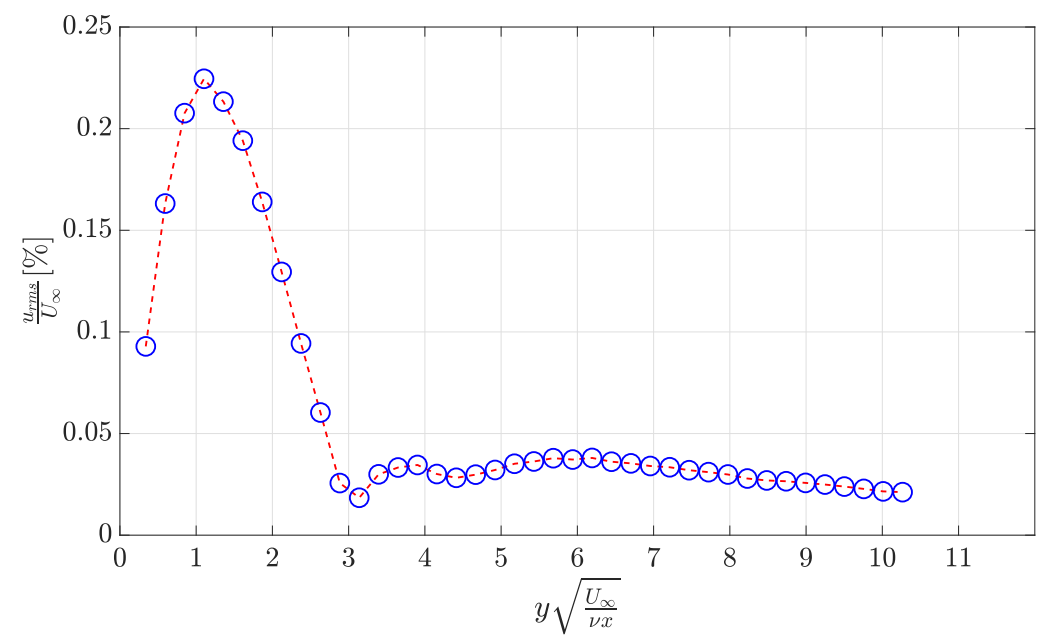

Figura 60 - Perfil de velocidades da perturbação medida a $200 \mathrm{~mm}$ da fonte.

\subsubsection{Experimento 3D}

Para demonstrar a tridimensionalidade do experimento, a autofunção foi mapeada em 11 posições, totalizando $50 \mathrm{~mm}$ de envergadura da placa, a uma distância de $200 \mathrm{~mm}$ da fonte de perturbação. Os resultados apresentados na Fig. 61 demonstram o comportamento tridimensional da onda TS, sendo a linha central $z=0$ a posição onde está localizada a fonte de perturbação. O valor máximo da onda TS, localizado a aproximadamente $20 \mathrm{~mm}$ da linha central da placa, é de $0,66 \%$ da velocidade do escoamento livre; estando portanto na região de comportamento não linear, considerando a linearidade equivale ao máximo de $0,1 \%$ do escoamento livre. 


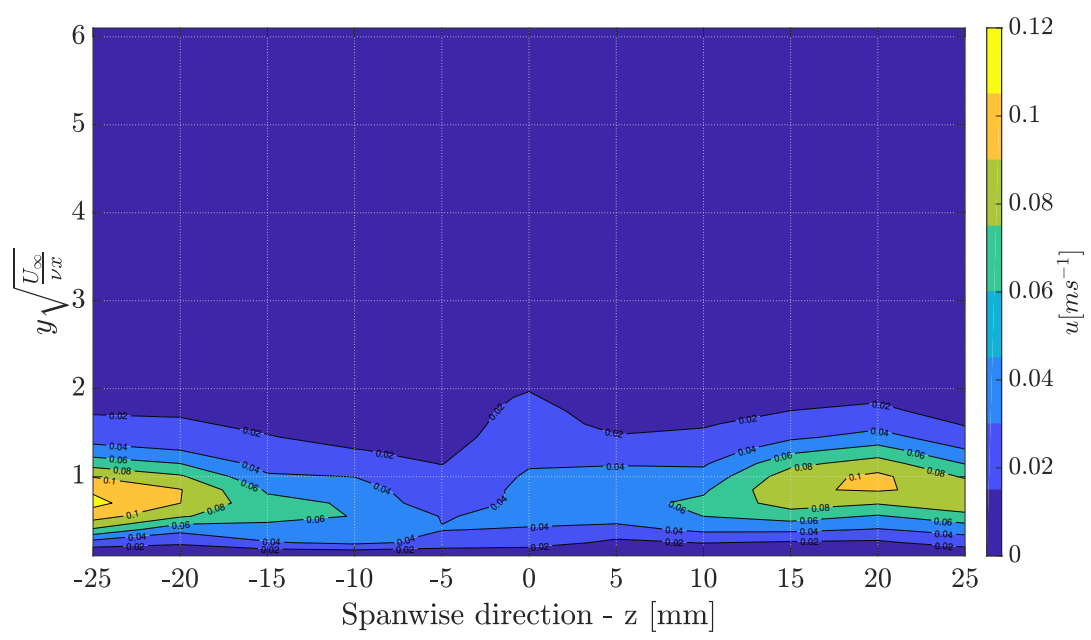

(a) Contorno do perfil da perturbação $u^{\prime}$ para diferentes valores de $z$.

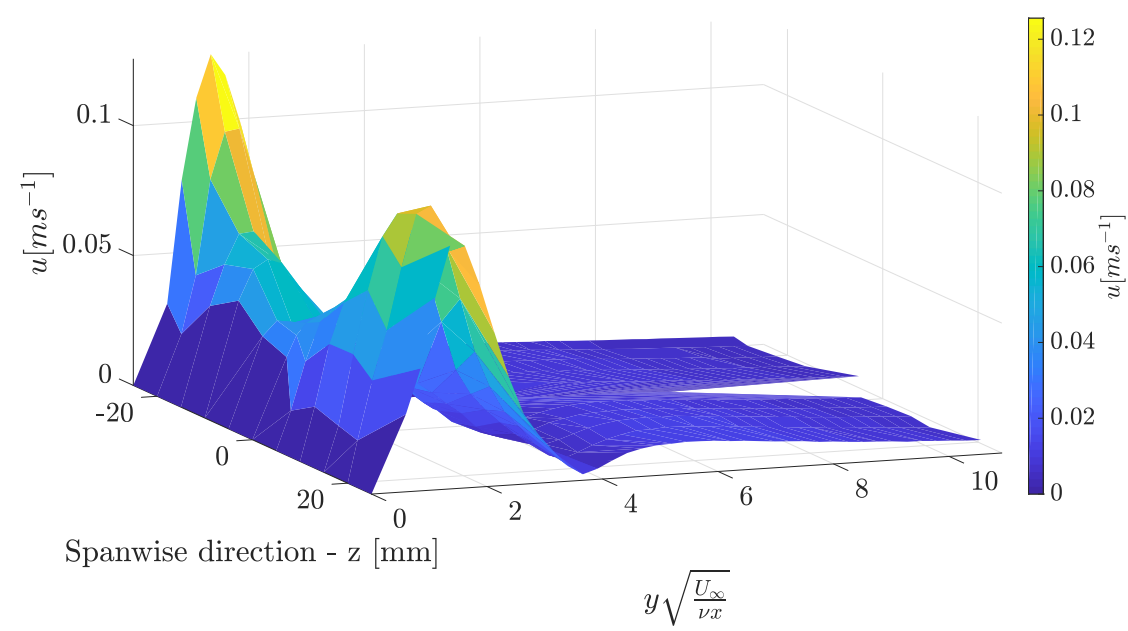

(b) Perfil da perturbação $u^{\prime}$ para diferentes valores de $z$.

Figura 61 - Tridimensionalidade da onda TS gerada artificialmente para a distância de $200 \mathrm{~mm}$ a partir da fonte.

\subsubsection{Comparação com a Teoria 2D}

Os resultados obtidos experimentalmente foram comparados com a previsão da teoria 2D, sendo para isto elaborado um novo programa de resolução com a ajuda de Marlon Mathias baseado novamente no trabalho de Juniper, Hanifi e Theofilis (2014). Entretanto, este novo programa resolve diretamente os modos instáveis em $\alpha$, sendo validado com o trabalho de Jordinson (1970).

A Fig. 62 mostra a comparação entre os resultados da teoria 2D e o experimento realizado. Nela, observa-se o comportamento esperado pela teoria como a existência de dois máximos, um interno e outro externo a camada limite, e a localização do máximo na posição $y=\delta^{*}$. Embora os resultados experimentais não sejam exatamente iguais a previsão teórica 2D, o que era esperado pois a perturbação original é pontual e 3D, eles demonstram a capacidade do LANT para execução de experimentos em transição. 


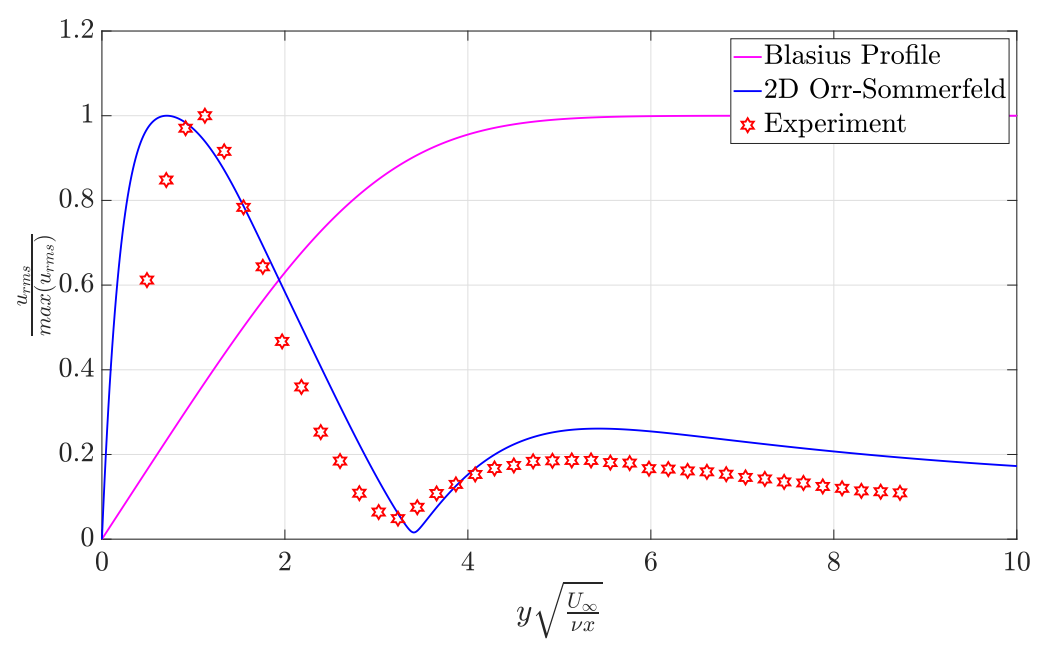

Figura 62 - Comparação entre a previsão da teoria linear 2D e os resultados experimentais para a distância de $400 \mathrm{~mm}$ da fonte.

Esta diferença entre os resultados experimentais e a teoria 2D podem ser atribuídas a dois fatores principais: (1) a perturbação original é tridimensional por natureza, e (2) a perturbação já se encontra no regime não linear. A validação do ponto um poderia ser feita utilizando um sistema para a solução da equação de Orr-Sommerfeld 3d. Em relação ao segundo fator, ele poderia ser tratado de duas maneiras: (1) seria realizar o experimento com uma perturbação menor e comparar com a teoria, ou (2) realizar uma simulação numérica direta (Direct Numeric Simulation - DNS) para o regime não linear. Entretanto, devido a escassez de tempo estas ações foram postergadas para um segundo momento.

\subsubsection{Taxa de Crescimento}

O crescimento da perturbação artificial foi aferido em diversas estações de medição, conforme a Fig. 59, e os resultados foram comparados com a teoria linear. Segundo Gaster (1974), a taxa de crescimento espacial da perturbação artificial pode ser escrita como

$$
\ln \left(\frac{A_{1}}{A_{0}}\right)=-\int_{x_{0}}^{x_{1}} \alpha_{i} d x
$$

em que $A_{1}$ e $A_{0}$ são as amplitudes medidas nas posições $x_{1}$ e $x_{0}$ respectivamente e $\alpha_{i}$ é a parte imaginária dimensional do modo mais instável. Para o experimento em estudo, os valores de $\alpha_{i}$ obtidas pelo programa de resolução descrito na seção 5.2.2.1, são apresentados na Fig. 63.

Para comparar os dados experimentais com a previsão teórica, foram utilizadas as amplitudes máximas em cada estação de medida e normalizadas pela amplitude máxima na primeira posição. Os resultados são apresentados na Fig. 64, podendo-se observar uma boa concordância com a previsão para a teoria linear $2 \mathrm{D}$ até $R e_{\delta^{*}} \approx 1650$; após este valor a medição diverge da teoria 2D. Embora esta concordância com a previsão 2D ocorra, deve-se 


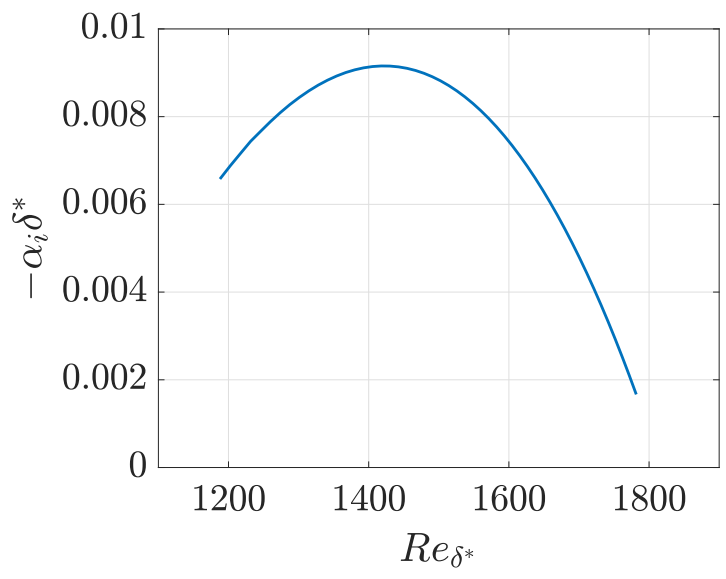

Figura 63 - Valores dimensionais da parte imaginária dos autovalores instáveis da onda TS 2D.

considerar este resultado como sendo fortuito, pois a perturbação inicial é tridimensional e o regime é não linear, conforme foi demonstrado nas seções anteriores.

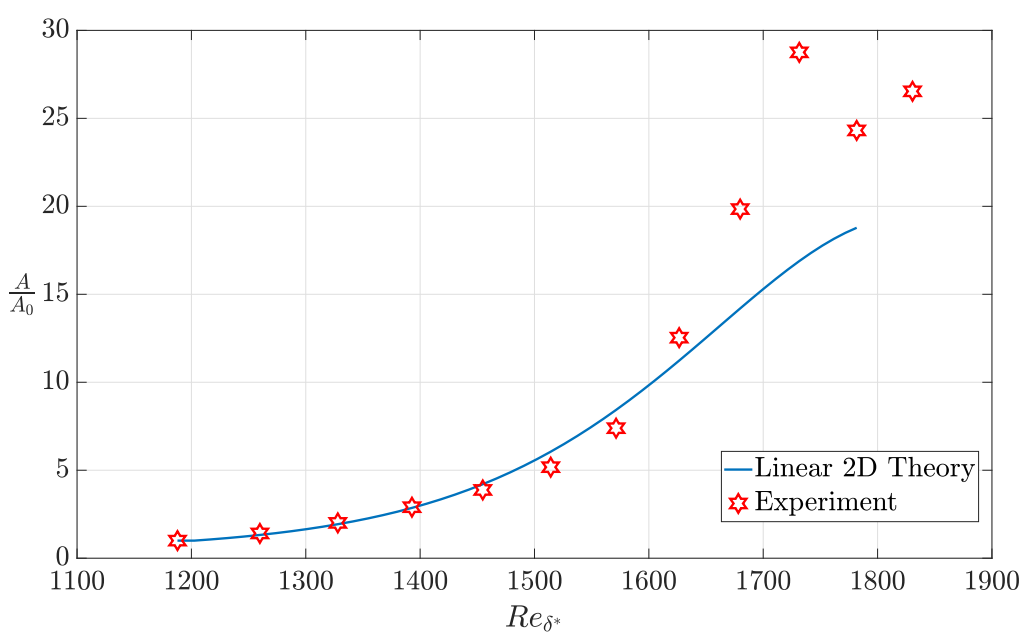

Figura 64 - Comparação entre a taxa de amplificação da perturbação medida experimentalmente e os valores previstos pela teoria linear 2D.

\subsubsection{Efeito da Perturbação Inicial}

Adicionalmente à caracterização da onda TS, também foram testados os efeitos da perturbação inicial no perfil da autofunção e na taxa de crescimento. Foram utilizadas três intensidades de perturbação, que, em termos de voltagem aplicada pelo gerador de sinal no alto-falante, foram: (1) 1,5 V pico a pico, (2) 2,0 V pico a pico e (3) 3,0 V pico a pico.

A Fig. 65 apresenta a autofunção TS para diferentes intensidades de perturbação inicial para a distância de $300 \mathrm{~mm}$ da fonte, sendo possível observar que a intensidade de perturbação não altera o formato da onda, conforme o esperado. 


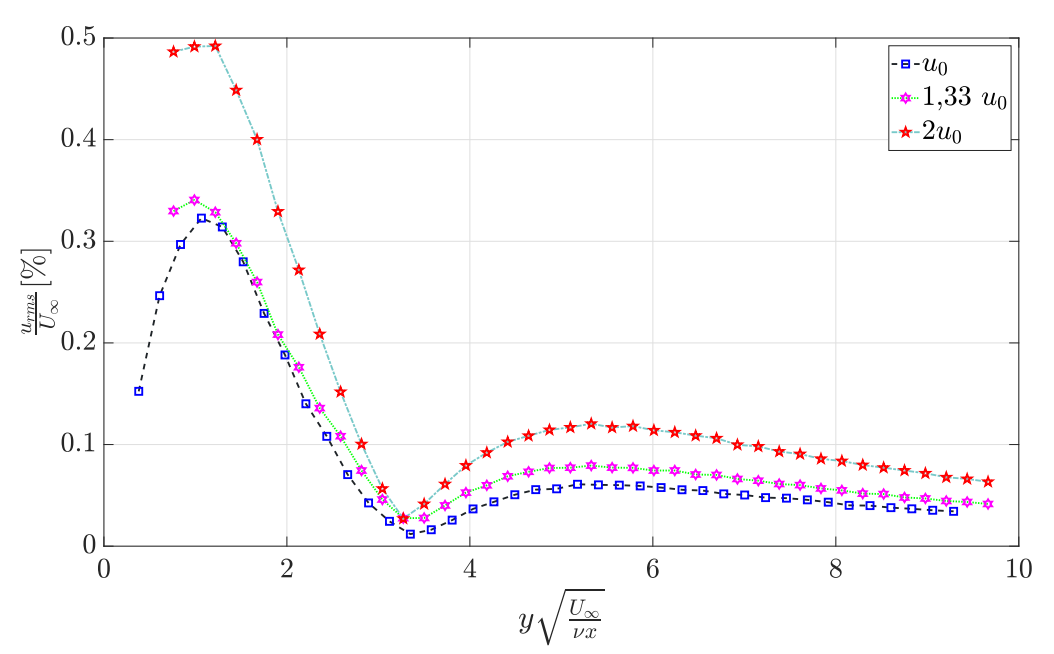

Figura 65 - Autofunção da onda TS para diferentes intensidades de perturbação inicial, medidas a $300 \mathrm{~mm}$ da fonte.

Por outro lado, a intensidade da perturbação inicial altera o crescimento da função, conforme a Fig. 66, que apresenta o valor máximo de rms para cada perturbação. Na intensidade máxima de perturbação, a transição ocorre por volta de $500 \mathrm{~mm}$ da fonte e para a intensidade intermediária, a transição ocorre a $600 \mathrm{~mm}$ da fonte. Por outro lado, para a perturbação inicial, provoca a transição acima de $800 \mathrm{~mm}$ da fonte.

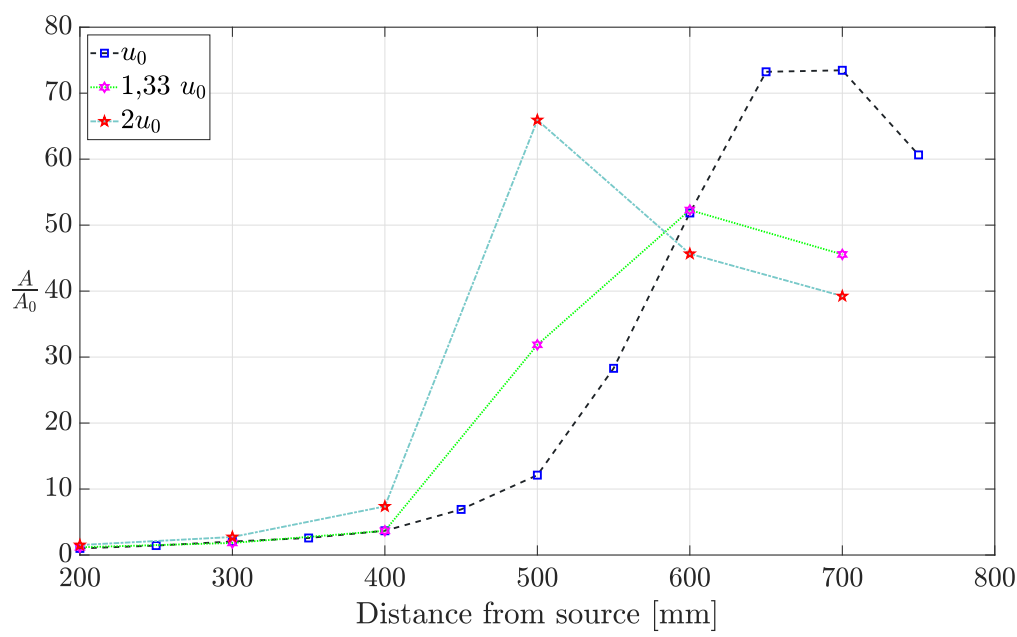

Figura 66 - Efeito da amplitude inicial de perturbação na taxa de amplificação medidas experimentalmente. 



\section{CONCLUSÃO}

Este trabalho de mestrado passou por diversas etapas, iniciado em fevereiro de 2016 como aluno especial cursando as disciplinas; passando pela aprovação de ingresso no programa e a montagem do LANT entre julho e novembro de 2016, em conjunto com os então doutorandos Juan Carlos Serrano Rico e Filipe Ramos do Amaral; operacionalização inicial e realização dos primeiros ensaios acústicos e de PIV; recuperação e operacionalização do sistema de anemometria à fio quente (HWA) e das sondas; a caracterização inicial de turbulência e a qualificação no programa ao final de 2017; atualização e construção do sistema de posicionamento com a ajuda do então mestrando Matheus Beraldo; a consequente caracterização final do LANT e a execução do experimento piloto; finalizando com a escrita desta dissertação de mestrado.

O trabalho de caracterização do LANT foi divido em duas etapas: (1) caracterização da qualidade do escoamento e (2) a execução do experimento piloto em transição da camada limite.

A caracterização do escoamento iniciou-se com uma avaliação das características térmicas do LANT. Por se tratar de um túnel de vento sem sistema de refrigeração, é necessário conhecer o comportamento térmico do escoamento no LANT, pois alguns experimentos, em especial os de anemometria à fio quente, são muito sensíveis à temperatura. Como esperado, o escoamento no LANT estabiliza em temperaturas diferentes para cada velocidade, e os tempos para esta estabilização foram determinados. A seguir, foi caracterizada a área útil da câmara de ensaios, uma análise não muito comum na literatura, que apresenta este como um valor dado; e mostrou-se que o LANT possuí uma área útil de aproximadamente $800 \mathrm{~mm} \times 800 \mathrm{~mm}$, correspondendo a $64 \%$ da área da câmara de ensaios. Para se ter uma ideia deste valor, o túnel MTL utiliza 47\% de sua área total para o experimento de caracterização da qualidade do escoamento (LINDGREN; JOHANSSON, 2002). Após a estimativa da área útil, foi mapeado o nível de uniformidade do escoamento, demonstrando que no LANT as não-uniformidades maiores não ultrapassam $1 \%$ da velocidade média na câmara de ensaios, colocando-o no patamar de túneis como o Klebanoff-Saric (HUNT et al., 2010). Por fim, foi mensurado o nível de turbulência e demonstrado que é da ordem de 0,07\% da velocidade do escoamento livre. Este valor do nível de turbulência coloca o LANT em posição de equivalência a túneis de referência no mundo, como o Klebanoff-Saric (HUNT et al., 2010), o MTL (LINDGREN; JOHANSSON, 2002) e o NDF (NAGIB et al., 1994).Finalizando o trabalho de caracterização do escoamento, foi realizada uma análise dos efeitos da rotação do ventilador nos níveis de turbulência e ruído no LANT. Esta análise demonstra que um aumento médio de $27 \%$ na rotação 
do ventilador, provoca um aumento médio de $71 \%$ no nível de turbulência.Isto sugere que a qualidade do escoamento do LANT pode ser melhorada, reduzindo-se a rotação do ventilador.

O experimento piloto foi selecionado de modo a mostrar que é possível realizar experimentos de transição no LANT, baseando-se nos trabalhos de Klebanoff, Tidstrom e Sargent (1962) e Medeiros (2004) sobre ondas Tollmien-Schlichting geradas artificialmente. Neste tipo de experimento, primeiramente é necessário demonstrar que é possível gerar uma camada limite laminar bidimensional sobre uma placa plana, sendo obtida com sucesso no LANT. Juntamente com esta camada limite laminar, foi também demonstrada que a transição natural ocorre para altos valores de $R e_{x}$, estando de acordo com o trabalho de Schubauer e Skramstad (1947), pois no LANT o nível de turbulência é baixo. A seguir, foi tentada a detecção de ondas TS geradas naturalmente, não logrando sucesso na sua execução, pois aparentemente há uma onda acústica no túnel. Esta onda deverá ser melhor estudada em um momento futuro, quando o grupo possuir equipamento adequado para sua caracterização. Por fim, foram geradas ondas TS artificialmente e sua caracterização foi obtida através da medição de sua autofunção e taxa de crescimento. Os resultados obtidos da caracterização de ondas TS foram então comparados com a teoria de instabilidade linear $2 \mathrm{D}$, apresentando uma boa concordância com o previsto tanto para a autofunção como para a taxa de crescimento, embora o experimento realizado seja claramente tridimensional. Este resultados demonstram com sucesso a capacidade do LANT para a realização de experimentos em transição da camada limite.

As sequência natural deste trabalho é a execução de experimentos mais sofisticados em transição da camada limite, tais como: (1) analisar a interação de ondas TS com estruturas, como por exemplo cavidades e degraus; (2) experimentos de ondas TS a partir de pacotes de onda (wave-packets); (3) uma combinação entre wave-packets e estruturas; (4) transição da camada e geração de ruído aeroacústico; (5) a caracterização acústica utilizando-se microfone inserido no escoamento; e (6) execução de experimentos acústicos sobre cavidades e degraus posicionados na camada limite da placa plana. O LANT apresenta muitas possibilidades para execução de experimentos necessitando apenas de modificações pontuais, como a melhoria nos sistemas de aquisição de dados e geração de sinais, bem como aprimoramentos no sistema de posicionamento. Sendo um excelente equipamento de pesquisa, o LANT pode ainda ser aprimorado com a construção de um ventilador mais eficiente, de modo que se reduza a rotação utilizada, e algumas alterações nos aspectos construtivos da câmara de ensaio, tornando-a de mais fácil operação, bem como permitir que se troque com maior facilidade o teto e o chão, para a mudança de configuração das paredes de rígida (hard-walls) para espumas (foamed-walls), transformando-a em uma câmara semi-anecoica.

Durante todo este período um número grande de realizações foram obtidas, entre eles 
pode-se destacar: (1) a montagem e operação do LANT, (2) a operacionalização dos sistemas de anemometria, (3) a construção e operacionalização do sistema de posicionamento tridimensional e (4) a capacidade para realização de experimentos em transição da camada limite conforme demonstrado neste trabalho. 



\section{REFERÊNCIAS}

AVELAR, A. C. Velocity Profile and Turbulence Intensity Measurements in the Ta-2 Wind Tunnel. 18th International Congress of Mechanical Engineering, 2005.

BLASIUS, H. "Grenzschichten in Fliissigkeitenmit kleiner Reibung" Zeitschriftffi Mathematik und Physik,. Zeitschrift fiirMthematik und Physik, v. 56, n. 1, p. 1-37, 1908.

. The Boundary Layers in Fluids with Littel Friction. N.A.C.A. Technical Memorandum No. 1256, 1950.

BRUUN, H. H. On the temperature dependence of constant temperature hotwire probes with small wire aspect ratio. Journal of Physics E: Scientific Instruments, v. 8, n. 11, p. $942-951,1975$.

Hot wire anemometry : principles and signal analysis. [S.l.]: Oxford University Press, 1995. ISBN 9780198563426.

CALAPRICE, A. The quotable \{Einstein \}. [S.l.: s.n.], 1996. ISBN 0-691-02696-3.

COHEN, J.; BREUER, K. S.; HARITONIDIS, J. H. On the evolution of a wave packet in a laminar boundary layer. Part 1. Weak disturbances. Journal of Fluid Mechanics, v. 225, p. 575-606, 1991. ISSN 0022-1120. Disponível em: <http://www.journals.cambridge.org/ abstract $\left\{\backslash \_\right.$S0022112091002>.

DRELA, M. XFOIL: An Analysis and Design System for Low Reynolds Number Airfoils. In: MUELLER, T. J. (Ed.). Low Reynolds Number Aerodynamics. Lecture Notes in Engineering. Volume 54. Berlin: Springer, Berlin, Heidelberg, 1989. p. 1-12.

DYKE, V. M. An Album of FluidMotion. [S.l.]: The Parabolic Press, 1988.

EMMONS, H. W. The laminar-turbulent transition in a boundary layer-Part I. Journal of the Aeronautical Sciences, 1951. Disponível em: <https://arc.aiaa.org/doi/pdf/ $10.2514 / 8.2010>$.

FEY, U.; KÖNIG, M.; ECKELMANN, H. A new Strouhal-Reynolds-number relationship for the circular cylinder in the range $47<\operatorname{Re}<2 \times 105$. Physics of Fluids, v. 10, n. 7, p. 1547-1549, 1998. ISSN 10706631.

GASTER, M. A note on the relation between temporally-increasing and spatially-increasing disturbances in hydrodynamic stability. Journal of Fluid Mechanics, v. 14, p. 222-224, 1962 .

On the generation of spatially growing waves in a boundary layer. Journal of Fluid Mechanics, v. 22, n. 3, p. 433-441, 1965. ISSN 14697645.

On the effects of boundary-layer growth on flow stability. Journal of Fluid Mechanics, v. 66, n. 3, p. 465-480, 1974. ISSN 14697645. 
GASTER, M.; GRANT, I. An Experimental Investigation of the Formation and Development of a Wave Packet in a Laminar Boundary Layer. Proceedings of the Royal Society A: Mathematical, Physical and Engineering Sciences, v. 347, n. 1649, p. 253-269, 1975. ISSN 1364-5021.

GROTH, J.; JOHANSSON, A. V. Turbulence reduction by screens. Journal of Fluid Mechanics, v. 197, p. 139-155, 1988. ISSN 14697645.

HOUGHTON, E. L. Aerodynamics for engineering students. 6th ed. ed. Oxford, UK: Elsevier B.V., 2013. ISBN 978-0-08-096632-8.

HUNT, L. E. et al. Flow Quality Measurements in the Klebanoff-Saric Wind Tunnel. 27th AIAA Aerodynamic Measurement Technology and Ground Testing Conference, n. July, p. 1-12, 2010.

INGEN, J. L. van. A suggested semi-empirical method for the calculation of the boundary layer transition region. Delft - Nederland: Technische Hogescholl Vliegtuigbouwkunde, 1956.

JORDINSON, R. The flat plate boundary layer. Part 1. Numerical integration of the Orr-Sommerfeld equation. Journal of Fluid Mechanics, v. 43, n. 4, p. 801-811, 1970. ISSN 14697645.

JORGENSEN, F. E. How to measure turbulence with hot-wire anemometers - a practical guide. Skovlunde, Denmark: DANTEC Dynamics, 2002.

JUNIPER, M. P.; HANIFI, A.; THEOFILIS, V. Modal Stability Theory Lecture notes from the FLOW-NORDITA Summer School on Advanced Instability Methods for Complex Flows, Stockholm, Sweden, 2013. Applied Mechanics Reviews, American Society of Mechanical Engineers, v. 66, n. 2, p. 024804, mar 2014. ISSN 0003-6900. Disponível em: <http://appliedmechanicsreviews.asmedigitalcollection.asme.org/article.aspx?doi= $10.1115 / 1.4026604>$.

KLEBANOFF, P. S.; TIDSTROM, K. D.; SARGENT, L. M. The three-dimensional nature of boundary-layer instability. Journal of Fluid Mechanics, 1962.

LANDAU, L. D. ON THE PROBlem OF TURBUlEnCE. C. R. Acad. Sci. URSS, v. 44, p. 1-6, 1944. Disponível em: <https://www.cambridge.org/core/journals/ journal-of-fluid-mechanics/article/threedimensional-nature-of-boundarylayer-instability / 53CCCEA2B878AF047BD3261DA051BE1C>.

LIGHTHILL, M. J. On Sound Generated Aerodynamically. I. General Theory. Proceedings of the Royal Society A: Mathematical, Physical and Engineering Sciences, v. 211, n. 1107, p. 564-587, 1952. ISSN 1364-5021.

LINDGREN, B. Flow Facility Design and Experimental Studies of Wall-Bounded Turbulent Shear-Flows. Technical Reports from Royal Institute of Technology Department of Mechanics, 2002.

LINDGREN, B.; JOHANSSON, A. V. Evaluation of the flow quality in the MTL windtunnel. Technical Reports from Royal Institute of Technology Department of Mechanics, 2002. 
LIU, P. et al. Design and performance of a small-scale aeroacoustic wind tunnel. Applied Acoustics, Elsevier Ltd, v. 116, p. 65-69, 2017. ISSN 1872910X. Disponível em: <http: //dx.doi.org/10.1016/j.apacoust.2016.09.014>.

LOEHRKE, R. I.; NAGRIB, H. M. Control of Free-Stream Turbulence by Means of Honeycombs: A Balance between Suppression and Generation. Journal of Fluid Engineers, v. 98, n. 3, p. 342-351, 1976. ISSN 00982202.

MEDEIROS, M. A. F. The nonlinear evolution of a wavetrain emanating from a point source in a boundary layer. Journal of Fluid Mechanics, v. 508, n. 508, p. 287-317, 2004. ISSN 00221120.

MEDEIROS, M. A. F.; GASTER, M. The production of subharmonic waves in the nonlinear evolution of wavepackets in boundary layers. Journal of Fluid Mechanics, v. 399, p. 301-318, 1999. ISSN 00221120.

NAGIB, H. et al. AIAA 94-2499 Flow Quality Documentation of the National Diagnostic Facility Illinois Institute of Technology Chicago. 18th AIAA Aerospace Ground Testing Conference, p. 1-32, 1994.

ORR, W. M. The Stability or Instability of the Steady Motions of a Perfect Liquid and of a Viscous Liquid. Part I: A Perfect Liquid. Source: Proceedings of the Royal Irish Academy. Section A: Mathematical and Physical Sciences,, v. 27, p. 9-68, 1909.

The Stability or Instability of the Steady Motions of a Perfect Liquid and of a Viscous Liquid. Part II: A Viscous Liquid. Source: Proceedings of the Royal Irish Academy. Section A: Mathematical and Physical Sciences, , v. 27, p. 66-138, 1909.

PERRY, A. E. A. E. Hot-wire anemometry. [S.l.]: Clarendon Press, 1982. 184 p. ISBN 9780198563273.

PLATZER, M. On the mechanism of the drag a moving body experiences in a flui. Progress in Aerospace Sciences journal, IV, p. 13-15, 2013.

PRANDTL, L. Üeber Flüessigkeitsbewegung bei sehr kleiner Reibung. Verhandlungen des dritten internationalen Mathematiker-Kongresses in Heidelberg, 1905.

. Motion of fluids with very little viscosity. N.A.C.A. Technical Memorandum No. 452, 1928.

RAYLEIGH, J. W. S. On the Stability, or Instability of Certain Fluid Motions. Proceedings of the London Mathematical Society, XI, p. 57-70, 1880.

REMILLIEUX, M. et al. Calibration and Demonstration of the New Virginia Tech Anechoic Wind Tunnel. 14th AIAA/CEAS Aeroacoustics Conference (29th AIAA Aeroacoustics Conference), n. May, p. 1-17, 2008. Disponível em: <http://arc.aiaa.org/ doi/abs/10.2514/6.2008-2911>.

RESHOTKO, E.; SARIC, W. S. Flow quality issues for large wind tunnels. 35th AIAA Aerospace Sciences Meeting, n. January, 1997. ISSN 0554-5587.

REYNOLDS, O. An Experimental Investigation of the Circumstances Which Determine Whether the Motion of Water Shall Be Direct or Sinuous, and of the Law of Resistance in Parallel Channels. Proceedings of the Royal Society of London. Series A, n. 35, p. 84-99, 1883. 
On the Dynamical Theory of Incompressible Viscous Fluids and the Determination of the Criterion. Philosophical Transactions of the Royal Society A: Mathematical, Physical and Engineering Sciences, v. 186, n. 0, p. 123-164, 1895. ISSN 1364-503X. Disponível em: < http://rsta.royalsocietypublishing.org/cgi/doi/10.1098/rsta.1895.0004>.

SAHLIN, A.; JOHANSSON, A. V. Design of guide vanes for minimizing the pressure loss in sharp bends. Physics of Fluids A, v. 3, n. 8, p. 1934-1940, 1991. ISSN 08998213.

SANTANA, L. D. et al. The update process and characterization of the Sao Paulo University wind-tunnel for aeroacoustics testing. 27th International Congress of the Aeronautical Sciences, 2010.

SARIC, W. S.; RESHOTKO, E. Review of Flow Quality Issues in Wind Tunnel Testing. 20th AIAA Advanced Measurement and Ground Testing Technology Conference, p. 2613, 1998.

SCHLICHTING, H. Laminare Strahlausbreitung. ZAMM - Journal of Applied Mathematics and Mechanics / Zeitschrift für Angewandte Mathematik und Mechanik, v. 13, n. 4, p. 260-263, 1933. ISSN 15214001.

SCHLICHTING, H.; GERSTEN, K. Boundary layer theory. Edition, 9. Berlin: Springer Berlin Heidelberg, 2017. 814 p. ISBN 978-3-662-52917-1.

SCHRAUF, G. Status and perspectives of laminar flow. Aeronautical Journal, v. 109, n. 1102, p. 639-644, 2005. ISSN 00019240.

SCHUBAUER, G. B.; KLEBANOFF, P. S. Contributions on the Mechanics of BoundaryLayer Transition. National Advisory Committee for Aeronautics - Technical Note 3489, Washington, p. 1-32, 1955.

SCHUBAUER, G. B.; SKRAMSTAD, H. K. Laminar-Boundary-Layer Oscillations and Transition on a Flat Plate. National Advisory Committee for Aeronautics - Report No. 909, 1947.

Serrano Rico, J. C. et al. Low Acoustic Noise and Turbulence ( LANT ) wind-tunnel at USP-EESC. 2018 Applied Aerodynamics Conference, AIAA AVIATION Forum, p. $3007,2018$.

Silva Junior, P. S. Física Experimental A - Apostila. São Carlos: Universidade Federal de São Carlos, 2014. 1-93 p.

SOMMERFELD, A. "Ein Beitrag zur hydrodynamische Erklärung der turbulenten Flüssigkeitsbewegungen". Proceedings of the 4th International Congress of Mathematicians. III. Rome., v. 3, p. 116-124, 1908.

SQUIRE, H. B. On the Stability for Three-Dimensional Disturbances of Viscous Fluid Flow between Parallel Walls. Proceedings of the Royal Society A: Mathematical, Physical and Engineering Sciences, v. 142, n. 847, p. 621-628, 1933. ISSN 1364-5021.

TOLLMIEN, W. Über die Entstehung der Turbulenz. 1. Mitteilung. Nachrichten von der Gesellschaft der Wissenschaften zu Göttingen, Mathematisch-Physikalische Klasse, p. 21-44, 1929. 
TYLER, J. M.; SOFRIN, T. G. Axial Flow Compressor Noise Studies. 1962. ISSN 13894986. Disponível em: <http://www.sae.org/technical/papers/620532>.

WHITEHEAD, L. G.; WU, L. Y.; WATERS, M. H. L. Contracting ducts of finite length. The Aeronautical Quarterly, v. 2, n. 4, p. 254-271, 1951. 